

Digitized by the Internet Archive in 2008 with funding from Microsoft Corporation 
MEMOIRS

OF

THE WISTAR INSTITUTE OF ANATOMY AND BIOLOGY

No. 4

\section{THE DEVELOPMENT OF}

\section{THE LYMPHATIC SYSTEM IN FISHES}

WITH ESPECIAL REFERENCE TO

ITS DEVELOPMENT IN THE TROUT ${ }^{1}$

FORTY-TWO FIGURES

CHARLES F. W. MCCLURE

DEPARTMENT OF COMPARATIVE ANATOMY PRINCETON UNIVERSITY

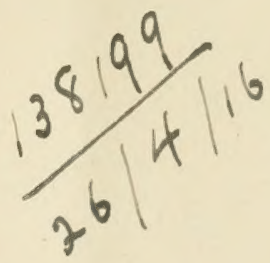

PHILADELPHIA, PA.

1915

${ }^{1}$ Read before Section I of the Seventeenth International Congress of Medicine, London, August, 1913, and published in the Proceedings; also read before the American Association of Anatomists, December, 1913, and published in the Proceedings, Anat. Rec., vol. 8, 1914. 


$$
\begin{aligned}
& Q L \\
& 841 \\
& M 3
\end{aligned}
$$




\section{CONTENTS}

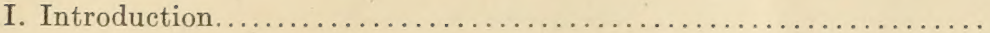

II. The embryonic ground-plan of the lymphatic system in the trout upon which that of the adult is built.................. 6

III. Are the lymphatics of fishes transformed veins?...............

IV. The modifications which the embryonic ground-plan of the lymphatic system undergoes in establishing the more advanced stages in the

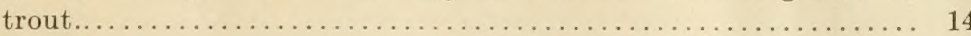

V. The embryonic ground-plan of the lymphatic system in ganoids and the subsequent transformations which it undergoes.............

VI. The development of the subocular lymph sacs in the trout....... 20

VII. The development of the lateral pharyngeal lymphatic in the trout...

1. The development of that portion of the lateral pharyngeal lymphatic which lies anterior to the points at which primary communications are established between it and the precardinal (jugular) veins.

2. The development of that portion of the lateral pharyngeal lymphatic which lies opposite to the points at which primary communications are established between it and the precardinal

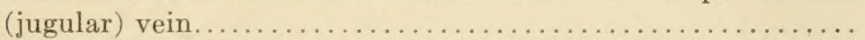

VIII. The development of the superficial facial lymphatic in the trout....

IX. The development of the precardinal (jugular) lymphatics in the

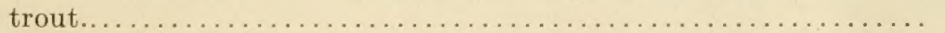

$\mathrm{X}$. The development of the medial pharyngeal lymphatic...........

XI. Variations in the rate at which the lymphatic system of the trout develops in different embryos of the same age, as well as upon

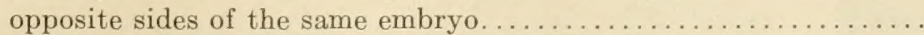

XII. Do the peripheral lymphaties form a closed system of endotheliallined vessels similar to those of the haemal system?...........

XIII. General considerations concerning the genesis and growth of the lymphatic system in its relations to the haemal system ........... 5

Literature cited $\ldots \ldots \ldots \ldots \ldots \ldots \ldots \ldots \ldots \ldots \ldots \ldots \ldots \ldots \ldots \ldots \ldots \ldots \ldots \ldots \ldots \ldots, \quad 72$

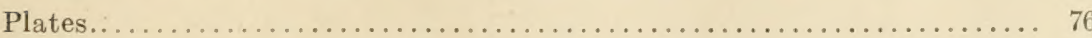





\section{INTRODUCTION}

My studies on the development of the lymphatic system in fishes have thus far been confined to the vessels of the head and pharynx. These vessels were chosen for the reason that they have not been dealt with by others to any extent and because they present a greater variety of conditions for study than those situated in the trunk and tail regions. The fishes thus far studied consist of ganoids and teleosts and include Amia calva, Lepidosteus osseous, Salvelinus fontinalis, Mitchill (brook trout), Salmo Gairdneri, Richardson (steelhead trout) and Salmo irideus, Gibbons (rainbow trout). The vascular system of between six and seven hundred trout embryos has been injected ${ }^{2}$ and the embryos studied during the process of injection, in transparent mounts after the method of Spalteholz, and in sections. Forty-two reconstructions have been made, after the method of Born, of the arteries, veins and lymphatics in the regions of the head and pharynx of Amia, Lepidosteus and the trout. These reconstructions form a fairly complete series which illustrate the development of the lymphaties from the time of their earliest appearance in the embryo, as a series of discontinuous anlagen or lymph vesicles, to the establishment of a condition in which a continuous system of lymph channels is present. Since the injection method has been employed in following the development of the lymphatics in the trout, I will deal, for the most part, with the conditions observed in this form. ${ }^{3}$

2 The embryos were injected by my Assistant, Mr. Charles F. Silvester, to whom I am much indebted for his efficient services in this connection.

${ }^{3}$ I wish to express my thanks and appreciation to Professor Raymond C. Osburn of the New York Aquarium and to Commissioner Hugh M. Smith of the U. S. Bureau of Fisheries, for their courtesy in supplying me with trout embryos. 
II. THE EMBRYONIC GROUND-PLAN OF THE LYMPHATIC SYSTEM IN THE TROUT UPON WHICH THAT OF THE ADULT IS BUILT

-The time at which the main lymphatic channels are first met with in the embryo in the form of a continuous system of vessels, naturally varies in relation to the temperature of the water in which development has taken place. It is therefore impossible to state definitely for any one of the species studied, that a system of continuous lymphatic channels will be uniformly met with on any particular day. In the rainbow and steelhead trout, when developed at an average temperature of about $10.5^{\circ} \mathrm{C}$., a continuous system of lymphatic channels was found to be present on both sides of the head and pharynx on the twenty-second day after fertilization in fully 90 per cent, and, on the twenty-third day, in practically all of the embryos injected. In another series of steelhead trout embryos developed at an average temperature of $11.5^{\circ} \mathrm{C}$, a continuous system of lymphatic channels was met with on both sides of the embryo on the twentieth day after fertilization in practically all of the embryos injected.

Figure 10 represents a reconstruction of the principal arteries, veins and lymphatics (main trunk lines) found in the regions of the head and pharynx of a rainbow trout embryo on the twentysecond day after fertilization. It represents the earliest condition met with in the trout embryo in which the principal or main lymphatic channels of the head and pharynx form, for the most part, a continuous system of vessels which drain into the veins at typical points. This particular reconstruction may be said to represent the ground-plan arrangement of the embryonic lymphatic system upon which that of the adult trout is built. It was reconstructed from sections of an uninjected embryo in order to emphasize the ease and accuracy with which the lumina of the lymphatics can be followed in sections, without the aid of injections, after continuous vessels have been established. The principal lymphatic channels are as follows:

1. The lateral pharyngeal lymphatic.

2. The subocular lymph sacs.

3. The medial pharyngeal lymphatic.

4. The precardinal or jugular lymphatics. 
1. The lateral pharyngeal lymphatic (3 in figure 10, truncus lymphaticus pharyngeus lateralis)

The lateral pharyngeal lymphatic occupies a superficial position in the lateral wall of the pharynx and forms, on each side of the body, a direct anterior continuation of the lymphatic of the lateral line of the trunk (truncus lymphaticus longitudinalis lateralis, 10 in fig. 10). The lateral pharyngeal lymphatic drains the subocular lymph sac, the dorsal region of the head and pharynx and, at a slightly later stage, the operculum and the lower jaw. In fact, with the exception of one other channel (medial pharyngeal lymphatic), the lateral pharyngeal lymphatic and its tributaries, together with the subocular lymph sac, constitute, on each side of the body, the entire continuous lymphatic system found in the regions of the head and pharynx at this stage of development. The lymphatic of the lateral line of the trunk (10, fig. 10) is also completely developed on the twenty-second day and can be traced caudad into the tail region.

The points of communication established between the lateral pharyngeal lymphatic (3) and the precardinal (jugular) vein (6) are confined, at this period of development, to that portion of the precardinal vein which extends between the caudal end of the otocyst and the point where the pre- and postcardinal veins $(6,11)$ unite to form the duct of Cuvier $(24$, cardino-Cuvierian junction). A point of communication commonly occurs at the cardino-Cuvierian junction (cardino-Cuvierian communication, 9 in fig. 10) where the lateral pharyngeal lymphatic (3) opens into the veins in common with the lymphatic of the lateral line of the trunk (10). This communication may be single or multiple in character, the latter being the case on both sides of the embryo under consideration. Another point of communication with the precardinal commonly occurs at about opposite the caudal end of the otocyst (otic communication) and in the embryo under consideration, was present only on the right side (13 in fig. 10). The otic communication may be present on both sides of the embryo, however, and, like that found at the cardino- 
Cuvierian junction, may be either single or multiple in character. In addition to these more typical points of communication, the lateral pharyngeal lymphatic may also communicate with the precardinal at almost any point between the two; so that the region of the precardinal vein which lies between the otic (13) and cardino-Cuvierian communications (9) may be regarded, in general, as constituting a district of lymphatico-venous communication.

2. The subocular lymph sacs (1 in figure 10, saccus lymphaticus subocularis)

The subocular lymph sacs consist of two relatively huge sacs, each of which is situated ventro-medially to the eye. They are more or less triangular in form, with their apices directed anteriorly. In the twenty-two-day trout under consideration, they extend between the hyoidean artery (15) and the olfactory pit (33 in fig. 14). They do not communicate with each other nor with the veins in the immediate neighborhood of the sacs. At its posterior lateral angle, each subocular lymph sac communicates directly with the lateral pharyngeal lymphatic (3) of its respective side and drains through the latter into the veins at the typical points of communication, mentioned above, which the lateral pharyngeal lymphatic establishes with the veins (9 and 13 in fig. 10).

3. The medial pharyngeal lymphatic (4 in figure 10, truncus lymphaticus pharyngeus medialis)

This vessel occupies a more medial position and is more deeply situated than the lateral pharyngeal lymphatic. It runs an oblique course, in a postero-anterior direction, from about the middle of the lateral pharyngeal lymphatic, with which it subsequently establishes a communication, to open into the precardinal (jugular) vein just caudal to the point where the latter emerges from the cranial cavity. This communication (medial pharyngeal communication, 2 in fig. 10), together with those 
mentioned above (9 and 13), constitute all of the typical points of communication, as far as I can determine, which are established in the trout embryo, in the regions of the head and pharynx, between the lymphatics and the veins.

4. The precardinal or jugular lymphatics ( $\mathbf{5}$ and $\mathbf{5}^{\prime}$ in figure 10 , truncus lymphaticus precardinalis vel jugularis)

The precardinal lymphatics are not completely established in the form of a continuous system of channels on the twenty-second day. They follow the course of the precardinal veins and, in the twenty-two-day rainbow trout embryo, are represented by several independent and discontinuous lymph vesicles or sacs $\left(5^{\prime}\right.$ in fig. 10) and by two irregularly-shaped sacs ( 5 in fig. 10). The latter lie in the region of the three posterior efferent aortic arches (17, 18 and 19, fig. 10), and communicate with the lateral pharyngeal lymphatic about opposite the caudal end of the otocyst ( 7 in fig. 10). At a slightly later stage of development the precardinal lymphatics form a continuous system of vessels which drain into the veins through the lateral and medial pharyngeal lymphatics.

The above constitute the main or principal continuous lymphatic channels which are found in the steelhead and rainbow trout embryo on the twenty-second day after fertilization, and also in the brook trout at a corresponding stage.

If one injects into the caudal vein at this stage of development, on account of the absence of lymphatico-venous valves, the injecta will pass freely into the lymphatics from the veins through any one or all of the typical points of communication which exist between the two. It will therefore fill up completely, on each side of the body, the lateral pharyngeal lymphatic, the subocular lymph sac, the lymphatic of the lateral line of the trunk, the medial pharyngeal lymphatic and that portion of the precardinal lymphatic (5) which has established a communication with the lateral pharyngeal lymphatic near the caudal end of the otocyst. The injecta will not pass into the independent 
and discontinuous anlagen of the precardinal lymphatics $\left(5^{\prime}\right)$ since these do not as yet communicate with the continuous lymphatic system as a whole. The abore-mentioned continuous lymphatic system, as well as the veins, can also be readily injected from the subocular lymph sacs.

Observations made upon the living trout embryo at this stage of development have also shown that, in the absence of lymphatico-venous valves, blood may pass from the veins into the lymphatics. In a great number of instances blood was observed to pass from the precardinal rein into the lateral pharyngeal lymphatic of a living trout embryo and, after filling completely the subocular lymph sac, to flow back into the reins. Figure 15 is a section of a twenty-day steelhead trout embryo which passes through both subocular lymph saes and in which it is seen that the sac on the right side is completely filled with blood, while that on the left side is empty. In all such cases as those mentioned above, the blood-filled subocular lymph sac has invariably established its connection with the lateral pharyngeal lymphatic and, in the case of the twenty-day steelhead trout embryo (fig. 15), this connection was established only upon the right side. In trout embryos older than twenty-two days, and in which lymphatico-venous valves have been formed, the application of chloretone was found to vitiate the normal function of the valves. Blood would even then flow freely into the lymphatics from the veins and fill up completely all of the lymphatic channels, including the subocular lymph sacs, which had established a communication with the veins. When such embryos were removed to water in which no chloretone was present, the blood usually flowed back into the veins from the lymphatics. There so-called blood-injected embryos proved of great service in many instances, in following the course of lymphatic channels. In abnormal living trout embryos, especially those with spinal currature, and at an age at which lymphaticovenous valves should be present; blood was frequently found in the subocular lymph sac and in the lateral pharyngeal lymphatic. 
There is no question whatever that venous blood may be present in the lymphatics of the living trout embryo during certain stages of development. The only possible question at issue is the significance which the presence of renous blood in the lymphatics implies.

\section{ARE THE LYMPHATICS OF FISHES TRANSFORMED VEINS?}

The presence of venous blood in the lymphatics has given rise to the view that the lymphatics of fishes are transformed reins and that they are more closely related to the veins than the lymphatics of the higher vertebrates. This view, I think, was originally advanced by Favaro ('06). More recently Mózejko ('13) has advocated the view that a true lymphatic system, similar to that found in mammals, is not even found in fishes but is met with for the first time in the amphibia.

If the view that the lymphatics of fishes are transformed veins signifies that certain vessels of the embryo which primarily function as veins subsequently assume a lymphatic function, I have positive proof, I believe, in the case of the subocular lymph sacs of the trout, that such is not the case and proof to this effect will, as we shall see, similarly disprove the contention of Mózejko. On the other hand, if the "transformation" theory merely signifies that the lympinaties of fishes are derived from the endothelium of the reins, that is another question and one which forms the main theme of this paper. As I interpret the "transformation" theory, it signifies that vessels which function primarily as veins may subsequently assume a lymphatic function.

If the lymphaties of fishes are transformed veins and are more closely related to the veins than the lymphatics of the higher vertebrates, they should invariably function in the capacity of veins, or, at least in the capacity of both veins and lymphaties, at the time of their first appearance in the embryo. This is positively not the case, howerer, with the subocular lymph sacs of the trout embryo and detailed evidence to this effect will be presented in the following pages. It may be stated here that during the earliest stages of their development the suboculat 
lymph sacs of the trout embryo function entirely independently of the reins and serve solely as independent reservoirs for the reception of lymph which they receive from the intercellular tissue spaces of the head region. At a later stage of development, however, these sacs then secondarily establish a communication with the veins through another lymphatic (lateral pharyngeal lymphatic, 3 in fig. 10) and, at such a time, and then only before lymphatico-renous valves have been formed, can the subocular lymph sacs of the trout receive venous blood from the veins: In view of these observations, those who maintain that the presence of venous blood in the lymphatics of fishes indicates that their lymphatics are transformed veins, or, contend that fishes do not possess a lymphatic system which is comparable to that of other vertebrates, will have to explain why the subocular lymph sacs of the trout embryo first function solely as lymphatics, and may then assume a so-called venous function, only after they have established a secondary and indirect connection with the veins.

As previously stated by IIuntington and McClure ('10), I believe that the lymphatics, as distinguished from the reins, are lymphatics from the time of their first appearance in the embryo. My observations on the trout embryo lead me to believe that the passage of venous blood from the veins into the lymphatics is a procedure of no physiological significance whatever and, under normal conditions, is alone made possible by the absence of lymphatico-venous valves. In ordinary circumstances and before lymphatico-renous valves have been formed in the trout embryo, the flow of renous blood into the lymphatics may possibly be related to an intermittent flow of lymph into the veins. In many cases observed in the living trout embryo it appeared to be largely accidental and could be induced by a rough handling of the embryo, by the application of chloretone, or by the shock produced at the time the embryo was placed in the fixing agent. In the absence of lymphatico-venous valves there is no physical impediment to prevent the blood from passing into the lymphatics from the veins. After these valves have been formed, however, it is extremely difficult to force the injecta into the 
lymphaties from the veins without causing extravasations, and I therefore doubt if the flow of blood through valves which are especially constructed to prevent its passage can be regarded at any time, either in fishes or in any other vertebrate, as a normal procedure. It is true that blood corpuscles are often found in the lymphatics of the trout after the lymphatico-venous valves have been established. In such cases, however, if these corpuscles have not been forced through the valves under unusual conditions, it is likely that they are either the remains of those which passed into the lymphatics before valves were formed, or corpuscles which the lymphatics have taken up from the tissue spaces.

Although I have not had the opportunity of studying the living embryos of Amia and Lepidosteus, I can state from a study of sections that, before lymphatico-venous valves have been formed, venous blood flows into the lymphatics from the veins. After the formation of valves, however, the blood no longer has free access to the lymphatics and, in this respect, the conditions found in the embryos of ganoids are the same as those in the trout.

It must be borne in mind that the passage of blood from the veins into the lymphaties is a phenomenon not exclusirely confined to the embryos of fishes. In the embryos of all other vertebrates, including mammals, blood must necessarily have free access to the lymphaties during those early stages of development in which lymphatico-venous valves are wanting and in which the lymphatics are capable of being freely injected from the veins. Since the passage of renous blood into the lymphatics normally ceases with the formation of lymphatico-venous valves, it is hardly probable that its presence in the lymphatics of the embryo, in either fish or mammal, is indicative of any physiological condition which is essential to the economy of the rascular system at a time before, but not after lymphatico-venous valves have been formed. It is quite possible in the ease of some fishes that lymphatico-renous valves may never be formed. Even in such cases, I believe that the influx of venous blood into the lymphaties would possess no physiological significance beyond that temporarily displayed in the embryos of rertebrates in gen- 
eral, at a time before lymphatico-venous valves have been formed. This influx we have seen is largely accidental in trout cmbryos and, even then, is practically only permissible in the absence of lymphatico-venous valves. In view of what has been stated above regarding the subocular lymph sacs of the trout, and the presence of blood in the lymphatics of vertebrates in general (in relation to the absence of lymphatico-venous valves), it is plain that the presence of blood in the lymphatics in no sense indicates that the lymphatics of fishes are transformed reins, or, that they are more closely related to the reins than the lymphatics of other vertebrates.

Miller ('13) and Huntington ('14) have applied the term 'haemophoric' to certain lymphatics of amniotes which convey blood corpuscles developed in the adjacent mesenchyme to the venous circulation. As far as I have been able to determine haematopoesis does not occur in the trout and ganoids in relation to the lymphatics of the head and pharynx. The influx of blood from the veins into the lymphatics of fishes is, therefore, in no sense comparable to what Huntington and Miller have described as the 'haemophoric' function of the lymphatics in the embryos of amniotes.

IV. THE MODIFICATIONS WHICH THE EMBRYONIC GROUND-PLAN OF THE LYMPHATIC SYSTEM UNDERGOES IN ESTABLISHING THE MORE ADVANCED STAGES IN THE TROUT

The lymphatic system as found in the head and pharynx of the twenty-two-day rainbow trout (fig. 10) represents a ground-plan upon which that of the adult is necessarily built. I have not followed in detail all of the transformations which lead up to the adult condition, but have examined and reconstructed several adranced stages in which the conditions cannot, in the main, be unlike those found in the adult, and which are easily interpreted on the basis of their origin from such a ground-plan.

The modifications which this primary ground-plan undergoes in subsequent stages of derelopment are largely related: (1) To the increasing importance gradually attained by the precardinal lymphatics and their tributaries; (2) to the apparently complete 
detachment and separation of the subocular lymph sacs from the rest of the lymphatic system, and (3) to the forward extension of the lateral pharyngeal lymphatic into the head region as the superficial facial lymphatic, which aids in draining this region in place of the subocular lymph sac. These modifications are shown in figure 11 which represents a reconstruction of the principal lymphaties, veins and arteries found on the left side of the head and pharynx in a $17.5 \mathrm{~mm}$. brook trout embryo.

In the $17.5 \mathrm{~mm}$. brook trout embryo (fig. 11) the precardinal lymphatics (5) form a much more extensive system of vessels than in the rainbow trout on the twenty-second day (fig. 10). They drain the gill arches, the walls of the pericardial cavity and the dorsal mesentery, and communicate with venous circulation through the medial and lateral pharyngeal lymphatics. As shown by the reconstruction, the lateral pharyngeal lymphatic (3) of the left side has lost its original connection with the lymphatic of the lateral line of the trunk (10) in the $17.5 \mathrm{~mm}$. brook trout embryo. The result is that the lymphatic drainage of the head and pharynx is now independent of that of the lymphatic of the lateral line of the trunk and enters the venous circulation only by way of the medial pharyngeal communication (2) and, to a lesser extent, at a point near the caudal end of the otocyst, where the lymphaties also communicate with the veins (13, otic communication). The medial pharyngeal communication appears to be retained in still later stages and in the adult trout, as the principal point at which the lymphatic drainage of the head and pharynx enters the venous circulation.

It has been stated above that the left lateral pharyngeal lymphatic has lost its connection with the lymphatic of the lateral line of the trunk and, in this $17.5 \mathrm{~mm}$. brook tront embryo, there seems to be no doubt that such is the case. I have evidence, however, which seems to show that the lateral pharyngeal lymphatic may not always establish a connection with the veins on both sides of the embryo, either at the cardino-Cuvierian junction, or near the caudal end of the otocyst (otic communication). It is evident, therefore, that variations found in advanced stages cannot always be attributed to the loss of com- 
munications which formerly existed in the embryo, since certain of these communications may never have been formed at the typical points. Fuch a condition is shown in the twenty-two day rainbow trout embryo (fig. 10) in which the otic communication (13) is present only on the right side. In general, such variations as those mentioned above would fall in line with those observed in mammals (Huntington and McClure 'OS; and MrCClure and Silvester '09). Here we know that the point s' of communication which the jugular lymph saes establish with the veins fall within two typical districts of communication (jugulo-subclavian and common jugular angles), and that communications may be established within only one of the two or within both of these districts.

The communication established between the subocular lymph sac and the lateral pharyngeal lymphatic on the twenty-second day (fig. 10) is, as far as I can determine, not permanently retained in quite advanced embryonic stages and in the adult. At a certain period after hatching the subocular lymph sac becomes detached from the lateral pharyngeal lymphatic so that the sac ceases to drain through the latter into the veins. Also, after its detachment, the subocular lymph sac of the trout appears to remain detached from the lateral pharyngeal lymphatic during all subsequent stages of development, and neither establishes any further communication with the veins, nor with any other portion of the lymphatic system. In correlation with the loss of the subocular lymph sac as an organic part of a connected lymphatic system, a new lymphatic channel makes its appearance in the embryo, the superficial facial lymphatic, which aids in draining the region of the head formerly drained by the subocular lymph sac. The superficial facial lymphatic (21), as shown in the $17.5 \mathrm{~mm}$. brook trout (fig. 11), forms the direct anterior continuation in the head region of the lateral pharyngeal lymphatic (3).

It is difficuit to establish definitely for the three species of trout embryos studied, the exact time at which the detachment and separation of the subocular lymph sac from the lateral pharyngeal lymphatic occurs. The sacs were invariably found to be de- 
tached in the more advanced embryonic stages, as in the 17.5 $\mathrm{mm}$. brook trout (fig. 11), and as early as in an $18.25 \mathrm{~mm}$. rainbow trout embryo. On treating an $18.25 \mathrm{~mm}$. rainbow trout embryo with chloretone the lateral pharyngeal lymphatic and its anterior continuation in the head region, the superf.cial facial lymphatic, rapidly filled with blood. A section taken through the caudal end of the subocular lymph sac of this embryo (fig. 16) shows that a partition has been formed between the sac (1) and the lateral pharyngeal lymphatic (3) which now prevents the blood from passing from the latter into the sac. A section (fig. 17) taken through the same embryo, somewhat anterior to the level of the former section, shows the independent character of the blood-filled superficial facial lymphatic (21), as well as its relation in the head region to the subocular lymph sac (1).

\section{THE EAIBRYONIC GROUND-PLAN OF THE LYMPHATIC SYSTEM IN GANOIDS AND THE SUBSEQUENT TRANSFOR- MATIONS WHICH IT UNDERGOES}

The embryonic ground-plan of the lymphatic system is exactly the same in ganoids as that described above for the twenty-twoday rainbow trout (fig. 10). In Amia and Lepidosteus, as in the trout, the subocular lymph sacs, the lateral and medial pharyngeal lymphatics, together with the precardinal lymphatics, constitute the framework upon which the structure found in the later stages of the embryo and in the adult is necessarily built. I have paid more attention to Amia than to Lepidosteus and will therefore confine my remarks, for the most part, to the conditions observed in this form.

In Amia and Lepidosteus each subocular lymph sac (1) early establishes a direct communication with the precardinal vein in the immediate neighborhood of the sac (29, fig. 12), instead of with the lateral pharyngeal lymphatic as is the casc in the trout (fig. 10). In embryos of Amia measuring somewhere between 10.5 and $12.5 \mathrm{~mm}$. in length and in those of Lepidosteus soon after they have attained the $14 \mathrm{~mm}$. stage, the subocular lymph sacs (1) then become detached from the veins (fig. 13). From this time on, with the exception of a doubtful communication in 
a $12.5 \mathrm{~mm}$. embryo of Amia between the subocular sac and the lateral pharyngeal lymphatic, the subocular lymph sac, as in the trout, appears to remain detached from the veins and from the remainder of the lymphatic system during all subsequent stages of development. It is therefore seen, in both ganoids and the trout, that the subocular lymph sacs function only temporarily in the embryo as lymphatics which drain into the veins, and that the route by way of which they drain into the reins in ganoids differs from that in the trout.

Another feature of interest is that the detachment of the subocular lymph sac from the reins occurs in ganoids at a relatively much earlier stage of development, than its detachment from the lateral pharyngeal lymphatic occurs in the trout. In correlation with this early detachment of the sac in ganoids, as compared with that in the trout, the superficial facial lymphatic makes its appearance in ganoids at a relatively much earlier stage of derclopment than is the case in the trout (compare 21 in figs. 11, 12 and 13 with fig. 10).

A comparison of the lymphatic ressels found in an adranced embryonic stage of Amia (fig. 13) with those found in a $17.5 \mathrm{~mm}$. brook trout (fig. 11), shows that the fundamental plan of the lymphatic system in the head and pharynx is the same in each. The precardinal lymphatics (5 in fig. 13) anastomose less frequently with the lateral pharyngeal lymphatic (3) in Amia than is the case in the trout. In both cases the precardinal lymphatics receive the same class of tributaries, however, and drain into the reins at corresponding typical points (9, cardino-Curierian and 2, medial pharyngeal communications, figs. 11 and 13).

W. F. Allen ('06) has described as the 'superficial facial' lymphatic in the adult Scorpaenichthys, a ressel which undoubtedly corresponds to the superficial facial lymphatic mentioned abore as being present in the embryos of Amia, Lepidosteus and the trout (compare 21 in figs. 11 and 13 of the trout and Amia with S. Fac. in Allen's figs. 4 and 5 of Scorpaenichthys). The 'profundus facial' lymphatic described by Allen in Scorpaenichthys may possibly correspond to the subocular lymph sac of the trout and ganoids and it is of interest to note that 
Allen was unable to determine the presence of any connection between this structure and the veins in the adult fish. Allen states as follows regarding this profundus facial trunk (page 47):

"The profundus facial trunk (figs. 4 and 5, P.Fac.L.V.) could only be found in the orbit; branches were seen to enter it from the adductor mandibulae muscles, and it was traced to a point in front of the proötic foramen, where it probably passed under the jugular and entered the abdominal sinus. This point, however, could not be determined."

The 'cephalic sinus' described by Allen in Scorpaenichthys and the 'Topf-Sinus' described by Jos. Hyrtl ('43) in the trout, correspond to the medial pharyngeal lymphatic (4 in figs. 13 and 11) found in the embryos of ganoids and the trout.

As the matter stands at present, considerable confusion would necessarily arise if one attempted to homologize the lymphatics as met with in the head and pharynx of adult ganoids and teleosts. Since the conditions in the adult have been found, in both cases, to be modifications of a common embryonic ground-plan, I have deemed it expedient to apply a set of terms to the lymphatics of the embryo which appear to be applicable to them, and to which the chief vessels in the head and pharynx of the adult can be uniformly referred.

What I take to be subocular lymph saes are also met with in the embryos of selachians. In a $50 \mathrm{~mm}$. embryo of Mustelus they were found to consist of exceedingly large semi-lunar shaped structures filled with blood, closely opposed to the medial side of the eyes, and to be in communication with the veins. A comparison of the subocular lymph sacs of fishes leads one to infer that their primitive function was to drain directly into the veins in the immediate vicinity of the sacs. It is seen that they function in this manner even at a relatively late stage of development in Mustelus and may possibly continue to do so in the adult; that they communicate in the same manner with the veins in ganoids during a short period of development; while in the trout and possibly in other primitive teleosts, like the trout, no direct communication is established between them and the veins, as in selachians and ganoids, in the immediate vicinity of the sacs. 
I have no definite explanation to offer concerning the significance of the detachment which the subocular lymph sacs subsequently undergo from the reins in ganoids, and from the lateral pharyngeal lymphatic in the trout. One might possibly class these sacs as evanescent structures of the same general character as the posterior lymph hearts found in the embryos of certain birds. The conditions observed in ganoids, for example, are remarkably like those in birds. In the common fowl the posterior lymph hearts function only temporarily in the embryo as structures which communicate with the veins, and, although traces of these hearts can be observed in young chicks thirty-five days after hatching (Sala '00), they never enter into the formation of the lymphatic system in the adult.

Although I have not made an exhaustive study of teleosts other than the trout, I have reason to suppose that in some of the more highly specialized teleosts it is quite possible that the subocular lymph sacs, although present in the embryo, may never at any time establish a communication with the veins or with any other lymphatic. In such cases one would expect to find the superficial facial lymphatic to be developed, and to function in the capacity of draining the head region at a relatively much earlier stage of development than is the case in the ganoids and the trout.

\section{THE DEVELOPIIENT OF THE SUBOCULAR LYIPH SACS IN THE TROUT}

The subocular lymph sacs can be observed in the liring trout embryo during the earlier as well as later stages of their derelopment; for this reason, as well as on account of the relatively large size they attain, they lend themselves in an unequalled manner to injection experiments in the living form.

In the living trout embryo the subocular lymph sacs appear as non-pulsatile, translucent, triangular-shaped sacs filled with lymph which can easily be withdrawn from the sacs by means of a cannula. These sacs (1) lie on each side of the head, ventromedial to the eye (fig. 18), and are lined by an endothelium around which no muscular coat is formed. 
By injecting into the subocular lymph sacs of the living trout embryo, as well as into other lymphatics (lymphatic of the lateral line of the trunk and lateral pharyngeal lymphatic), or, into the caudal artery or caudal vein, the following observations have been made:

1. The subocular lymph sacs of the trout do not communicate with each other.

2. The subocular lymph sacs of the trout do not communicate with the veins, nor with any other lymphatic vessel during the earlier stages of their development (figs. 1 to 9 , inclusive).

In the steelhead and rainbow trout embryos for a period of from five to seven days after fortilization, and in the brook trout for a relatively longer period, each subocular lymph sac serves as a local and independent reservoir for the reception of lymph which it receives from the head region. This lymph is temporarily retained by the sac until it establishes a connection with the lateral pharyngeal lymphatic through which the sac then drains into the veins. Prior to the establishment of this connection with the lateral pharyngeal lymphatic, it has thus far proved impossible either to inject the subocular lymph sacs by way of the lateral pharyngeal lymphatic or the veins, or, to inject the lateral pharyngeal lymphatic or the veins by injecting into the subocular sacs.

Figure 18 is a photograph of a Spalteholz preparation of a twenty-day rainbow trout embryo (ventral view) on which the attempt was made to inject the lymphatic system by way of the subocular lymph sacs. The photograph shows that the subocular lymph sacs alone have received the injecta and that none of it has passed from the sacs into the lateral pharyngeal lymphatic or into the veins. Sixteen injections of this character were made of the subocular lymph sacs of the trout during the early stages of their development, and in three cases the injecta was observed to pass into the veins. On sectioning these three embryos, however, it was found that the inner wall of the sac had, in each case, been punctured by the cannula and that the injecta had extravasated into the capillaries and the veins. In other cases in which the injecta was forced into the subocular lymph 
sac of a living trout embryo and the embryo kept alive for some hours, it was found that none of the injecta had passed from the sac into the lateral pharyngeal lymphatic or into the veins.

The above observations on the living trout embryo are fully borne out by a study of sections and they seem to prove conclusively that the subocular lymph sacs of the trout embryo are entirely independent of the veins and of the lateral pharyngeal lymphatic during the earliest stages of their development (figs. 1 to 9 , inclusive). Injection experiments also prove that the subocular lymph sacs of the trout embryo do not increase in extent in a caudal direction.

The subocular lymph sacs of the trout therefore furnish us with a striking example of the fact that, not only do independent anlagen of the lymphatic system actually exist, but that they can also be observed and experimented upon in the living embryo. Also, in view of the circumstance that the subocular lymph sacs of the trout do not communicate with the veins during the earliest stages of their derelopment, it is evident that they do not at first function as reins and that they therefore can not be regarded as transformed veins.

3. The originally independent subocular lymph sacs of the trout embryo establish a temporary communication with the lateral pharyngeal lymphatic (fig. 10).

In steelhead and rainbow trout embryos, dereloped at a temperature of about $10.5^{\circ} \mathrm{C}$. the subocular sacs establish a direct communication with the lateral pharyngeal lymphatic on approximately the twenty-second day after fertilization. As soon as this communication has been established, the sacs can then be readily injected from the reins by way of the lateral pharyngeal lymphatic, which is the only route by means of which the injecta or blood from the reins can, at any stage of derelopment, reach the subocular lymph sacs.

If, on account of its independent character, the presence of the subocular lymph sac happened to be unknown, it is erident by injecting into the reins or into the lateral pharyngeal lymphatic, that its presence would still remain undetected until the sac had established its connection with the lateral pharyngeal 
lymphatic, and the sac might then be erroneously interpreted as an outgrowth of the latter (compare 1 in figs. 9 and 10). It is also evident if one attempted to follow the development of the lymphatics by injecting into the subocular sacs, that none of the other lymphatics already established in the embryo (lateral and medial pharyngeal and precardinal lymphatics, fig. 9), would receive the injecta until a communication had been established between the sacs and the lateral pharyngeal lymphatic; in which case one might also erroneously infer that all of the lymphatics of the head and pharynx had sprouted from the subocular sacs.

The above observations can be easily verified on living trout embryos and serve among the best examples I know of in proof of the inadequacy of the injection method as a means of determining even the presence in the embryo of the actual anlagen of the lymphatic system. The injection method is still consistently employed by Professor Sabin and is the one upon which her conception of the development of the lymphatics, as continuous hollow outgrowths from the veins, was originally based (Sabin '02).

4. The subocular lymph sacs of the trout embryo subsequently become detached from the lateral pharyngeal lymphatic (fig. 11).

As stated on a preceding page (p. 16), the subocular lymph sacs of the trout subsequently sever their connection with the lateral pharyngeal lymphatic and, from this time on, apparently neither establish any further communication with the veins, nor with any other portion of the lymphatic system. Although the independent character of the sac in the more advanced stages can be demonstrated by the injection method, the extravasations produced by forcing the injecta through the lymphaticovenous valves has proved this method to be unsatisfactory. The most conclusive proof of the independent character finally assumed by the sacs was obtained by observing the course followed by the blood in the lymphatics of the living embryo, after the latter had been subjected to a treatment of chloretone. In such embryos (see p. 10) the blood was observed to flow from the veins into the lateral pharyngeal lymphatic and thence into its anterior continuation in the head region, the superficial facial lymphatic, without entering the subocular lymph sac. 
Having considered the derelopment of the subocular lymph sacs of the trout, as far as can be observed by following the course of the injecta in the living embryo, let us now turn our attention to their study by means of sections.

The embryos were fixed in aceto-sublimate, picro-sublimate, Zenker's and Tellyesnickzky's fluids, all of which gave good results. Transverse, frontal and sagittal sections were studied, ranging in thickness from six to twenty micra. The sections were stained in borax carmine, Delafield's hematoxylin, Ehrlich's hematoxylin, Delafield's hematoxylin-orange G, Delafield's hematoxylin-cosin, and Mann's methyl blue-eosin, as recently modified by Reagan ('14). The last-mentioned stain is especially favorable for the demonstration of endothelium.

It has already been mentioned on a preceding page that the rate at which the lymphatic system develops depends largely upon the temperature of the water in which development takes place. Such being the case, it is evident, even for the same species of trout, that a particular stage of development cannot be uniformly designated as occurring upon any particular day. Even when developed under the same conditions of temperature individual rariations are also of frequent occurrence; not only among different individuals of the same age, but even upon opposite sides of the same individual. When the age of an embryo is mentioned in the following pages, it must not be regarded, therefore, as uniformly related, in all cases, to the degree of development to which it is assigned.

The progressive increase in size which the subocular lymph sacs of the trout undergo during the course of development is shown in the series of reconstructions illustrated by figures 1 to 10 , inclusive. These figures also show the independent character of the subocular lympln sacs (1, figs. 1 to 9 , inclusive) during the early stages of derelopment, and the connection which they secondarily establish with the lateral pharyngeal lymphatic (fig. 10).

The earliest stages in the development of the subocular lymph sace, as obserred in sections, are shown in figures 19, 20, 21, 22 and 23 , which are photomicrographs of sections (10 micra in thickness) that pass through the region occupied by the anlagen 
of the sacs. These five sections are all of the steelhead trout and it is unnecessary to state that the corresponding stages can also be found in brook and rainbow trout embryos. Figures 19, 20, 22 and 23 are photomicrographs of sections of injected embryos which were developed at a temperature of about $10.5^{\circ} \mathrm{C}$ (Series II, 1913); figure 21 is a section of another steelhead trout embryo developed at a still lower temperature and belonging to another series (Series 1912).

The very earliest indication of the anlagen of the subocular lymph sacs, as met with in the trout embryo, is shown in figure 19. These anlagen (1) appear as clear areas within a denser mesenchyme and lie lateral to the carotid arteries (22) and slightly caudal and ventro-medial to the eyes. The area occupied by these anlagen is included within the leaders in the figure. The section represented by figure 19 was cut in the frontal plane.

So much variation occurs in the rate at which the subocular lymph sac of the trout develops, that one is actually able to follow every gradation in its development, from the time of its first appearance until it has become a well-defined sac, even within a single group of embryos of exactly the same age which have developed together under similar conditions of temperature. For example, among twelve steelhead trout embryos (Series II, 1913) developed in the same tank and which were killed on the fourteenth day after fertilization, the following observations were made: In two embryos no indication of the anlagen of the subocular sacs could be observed; in one embryo the anlagen of the sacs (1) were represented as clear areas in the mesenchyme as shown in figure 19; in three embryos the anlagen of the sacs were clearly defined spaces in the mesenchyme as shown in figure 20 and, in each case, were included in one section; in one embryo both sacs were included in two sections; in one embryo the sac was included in two sections on one side of the body and in three on the other; in one embryo the sac was included in two sections on one side of the embryo and in five on the other; in one embryo the sac was included in three sections on one side of the body and in four on the other; in one embryo the sac was included in five sections on one side of the body and in four on the other, 
and, in one embryo the sac was included in six sections on each side of the body (fig. 22). All of the above-mentioned sections were ten micra in thickness.

It is thus seen, within a particular group of trout embryos. of exactly the same age and developed under similar conditions of temperature, that every gradation in the bilateral establishment of the subocular lymph sacs can be observed; from their very first appearance in the embryo until they have approached in size and importance a degree of development which may even be found in embryos on the fifteenth day after fertilization (fig. 23). Compare figures 22 and 23, which are photomicrographs of sections taken through the subocular lymph sacs of steelhead trout embryos, developed under similar conditions, on the fourteenth and fifteenth days, respectively, after fertilization. It is unnecessary to state that a similar set of observations could be made upon other groups of the same, or upon other groups of different species of trout embryos, which have developed under the same or under different conditions of temperature. I think there can be no question, therefore, that the clear areas (1) shown in figure 19 constitute the earliest anlagen of the subocular lymph sacs and to these we will now turn our attention.

The origin of these earliest anlagen of the subocular lymph sacs is naturally the main question at issue. Do these anlagen communicate with the veins at the time of their inception and can they be injected from the veins? Do these early anlagen at first possess what one might regard as an endothelium? Are these early anlagen of the subocular lymph sacs connected with the endothelium of the veins by solid cords of cells which might indicate that they are outgrowths from the veins?

Do the anlagen of the subocular lymph sacs communicate with the veins at the time of their inception and can they be injected from the veins?

As the result of numerous observations made on all three species of trout embryos and without exceptions, it has been my experience that the study of sections completely corroborates all of the above-mentioned observations made on the living trout embryo. Barring self-evident extravasations, I have been unable to inject 
the subocular lymph sacs of the trout embryo from the veins prior to a relatively late stage of development, when a connection is then secondarily established between the sacs and the lateral pharyngeal lymphatic. It can be definitely stated, therefore, that at the time of their inception and during the early stages of their development, the subocular lymph sacs of the trout embryo do not communicate with the veins. Since the anlagen of the subocular lymph sacs cannot be injected from the veins, it is evident that the injection method neither reveals their presence in the living embryo, nor does it throw any light upon their actual mode of origin.

Do the anlagen of the subocular lymph sacs of the trout embryo at first possess an endothelium?

As shown in figures 19 and 20, the earliest anlagen of the subocular lymph sacs (1) appear as clear areas in the mesenchyme which are bounded on all sides by more closely arranged mesenchymal cells. Figures 1 and 2 are reconstructions of the left and right sides, respectively, of the embryo from which figure 20 is taken, and they show the position and relative size of the anlagen of the subocular lymph sacs (1) at about the time of their first appearance in the embryo. The anlage of the sac shown on the left side of figures 19 and 20 is more clearly defined in section than that on the right side. An examination of these clear areas (1) under high magnification shows that they have not been injected and that the clear appearance they present is due to the presence of a loosely arranged mesenchyme, between the strands of which intercellular lymph spaces are present. As these intercellular lymph spaces gradually increase in size, the anlagen of the subocular lymph sacs often present a multilocular appearance (fig. 21), due to the presence of mesenchymal strands or bridges which extend between their walls and divide the anlage of the sac into a number of compartments. These bridges rapidly break down, however, so that a single-chambered sac finally results (fig. 22). The presence of nuclei within the anlagen of the subocular sacs (left side, figs. 19 and 20), is a feature quite characteristic of developing lymph vesicles found elsewhere in the embryo. Such nuclei often appear as isolated bodies in an other- 
wise clear lymph space and, as is the case of the subocular sacs, are undoubtedly related to the mesenchymal strands which formerly bridged the space.

I have been unable to determine the presence of a definite endothelium in the earliest anlagen of the subocular lymph sacs. The cells which form their walls cannot be distinguished from those of the surrounding mesenchyme. As soon as the subocular lymph sacs assume the character of definite collecting centers for lymph, the cells which form their walls begin to arrange themselves in the form of a definite endothelium. Such a condition signifies that certain cells of the embryo are undergoing a differentiation to form the definite lymphatic endothelium, otherwise it is difficult to see why transitional stages should be found.

Exactly the same transitional stages from mesenchyme to endothelium can be observed in connection with the establishment of the definite endothelium of the reins. At an early stage of development the cells which form the walls of venous channels cannot be distinguished from those of the surrounding mesenchyme and it is only later that they become spindle-shaped and assume the typical endothelial form.

Are the early anlagen of the subocular lymph sacs connected with the endothelium of the veins by solid cords of cells which might indicate that they are outgrowths from the veins?

I have also been unable to determine the presence of solid cords of cells which might extend between the endothelium of the reins and the anlagen of the subocular lymph sacs. The only veins with which such solid cords of cells could posibly be connected are the precardinal (jugular) and the infraorbital reins. The precardinal reins (6, figs. 19 and 20) lie dorsally and widely separated from the sacs. The infraorbital veins (23, figs. 1 and 2) which are tributaries of the precardinal, lie at first anterior to the anlagen of the subocular sacs, and in the embryos from which figures 19 and 20 are taken, are situated about sixty and seventy micra, respectively, anterior to these anlagen (compare 1 and 23 in figs. 1 and 2). Figure 25 is a photomicrograph of a section taken through a fourteen-day steelhead trout embryo at the level 
of the infraorbital rein (23), in which region it is seen that the subocular sac has not yet made its appearance. The embryo from which figure 25 was taken, is represented in reconstructions by figures 1 and 2 .

In view of the observations thus far made on the living embryo and by means of sections, it may be stated that: (1) The development of the anlagen of the subocular lymph sacs of the trout is initiated soon after a definite haemal circulation has been established. The lymph present in the intercellular tissue spaces of the head region is then directed toward these anlagen which are uniformly situated at definite focal points within an otherwise densely arranged mesenchyme; (2) the gradual increase in the amount of lymph received by the subocular lymph sacs during the stage of their independence, results in the application of a constant and continuous pressure to the mesenchymal cells forming their walls, which in itself must be a positive factor in causing these cells to flatten out and gradually to assume an endothelial form. In fact, the recent experimental investigations of W. C. Clarke ('14) appear to bear out this view in a most decisive manner. Clarke's observations are as follows:

Following a purely physical injury which destroys the free surface cells of the peritoneum, pleura, or the lining cells of blood vessels, two possibilities exist as to how regeneration of the damaged zone proceeds. (1) Cells grow from the periphery of the given denuded area, taking origin from the adjacent, previously existing and intact flat surface cells; (2) the exposed deep connective tissue cells making up the floor of the injured area proliferate, change in form, becoming flattened.

These experiments were undertaken in reference to the latter possibility in the regeneration of surface cells to learn what happens as regards connective tissue cells in contact with a smooth surface, whether solid or fluid; in other words to learn what change in form takes place in the investing connective tissue cells in contact with the surface of a non-irritating body, placed for a time in the subcutaneous tissue of a living animal.

The sections showed that the cells in contact with the surface of the foreign bodies were changed in form in all of the specimens into large, flat cells placed edge to edge resulting in a definite sheet. The silver salt demonstrated a mosaic of black silvered lines marking the cell outlines of the lining of surface cells. 
The fact demonstrated in the above experiments that connective tissue-cells are changed in form by physical agents into flat, closely disposed cells, the outline of which may be defined by silver salts, makes tenable the conclusion that the exposed connective tissue cells, exposed through sacrifice of surface mesothelial cells of pleura, peritoneum, or pericardium or of the lining endothelial cells of vessels, may become flattened by pressure or friction or both, resulting in regeneration of the surface cells.

Tp to this point we hare considered only the earliest stages in the development of the subocular lymph sacs and will now turn our attention to the later stages.

Soon after their first appearance as definite single-chambered structures, the subocular lymph sacs of the trout gradually increase in size and extent, and by the time a connection is about to be established between them and the lateral pharyngeal lymphatic, they have become relatively huge structures (fig. 42).

As shown by injection experiments and by reconstructions (figs. 1 to 10, inclusive), the subocular lymph sacs do not increase in extent in a caudal direction. The base or caudal end of the sac remains practically stationary during all stages of development and lies just in front of the hyoidean artery (15). ${ }^{4}$ The extension of the subocular sacs takes place in an anterior direction and can be followed through the different stages of development. During the course of their forward extension the subocular sacs gradually approach and finally come into close contact with the infraorbital reins, and it might be reasonably expected that a temporary communication, as occurs in ganoids, would be established between the independently formed sacs and the veins. Such, however, has not been found to be the case. In no instance has a communication been observed between the subocular lymph sacs of the trout and the infraorbital reins, in sections either of injected or uninjected embryos. Even if a communication were established it would not be a primary one

1 In the trout (fig. 10) and in Amia (fig. 12) the first or most anterior pair of efferent aortic arches (15) subsequently become detached from the roots of the dorsal aorta and then function as the efferent (ophthalmic) arteries of the pseudobranch (15', figs. 11 and 13). For a detailed description of the pseudobranchial arteries in adult teleosts see Silvester's paper ('0t) The blood vascular system of the tile-fish (Lopholatilus chamaeleonticeps). 
since, as already demonstrated by figures 1,2 and 25 , the subocular lymph sacs develop at first remote from the infraorbital veins (23) and only subsequently come into contact with them in the course of their forward extension. Figure 24 is a section taken through the subocular lymph sacs of a sixteen-day rainbow trout embryo in the region where the saes (1) and the infraorbital veins (23) are in close contact with each other (compare figures 24 and 25). Although the infraorbital veins in the sixtcen-day trout embryo have been injected to their fullest extent, it is seen that the subocular lymph sacs have not received any of the injecta. This has been found invariably to be the case in all trout embryos which have been injected. When blood corpuscles are met with in the subocular lymph sacs, in stages where the latter are still independent, their presence must therefore be attributed to other causes than to a connection between these sacs and the reins. Although never abundant, such corpuscles are, however, sometimes met with and, if they have not been extravasated into the sacs from the veins, or floated over into them in the balsam, they must have been derived from the walls of the sacs, or taken up from the adjacent mesenchyme.

The method by which the caliber of the subocular lymph sac increases in size and by which the original anlage of the sac extends in an anterior direction, are questions of considerable interest and importance.

Soon after the subocular lymph sac of the trout has been established in the form of a single-chambered structure, it rapidly increases in caliber. This appears to take place by division of the cells which form its walls and not by the further addition to it of mesenchymal spaces. In other words, the increase in caliber or expansion of the sac along its transverse and dorso-ventral diameters, results from a growth of the walls of the sac and, in this respect, resembles the embryonic aorta which, after it has once been laid down, gradually increases in caliber in this same manner with the growth of the embryo.

The extension of the subocular sac in an anterior direction does not appear to take place, however, in exactly the same manner. Sections taken through the anterior end of the sub- 
ocular sac of the trout often present a multilocular appearance and, in this respect, resemble the conditions found in its original anlage (fig. 21). Figure 26 represents such a section taken through the anterior end of the left subocular lymph sac of a twenty-two-day rainbow trout embryo. The subocular sac is seen to be divided into three compartments by two strands of mesenchymal tissue and faint traces of strands were also observed in the sac of the opposite side when examined under high magnification. Compare figure 26 with figure 21, which is a section taken through the subocular sac soon after its first appearance in the embryo. As such compartments are not met elsewhere in the subocular sac, their presence at the cranial end of the sac in the twenty-two-day trout embryo is undoubtedly indicative of a primary and transitional condition, in which this portion of the sac is still incomplete and is still in the process of formation. Such a condition cannot be accounted for on the ground that a single-chambered anlage of the sac (1), as shown in figure 23, has gradually expanded forward. It is therefore evident that the forward extension of the subocular lymph sac takes place, not only by a growth of its walls which keeps pace with the growth of the embryo but also, like the earliest anlage of the sac (fig. 21), by the addition and confluence of independent anlagen.

VII. THE DEVELOPMENT OF THE LATERAL PHARYNGEAL LYMPHATIC IN THE TROUT

It is by means of the anlagen of the lateral pharyngeal lymphatic that a communication is first established in the regions of the head and pharynx between the lymphatics and the reins. The earliest anlagen of the lateral pharyngeal lymphatic to make their appearance in the trout embryo may establish communications with the precardinal (jugular) rein near the caudal end of the otocyst, at the cardino-Cuvierian junction, and at almost any point between the two. These points of communication may be retained in the later stages and, as far as determined, constitute the only points of communication which the 
anlagen of the lateral pharyngeal lymphatic ever establish with the precardinal vein.

If the lateral pharyngeal lymphatic sprouts centrifugally, continuously and uninterruptedly from the endothelium of the veins, the supporters of the 'centrifugal' theory would necessarily maintain that it should do so only from the primary and typical points at which it can be observed to connect with the veins. Such being the case, they would also maintain that that portion of the lateral pharyngeal lymphatic which lies anterior to the points at which communications are established with the veins (between 13 and 1 in fig. 10), should be formed as the result of the forward extension of the more caudally situated anlagen of the lateral pharyngeal lymphatic which do connect with the veins. Also, in accordance with the 'tests' they have made, Sabin ('11) and E. R. Clark ('11 a) would necessarily agree that this anterior portion of the lateral pharyngeal lymphatic should always remain in continuity with the veins and that it should be potentially capable of being injected from the veins.

Let us see to what extent these conditions are fulfilled as shown by a study of injected trout embryos. We will first consider the development of that portion of the lateral pharyngeal lymphatic which lies anterior to the points at which primary communications are established between it and the veins; and second, that portion of the vessel which arises contiguous to and which communicates with the precardinal vein.

1. The development of that portion of the lateral pharyngeal lymphatic which lies anterior to the points at which primary communications are established between it and the precardinal vein

This portion of the lateral pharyngeal lymphatic, as stated above, extends between the otic communication and the subocular lymph sac (between 13 and 1 in fig. 10), and develops slightly later than the more caudally situated portion of the vessel which establishes typical communications with the precardinal vein. A study of injected trout embryos shows that this anterior portion of the lateral pharyngeal lymphatic makes 
its first appearance in the form of a series of independent and discontinuous vesicles, which can neither be injected from the veins at points contiguous to them, from the subocular lymph sacs,.nor from the more caudally situated anlagen of the lateral pharyngeal lymphatic which can be injected from the veins. These anterior independent anlagen subsequently become connected with one another and with the more caudally situated anlagen of the lateral pharyngeal lymphatic, to form a continuous vessel which can then be injected from the veins along its entire extent, and which finally establishes a communication with the subocular lymph sac. After this confluence is completed we meet with a condition similar to that shown in figure 10 .

The progressive appearance of the independent anlagen of this anterior portion of the lateral pharyngeal lymphatic is well illustrated by a series of reconstructions which were made of injected embryos of the steelhead and rainbow trout.

In a sixteen-day steelhead trout (fig. 5) a single independent anlage $\left(3^{\prime}\right)$ has alone made its appearance on the right side of the embryo (left side of figure) which lies about opposite the first efferent aortic arch (16). In a seventeen-day steelhead trout (fig. 6) similar corresponding, and other independent anlagen $\left(3^{\prime}\right)$ have made their appearance on both sides of the embryo, and the position occupied by them now clearly indicates the course subsequently followed by the anterior portion of the lateral pharyngeal lymphatic. From this point on, if we follow thefurther development of these anterior independent anlagen $\left(3^{\prime}\right)$ in the rainbow trout, we find on the twentieth (fig. 8) and twenty-first days (fig. 9) that they have also made their appearance on both sides of the embryos, and that on the twenty-first day (fig. 9) they have reached a stage of development which immediately precedes that in which they have become confluent to form a continuous vessel (3, fig. 10).

The above-mentioned reconstructions were especially chosen from among others in order to illustrate the principle that the anterior portion of the lateral pharyngeal lymphatic is formed through the concrescence of independent and discontinuous lymph resicles. They by no means illustrate completely, how- 
ever, the marked variations which occur in the rate at which these anterior independent vesicles may develop, and may become concrescent with one another, not only among different embryos of the same age, but even upon opposite sides of the same embryo. Such variations are of frequent occurrence and an example is shown in figure 5 , in which it is seen that a single independent anlage $\left(3^{\prime}\right)$ of the anterior portion of the lateral pharyngeal lymphatic has made its appearance only upon one side of the embryo. This question will be dealt with further on in connection with another topic (Section XI, page 50).

I will not attempt to illustrate all of the independent anlagen of the anterior portion of the lateral pharyngeal lymphatic which are shown in the figures of the reconstructions. The examination of a few typical sections taken from different embryos, at approximately corresponding levels, will suffice to show that these anlagen make their appearance in a uniform manner in a graded series of embryos, and that they therefore cannot be regarded as artifacts.

The earliest of these anlagen to make their appearance arise about opposite the origin of the first efferent aortic arches (16). An examination of the reconstructions shows such anlagen $\left(3^{\prime}\right)$ to be present on the right side of the sixteen-day steelhead (fig. 5 , left side) and on both sides of the embryo in all of the subsequent stages, as illustrated by figures 6 to 9 , inclusive.

Transverse sections of a sixteen (fig. 27) and seventeen-day steelhead (fig. 28) and of a twenty-day rainbow trout (fig. 29) taken near the dorsal end of the first efferent aortic arches (16), pass through these earliest independent anlagen $\left(3^{\prime}\right)$. When compared with figure 30 , which is a section of a twenty-two-day rainbow trout taken at a corresponding level, it is seen that the continuous lateral pharyngeal lymphatic (3) in the twenty-twoday embryo occupies the same relative position in the walls of the pharynx as its independent anlagen of earlier stages.

Transverse sections taken through a seventeen-day steelhead (fig. 31) and a twenty-day rainbow trout (fig. 32) in the region of the hyoidean arteries (15), also pass through independent anlagen $\left(3^{\prime}\right)$ which correspond in their position to that occupied 
by the continuous lateral pharyngeal lymphatic (3) in the twenty-two-day rainbow trout (fig. 33). The levels at which the above-mentioned figures (figs. 27 to 33 , inclusive) are taken are indicated in figures $5,6,8$ and 10 .

In view of these observations, which could be multiplied indefinitely, I think there can be no doubt concerning the lymphatic character of these independent lymph resicles and that they cannot be regarded as artifacts.

Injection experiments have shown that these independent anlagen of the anterior portion of the lateral pharyngeal lymphatic do not communicate with the precardinal vein opposite to the points at which they lie. They have also shown that these anlagen do not communicate with the subocular lymph sac, nor with the more caudally situated anlagen of the lateral pharyngeal lymphatic which do communicate with the veins. It is evident that the results obtained by the injection method do not in the least degree support the view that these independent anlagen have been derived from the reins. It is also erident that they could not be observed in following the course pursued by the injecta in the living embryo, nor in injected embryos prepared by the Spalteholz method. Since these independent lymph vesicles are not hollow outgrouths from the reins, there can therefore be but two possibilities regarding their origin: They must either develop in situ in the mesenchyme independently of the reins, or, as described by Fedorowicz ('13) and more recently by Tampmeier ('15) for the lymphaties of amphibia, be formed as the result of a secondary vacuolization within a solid cord of cells which has grown out from some preexisting endothelium. In either case the contention so often made by Huntington and the writer would still be maintained, that the lymphatics are formed by a concrescence of independent and discontinuous vascular spaces which cannot be injected from the veins. Proof that these independent anlagen are established in relation to some preexisting endothelium lies in the determination of the presence of an actual continuity between them and some definite endothelial structure. Such a continuity I have thus far been unable to find, either with the endothelium of the subocular lymph sacs, 
with that of the precardinal rein at points opposite to them, or, with that of any of the more caudally situated anlagen of the lateral pharyngeal lymphatic which do connect with the veins.

As far as my own observations are conecrned, the independent anlagen of the anterior portion of the lateral pharyngeal lymphatic first appear as small lymph vesicles or lymph sacs which lie often remote from the veins in an otherwise densely arranged and apparently undifferentiated mesenchyme. In later stages, however, the mesenchymal cells which bound these vesicles begin to arrange themselves in a more regular manner and to assume an endothelial form. If it would not lead to confusion, one might speak of these independent anlagen as lymph vesicles before and as lymph sacs after a definite endothelium has been formed. As far as I can determine by the aid of injections and by a study of sections, the independent anlagen of the anterior portion of the lateral pharyngeal lymphatic (between 13 and 1 in figure 10) arise in situ in the mesenchyme independently of any preexisting endothelium, and their mode of development appears to be a replica of that which has been described above for the subocular lymph sacs.

2. The development of that portion of the lateral pharyngeal lymphatic which lies opposite to the points at which primary communications are established between it and the precardinal (jugular) vein

We now pass to a consideration of those anlagen of the lateral pharyngeal lymphatic which arise contiguous to the precardinal vein and contiguous to the points at which we know the lymphatics may establish direct and typical communications with the veins. As stated above, these anlagen are confined to a district which lies between the caudal end of the otocyst and the cardino-Cuvierian junction, and we have seen that much variation also exists as regards the location and number of the communications which may be established within this district. The multiplicity of communications which these anlagen may effect with the veins, is apparently analogous to the somewhat similar 
condition presented by the early anlagen of the mammalian jugular lymph sacs. It is therefore evident that the development of these anlagen should, in all probability, follow the same genetic plan as those of the mammalian jugular lymph sac.

The anlagen of the lateral pharyngeal lymphatic first to make their appearance in the embryo arise in the cardino-Cuvierian district. These anlagen $\left(\mathbf{3}^{\prime \prime \prime}\right)$ are shown in figures 1 and 2 , which represent reconstructions of the left and right sides, respectively, of a fourteen-day steelhead trout embryo. On the left side of the embryo (fig. 1) a single anlage (cardino-Cuvierian lymph sac, $3^{\prime \prime \prime}$ ) is present and lies about opposite the cardinoCuvierian junction. On the right side of the embryo (fig. 2), however, two anlagen $\left(\mathbf{3}^{\prime \prime \prime}\right)$ are met with in the cardino-Cuvierian district, one of which lies opposite the cardino-Cuvierian junction and the other slightly anterior to it.

These anlagen appear as clear areas which are situated in an otherwise densely arranged mesenchyme. Figure 34 represents a transverse section which passes through the anlage on the left side ( $3^{\prime \prime \prime}$, fig. 1 ), and through the more anterior of the two anlagen $\left(3^{\prime \prime \prime}\right)$ present on the right side of the fourteen-day steelhead trout embryo ( $3^{\prime \prime \prime}$, fig. 2). The anlage on the left side of the embryo ( $3^{\prime \prime \prime}$, fig. 1) is found in three sections (10 micra each) and that on the right (fig. 2) in one. On the left side of the embryo (right side of figure 34 ) the anlage $\left(3^{\prime \prime \prime}\right)$ is connected with the precardinal rein (6) by what appears to be a very narrow extension either of the vein or of the sac, and traces of the injecta can be observed in the walls of the cardino-Cuvierian lymph sac. On the right side of the embryo (left side of fig. 34) the precardinal rein sends out a blind process in the direction of the sac but does not communicate or connect with it. The more posterior of the two anlagen present on the right side of the embryo ( $3^{\prime \prime \prime}$, figs. 2 and 35) lies free in the mesenchyme, and no observable connection or communication exists between it and the precardinal rein. The conditions observed in this fourteen-day embryo would indicate that the cardino-Cuvierian lymph sacs of the trout are not invariably connected with the veins at the time of their inception. This is a feature of primary 
significance, as it is by means of these sacs that permanent communications are subsequently established between the lymphatics and the veins in the cardino-Cuvierian district. The presence, therefore, of a connection between these sacs and the veins, as met with in certain stages, does not necessarily indicate that the cardino-Cuvierian lymph sacs have been derived from the veins, since their connection with the veins may have been formed secondarily; either through a growth or extension of the endothelium of the veins, or by a further in situ differentiation into endothelium of the mesenchyme that intervenes between them.

What the subsequent fate of these individual lymph sacs might be, can best be surmised by observing the conditions found in a consecutive series of embryos. An examination of such a series shows considerable variation as regards the number and location of the communications which may be established between the anlagen of the lateral pharyngeal lymphatic and the veins in the cardino-Cuvierian district. These lymph sacs ( $\left.3^{\prime \prime \prime}\right)$ may establish a communication with the veins some distance anterior to the cardino-Cuvierian junction (9, figs. 3 and 4); they may communicate with the veins at two points, one anterior and the other posterior to the cardino-Cuvierian junction (9, fig. 5, right side of embryo); they may communicate with the veins at the cardino-Cuvierian junction (9, fig. 6 , both sides of embryo); they may communicate with the veins at two points at the cardino-Cuvierian junction (9, fig. 7 , left side of embryo and 9, fig. 10, both sides); or, they may communicate with the veins at three points, one at the cardino-Cuvierian junction and at two points anterior to the latter (9, fig. 9, left side of embryo). An examination of the reconstructions of the later stages also shows that lymph sacs are met with in the cardino-Cuvierian district which do not communicate with the veins. Two of these independent sacs $\left(3^{\prime \prime \prime}\right)$ are shown in the reconstruction of a fifteenday steelhead (fig. 3), and one on the right side of the twenty-day rainbow trout (fig. 8). In neither case have these independent sacs received the injecta, nor can any connection be observed between them and the veins. 
Coincident with or soon after the appearance of the cardinoCuvierian lymph sacs, other lymph sacs make their appearance contiguous to the precardinal vein in the neighborhood of the caudal end of the otocyst. The otic lymph sacs $\left(3^{\prime \prime}\right)$, as these may be termed, are shown in figures 3 and 4 which are reconstructions of the left and right sides, respectively, of a fifteenday steelhead trout embryo. These lymph sacs, like those in the cardino-Cuvierian district, may also establish a communication with the precardinal vein. On the right side of the fifteenday steelhead trout embryo (fig. 4) the cranial end of the otic lymph sac $\left(3^{\prime \prime}\right)$ lies fairly close to the precardinal vein (6) and, although the vein was fully injected, as shown in a section taken through the sac $\left(3^{\prime \prime}\right.$, fig. 36$)$ the sac is not connected with the vein (6), nor has the injecta entered the sac. On the left side of the same embryo the otic sac $\left(3^{\prime \prime}\right.$, fig. 3 ) is also independent of the vein (6) but in this case an extension from the vein runs out in the direction of the sac.

As in the case of the lymph sacs in the cardino-Cuvierian district, an examination of the reconstructions of the later stages shows that variations also occur as regards the relations of the otic lymph sacs to the veins. In the sixteen-day steelhead trout embryo (fig. 5) the otic lymph sacs $\left(3^{\prime \prime}\right)$ communicate freely with the precardinal veins on both sides of the embryo, and the relations which the sac of the right side bears to the vein resembles a condition previously described by Huntington and McClure ('10, page 203) as 'fenestration.' In the seventeenday steelhead trout (fig. 6) and in the nineteen (fig. 7) and twenty-day (fig. 8) rainbow trout no communication exists between the anlagen of the lateral pharyngeal lymphatic and the veins in the neighborhood of the caudal end of the otocyst. In the twenty-one-day rainbow trout (fig. 9) an otic communication (13) is present on the left side of the embryo, and in the twenty-two-day rainbow trout (fig. 10), in which the cardinioCuvierian and otic lymph sacs have become confluent to form a continuous channel, the otic communication (13) is present only on the right side. 
The above observations, as illustrated by sections of injected embryos and by reconstructions, fairly represent the average conditions presented by all of the anlagen of the lateral pharyngeal lymphatic at a time before, during, and after their confluence to form a continuous vessel by means of which the subocular lymph sac drains into the veins. We have already considered in detail the development of the more anterior anlagen of the lateral pharyngeal lymphatic, and it now remains for us to consider more closely the relations which the otic and cardino-Cuvierian lymph sacs bear to the veins.

From what has been said concerning the variable relations which the otic and cardino-Cuvierian lymph sacs bear to the veins, it is evident that direct and positive proof is wanting either in favor of or against their being of venous origin; this being so for the reason that, amongst the earliest stages examined, some of these sacs were found to be independent of the veins while others were connected with the veins at the typical points of lymphatico-venous entry. In view of the circumstance that in certain instances these sacs were found to connect with the veins one might infer, in the case of those sacs which did not connect with the veins, either that they had been derived from the veins and had secondarily severed their connection with them, or, that they had developed in situ in the mesenchyme and had not yet established a connection with the veins at the typical points of lymphatico-venous communication. In order to prove that the otic and cardino-Cuvierian lymph sacs have been derived from the veins, it would be necessary to show that a primary continuity invariably exists between the cells which form the walls of these sacs and the endothelium of the veins. This, we have seen, has not been found to be the case.

It has already been stated that a definite endothelium which can be distinguished from mesenchyme is wanting in the subocular lymph sacs and in the independent anlagen of the more anterior portion of the lateral pharyngeal lymphatic, at the time of their inception. I may also state that what one might regard as a definite endothelium, similar to that of the veins, is also wanting 
in the otic and cardino-Cuvierian lymph sacs at a corresponding stage. I therefore believe that the balance of evidence favors the view that, like the subocular lymph sac and the independent anlagen of the more anterior portion of the lateral pharyngeal lymphatic, the lymph sacs in the otic and cardino-Cuvierian districts develop in situ in the mesenchyme and that, while certain of these sacs may secondarily establish venous connections, others may enter directly into the formation of the lateral pharyngeal lymphatic without previously joining the veins.

Felix ('97) has described the development of the aorta and cardinal veins in the trout and salmon and finds that these vessels not only arise in situ but that their lumina are formed by a confluence of vascular spaces which make their appearance in a discontinuous manner in a solid cord of cells. The recent experimental work of Stockard ('15) on Fundulus has verified these results in all essential details. If we compare the development of the lateral pharyngeal lymphatic with that of the aorta and cardinal veins, we find that the lateral pharyngeal lymphatic, like the aorta and the cardinal veins, presents a temporary ontogenetic condition in which a continuous channel is invariably preceded by a series of discontinuous vascular spaces. This is an incontrovertible fact which can be definitely established by the aid of the injection method and by a study of sections. Such a similarity certainly signifies a common genetic plan of development for all of these independent vascular spaces, and for the endothelium which forms their walls, rather than that the plan of development for the lymphatics differs from that of the arteries and veins. This question will be more fully considered in connection with another topic (Section XIII, p. 57).

\section{THE DEVELOPMENT OF THE SUPERFICIAL FACTAL} LYMPHATIC IN THE TROUT

It has already been stated that the subocular lymph sac of the trout embryo subsequently severs its connection with the lateral pharyngeal lymphatic (page 23) and that the latter is then continued into the head region as a vessel which has been designated as the superficial facial lymphatic. This vessel (21) is 
shown in the reconstruction of the $17.5 \mathrm{~mm}$. brook trout (fig. 11) and in section in an $18.25 \mathrm{~mm}$. rainbow trout (21, fig. 17). It has proved a more difficult matter to follow the development of the superficial facial lymphatic than that of any of the other main lymphatic vessels found in the trout. One reason for this difficulty lies in the circumstance that the superficial facial lymphatic develops in an extremely loose mesenchyme the cells of which, in the earlier stages of development, cannot be distinguished from those that line the subocular lymph sac, or, from those that form the walls of the superficial facial lymphatic. Even in the later stages when the superficial facial lymphatic can be easily injected and its presence positively established, it is often quite impossible to distinguish any difference between its endothelial wall and the contiguous mesenchymal cells. It is therefore only with difficulty, and in a most favorable series of sections, that the earliest anlagen of the superficial facial lymphatic can even be identified at all.

The earliest anlage of the superficial facial lymphatic that could be identified by the writer may be described as it appeared in a rainbow trout embryo on the twenty-third day after fertilization. The anlage could be determined definitely in this particular embryo only upon the left side of the body. On the right side of the embryo, if present, the anlage was indistinguishable in section from a mesenchymal cleft. On the left side of the embryo the anlage of the lateral pharyngeal lymphatic consisted, in part, of a short vessel which communicated with the lateral pharyngeal lymphatic near a point where the latter opened into the subocular lymph sac; and, in part, of an entirely independent and separate anlage. The former could be followed anteriorly through fourteen sections and is shown in section in figure 37 , at the point where it (21) connects with the lateral pharyngeal lymphatic and the subocular lymph sac.(1), and in figure 38 eleven sections anterior to the latter.

In principle, the plan of development of the superficial facial lymphatic is similar to that of other main lymphatic channels. It develops forward into the head region, by the gradual addition to the anterior end of the lateral pharyngeal lymphatic, of 
mesenchymal strands, between which clefts or vesicles-the future lumen of the vessel-make their appearance. If one were to follow its development solely by means of the injection method, the superficial facial lymphatic would present the appearance of gradually growing continuously forward from the anterior end of the lateral pharyngeal lymphatic. As a matter of fact, however, such an appearance would only be simulated, since its forward extension, and the extent to which it can be injected, are directly dependent upon the extent to which its independent anlagen have become concrescent with the lateral pharyngeal lymphatic.

IX. THE DEVELOPMENT OF THE PRECARDINAL (JUGULAR) LYMPHATICS IN THE TROUT

In advanced embryonic stages of the trout (fig. 11) and of Amia (fig. 13) the precardinal lymphatics (5) form an extensive system of vessels which communicate indirectly with the veins by means of the lateral and medial pharyngeal lymphatics.

The development of the precardinal lymphatics parallels that of the lateral pharyngeal and superficial facial lymphatics just described. Discontinuous lymph vesicles make their appearance along the course of the precardinal veins. These discontinuous anlagen subsequently become connected with one another and with the lateral pharyngeal lymphatic, at about the level of the otic lymph sac, to form a system of vessels which can then be injected from the veins. Prior to the connection of these anlagen with one another and with the lateral pharyngeal lymphatic, I have been unable to inject them from the veins without producing extravasations.

The anlagen of the precardinal lymphatics first to make their appearance arise at about the level of the otic lymph sacs. These anlagen $\left(5^{\prime \prime}\right)$ are shown in figures 4 to 8 , inclusive. Sooner or later (figs. 5, 9 and 10), a communication (7) is invariably established between them and the lateral pharyngeal lymphatic in the region of the otic communication (13). In a fifteen-day steelhead (fig. 4) a single anlage (5") has made its appearance on the 
right side of the embryo which may possibly communicate with the otic lymph sac $\left(3^{\prime \prime}\right)$ through an exceedingly narrow intercellular connection. This anlage $\left(\mathbf{5}^{\prime \prime}\right)$, as shown in section (fig. $36)$, lies closely in contact with the precardinal vein (6) and, as the otic lymph sac $\left(3^{\prime \prime}\right)$ does not communicate with the vein, neither the otic lymph sac nor this anlage of the precardinal lymphatic has received any injecta from the vein. In a sixteenday steelhead trout (fig. 5) two of these earliest anlagen $\left(5^{\prime \prime}\right)$ have made their appearance and they not only communicate in this embryo with the otic lymph saes $\left(3^{\prime \prime}\right)$, but also through the latter with the veins at the otic communication (13). From the conditions shown in the fifteen and sixteen-day steelhead trout embryos, one might infer that these earliest anlagen of the precardinal lymphatics were not formed independently of the otic lymph sacs but were extensions of the latter, and such may possibly be the case for these particular anlagen. In view of the circumstance, however, that in relatively much later stages of development (figs. 6, 7 and 8) these same anlagen $\left(\mathbf{5}^{\prime \prime}\right)$ may also be found to be independent of the otic lymph sacs $\left(3^{\prime \prime}\right)$, I am lead to believe that they arise independently of the latter and secondarily connect with them. In other words, the independent character of these anlagen $\left(5^{\prime \prime}\right)$ in figures 6,7 and 8 , probably indicates a condition in which the establishment of a connection between them and the otic lymph sacs $\left(3^{\prime \prime}\right)$ has been temporarily delayed (see Section XI, p. 50).

We now pass to a consideration of those independent anlagen of the precardinal lymphatics which arise remote from the otic lymph sacs and remote from the typical points at which the lymphatics of the trout communicate with the veins.

In general, these anlagen of the precardinal lymphatics may be divided into two groups: One of which is situated posterior and the other anterior to the anlagen which arise contiguous to the otic lymph sacs. The position occupied by the more posterior anlagen is shown on the left side of figure 7 which is a reconstruction of a nineteen-day rainbow trout embryo. This anlage $\left(5^{\prime \prime \prime}\right)$ lies at about the level of the third efferent aortic arch (18) and, as far as can be determined, does not communicate with the 
precardinal vein $(6)$, with the anlage $\left(5^{\prime \prime}\right)$ near the otic lymph sac, nor is it connected with the vein by a solid endothelial strand. In the twenty-two-day rainbow trout (fig. 10) this anlage $\left(\mathbf{5}^{\prime \prime \prime}\right)$ connects with the precardinal sac $\left(\mathbf{5}^{\prime \prime}\right)$ which arises near the otic communication and with the former forms a continuous ressel or sac (5) which can now be injected from the veins.

The only point at which an extraintimal replacement of a degenerating rein by a dereloping lymphatic could oceur in the trout would be in connection with the precardinal lymphatics although, as far as I have been able to determine, such a replacement does not take place. It is evident, however, if the precardinal vein (6) in figure 39 were to undergo atrophy and the precardinal lymphatic (5) to increase in size, we would then have a typical example of the extraintimal replacement of a vein by a lymphatic, as described by Huntington and the writer in connection with the derelopment of the thoracic ducts and mesenteric lymphatics in mammals.

In addition to the posterior anlagen of the precardinal lymphatics just mentioned, additional independent anlagen arise in the region anterior to the otic lymph sacs. These anlagen $\left(\mathbf{5}^{\prime}\right)$ make their appearance on about the twenty-first day in the rainbow trout and, as shown in the reconstruction of the twentytwo-day rainbow trout embryo (fig. 10) they lie remote from the point at which they will subsequently connect with the lateral pharyngeal lymphatic (7). These anlagen $\left(5^{\prime}\right)$ are also shown in section (fig. 33) in which it is seen that they arise contiguous to the precardinal vein $(6)$.

The question concerning the method by means of which connections are established between the independent anlagen of the lateral pharyngeal lymphatic, and betwoen the lymphatics and the reins, is of secondary consideration at present and will be fully considered further on (Section XIII, p.57). The main question at issue is whether or not such independent endotheliallined anlagen actually exist. If they do exist, the contention that lymphatic cndothelium is specific, in the sense that it is invariably derived from that of the veins, can no longer be 
maintained and the theory that lymphatic endothelium, in general, is of venous origin would then necessarily fall completely to the ground.

\section{THE DEVELOPMENT OF THE MEDIAL PHARYNGEAL LYMPHATIC}

The earliest continuous vessel in the trout embryo which conveys lymph from the head and pharynx to the venous circulation is the lateral pharyngeal lymphatic, which may communicate with the veins in the cardino-Cuvierian and otic districts of communication. Although the otic communication is wanting, this stage is represented on the left side of the twenty-two-day rainbow trout embryo (right side of fig. 10). This early plan of drainage soon becomes modified in the trout embryo, howerer, by the formation of a new lymphatic channel, the medial pharyngeal lymphatic (4, fig. 10). This vessel taps the lateral pharyngeal lymphatic secondarily and then directs the lymph from the latter to the precardinal (jugular) vein (6); with which it communicates at a point near the exit of this vein from the cranial cavity (2, medial pharyngeal communication, left side of fig 10$)$. This modified plan of drainage has been established on the right side of the twenty-two-day rainbow trout embryo (left side of fig. 10; see also 4 in fig. 11).

From what has been stated abore, it is evident that the medial pharyngeal lymphatic makes its appearance in the trout embryo at a relatively late stage of derelopment, and that it then serves only in the capacity of conveying to the venous circulation by an additional route, lymph originally collected by an independently formed system of lymphatics (subocular lymph sac and lateral pharyngeal lymphatic).

In a series of rainbow trout embryos which were developed at a temperature of about $10.5^{\circ} \mathrm{C}$, the medial pharyngeal lymphatic made its first appearance between the twentieth and twenty-first days. On the twenty-first day $(4$, fig. 9$)$ it was found to be present on both sides of the embryo and to be connected with the veins at the medial pharyngeal communication (2, fig. 9). 
We hate already seen that the ennstituent ressels of which the (mulnyonic ground-plan of the lymphatic system is composed are the same in ganoids as in the trout. It is interesting to note, however, that the order in which these vessels appear in the embryo, in the course of their ontogenetic derelopment, is somewhat different in ganoids than in the trout.

In ganoids (fig. 12) the medial pharyngeal lymphatic develops into a large and prominent sinus (4) which drains the lateral walls of the head (21) and pharynx before a continuous lateral pharyngeal lympliatic $\left(3^{\prime \prime \prime}\right)$ has been formed. In the trout embryo, on the other hand, the medial pharyngeal lymphatic (4, fig. 10) is one of the last of the principal lymphatics of the pharynx to be developed, and it then serves only in a subsidiary capacity, after connecting with the lateral pharyngeal lymphatic, of aiding the lymph collected by the latter to drain into the veins. In the earlier embryonic stages of ganoids we therefore find that the medial pharyngeal lymphatic plays a more important rôle than the lateral pharyngeal lymphatic in conveying lymph to the venous circulation, while the reverse is the case in the trout.

The superficial facial lymphatic (21, fig. 12) also makes its appearance in the embryos of ganoids (Amia and Lepidosteus) before a continuous lateral pharyngeal lymphatic has been formed. In the trout embryo, on the other hand, the superficial facial lymphatic does not make its appearance until a relatively late stage of derelopment, and until after a continuous lateral pharyngeal lymphatic has been formed (21, fig. 11; compare with fig. 10).

In the more adranced stages, in which a continuous system of lymphatics has been established, the medial pharyngeal lymphatic serves in a similar manner, in both the trout and ganoids, as a prominent pathway or sinus, through which the lateral pharyngeal and superficial facial lymphatics drain into the reins (4, figs. 11 and 13).

For the reason that the medial pharyngeal lymphatic is a structure of relatively greater importance in the embryos of ganoids than in those of the trout, the carliest stages of its de- 
velopment are more easily followed in ganoids than in the trout. The earliest anlage of the medial pharyngeal lymphatic was met with in a $7.5 \mathrm{~mm}$. embryo of Amia $(6.81 \mathrm{~mm}$., measured by sections) and is shown in section in figure 40. 'This anlage $\left(4^{\prime}\right)$ was included in two sections (10 micra each) and, as shown in the figure, it neither communicates with the precardinal vein (6), nor is it comnected with the latter in this, or in any other section, by a solid endothelial strand. I study of the later stages shows that this independent anlage invariably establishes a connection with the precardinal vein (4, figs. 12 and 13), and it can then be easily injected from the veins before lymphatico-venous valves are formed. The vascular system of the embryo from which figure 40 is taken was fully reconstructed in order to prove that the anlage in question was that of the medial pharyngeal lymphatic. Since this independent anlage was found to occupy identically the same relative position in this embryo as that of the medial pharyngeal sac of later stages, no possible doubt can exist regarding it.

The anlagen of the lymphatic system, which develop in close relation to the typical points at which the lymphatics establish communications with the veins, have been described by Huntington and McClure ('10) in mammals as 'venolymphatics.' The term 'venolymphatic' may therefore be similarly applied to those anlagen of the lymphatic system of fishes which develop contiguous to the typical points at which the lymphatics communicate with the veins. These anlagen include the otic, the cardino-Cuvierian and the medial pharyngeal lymph sacs in the trout; the cardino-Cuvierian, the subocular and medial pharyngeal lymph sacs in ganoids. In view of the interpretation placed by the writer upon the genesis of the lymphatics in general, the use of the term 'venolymphatic,' we shall see (Section XIII, p. 57), becomes entirely unnecessary in distinguishing these anlagen of the lymphatic system from those which develop elsewhere in the body remote from the typical points of lymphatico-renous entry. The medial pharyngeal lymphatic of Amia serves to illustrate the principle of lymphatic, as well as that of rascular derelopment, in general, for the reason that, being classed as a "veno- 
lymphatic,' it ean be demonstrated that its anlage first appears in the mesenchyme independently of the veins, and that a connection between it and the veins is established secondarily. It is highly improbable that homologous structures, like the subocular lymph sacs of fishes, could differ fundamentally in their mode of derelopment. We have seen that the subocular lymph sacs of ganoids would be classed as 'venolymphatics,' on the basis of the direct connections which they establish with the reins in the immediate neighborhood of the sacs; the subocular lymph sacs of the trout, however, could not be designated as 'venolymphatics' on this basis, since they never communicate with the veins in the neighborhood of the sacs. The development of the subocular lymph sacs of fishes therefore serves as another illustration of the fact that no distinction really exists between 'venolymphatics' and other anlagen of the lymphatic system.

XI. VARIATIONS IN THE RATE AT WHICH THE LYMPHATIC SYSTEM OF THE TROU'T DEVELOPS IN DIFFERENT EMBRYOS OF THE SAME AGE, AS WELL AS UPON OPPOSITE SIDES OF THE SAME EMBRYO

It has already been stated that much variation exists in the rate at which the lymphatic system develops in different indivicluals of the same age, as well as upon opposite sides of the same individual. This rariability has been partially illustrated in the figures of the reconstructions, but is more fully borne out by the following observations which were made in following the course of the injecta in the lateral pharyngeal lymphatic of the living embryo. In order to illustrate this variability more fully, I will give the results observed in connection with a particular series of steelhead trout embryos which were developed at a temperature of about $10.5^{\circ} \mathrm{C}$ and injected under the binocular microscope. All injections were made through the caudal vein.

In this particular series of trout embryos the lymphatic system could not be injected until the fourteenth day after fertilization. On the fourteenth and fifteenth days after fertilization the cardino-Curierian and otic lymph sacs could be injected in a few 
cases, although in most of the embryos injected no indications of these sacs could be observed.

On the sixteenth day the following observations were made upon sixteen (16) embryos:

In three embryos the injecta could be forced into the lateral pharyngeal lymphatic from the cardino-C'uvierian communications, as far forward as the caudal end of the otocyst, on both sides of the body; in one embryo the cardino-Cuvierian lymph sac could be injected on one side of the body; in the remaining twelve embryos no definite observations could be made concerning the presence of lymphatic anlagen, either at the cardinoCuvierian or otic points of communication.

On the seventeenth day the following observations were made upon eleven (11) embryos:

In four embryos the lymphatics could not be injected even under pressure; in two embryos a small cardino-Cuvierian lymph sac was filled with the injecta on each side of the body; in five embryos the lateral pharyngeal lymphatic could be injected as far forward as the caudal end of the otocyst on both sides of the body and, in three of these embryos, this vessel appeared to communicate with the veins at both the cardino-Cuvierian and otic points of communication.

On the eighteenth day the following observations were made upon twenty-one (21) embryos:

In eighteen embryos the lateral pharyngeal lymphatic could be injected on both sides of the body as far forward as the caudal end of the otocyst and, in about half of the embryos, it connected with the veins at the cardino-Cuvierian and otic points of communication; in two embryos the lateral pharyngeal lymphatic could be injected on both sides of the body to about the middle of the otocyst, and in one embryo it could be injected only half way to the otocyst on one side of the body and to the caudal end of the otocyst on the other.

On the nineteenth day the following observations were made upon eighteen (18) embryos:

In four embryos the subocular lymph sacs could be injected for the first time through the lateral pharyngeal lymphatic, but 
only on one side of the body, while the lateral pharyngeal lymphatic of the opposite side of the same embryo injected to the caudal end of the otocyst in one case, to the middle of the otocyst in two cases and as far forward as the eye in the other; in three embryos the lateral pharyngeal lymphatic could be injected as far forward as the eye on one side of the body, while the lateral pharyngeal lymphatic of the opposite side injected to the middle of the otocyst in one of these embryos and to the caudal end of the otocyst in the remaining two; in five embryos the lateral pharyngeal lymphatic could be injected only to the caudal end of the otocyst on both sides of the body; in one embryo the lateral pharyngeal lymphatic could be injected as far forward as the anterior end of the otocyst on both sides of the body; in one embryo the lateral pharyngeal lymphatic could be injected to the caudal end of the otocyst on one side of the body and to the middle of the otocyst on the other; in two embryos the lateral pharyngeal lymphatic could be injected to the anterior end of the otocyst on one side of the body and, only to the caudal end of the otocyst on the other; in two embryos only a small cardinoCurierian lymph sac could be injected on one side of the body, while the lateral pharyngeal lymphatic of the opposite side injected to the caudal end of the otocyst in one of these embryos, and to the anterior end of the otocyst in the remaining two.

On the twenticth day the following obscrvations were made upon twelve (12) embryos:

In three embryos the subocular lymph sacs could be injected through the lateral pharyngeal lymphatic on both sides of the embryo; in two embryos the subocular lymph sac could be injected through the lateral pharyngeal lymphatic on one side of the embryo (fig. 15), while the lateral pharyngeal lymphatic of the opposite side injected up to the subocular sac but did not communicate with it; in one embryo the subocular lymph sac could be injected through the lateral pharyngeal lymphatic on one side of the body, while the lateral pharyngeal lymphatic of the opposite side injected only to the caudal end of the otocyst; in two embryos the subocular lymph sacs could be injected through the lateral pharyngeal lymphatic on one side of the body, while 
the lateral pharyngeal lymphatic of the opposite side could not be injected under pressure; in two embryos the lateral pharyngeal lymphatic could be injected on both sides of the body, only as far forward as the caudal end of the otocyst; in one embryo the lateral pharyngeal lymphatic could be injected on both sides of the body as far forward as the subocular lymph sacs but did not communicate with them; in one embryo the lateral pharyngeal lymphatic could be injected only to the caudal end of the otocyst on one side of the body, and to the anterior end of the otocyst on the other.

On the twenty-first day the following observations were made upon thirteen (13) embryos:

In five embryos the subocular lymph sacs could be injected on both sides of the body through the lateral pharyngeal lymphatic; in six embryos the subocular lymph sac could be injected only on one side of the body and, in each case, the lateral pharyngeal lymphatic of the opposite side injected up to the sac but did not communicate with it; in one embryo the lateral pharyngeal lymphatic could be injected only as far forward as the caudal end of the otocyst; in one embryo the lateral pharyngeal lymphatic could be injected on both sides of the body as far forward as the middle of the otocyst.

On the twenty-second day both subocular lymph sacs could be injected through the lateral pharyngeal Iymphatic in almost every case (about 90 per cent). Soon after the establishment of a connection between the subocular lymph sac and the lateral pharyngeal lymphatic, valves begin to be formed at the typical points at which the lymphatics permanently communicate with the veins. It then becomes more difficult to inject the lymphatics from the veins without causing extravasations.

I fully appreciate that the above-mentioned results apply to the conditions found in relatively few embryos and that, in all probability, the injection may not, in all cases, have been complete. In view of the fact, however, that essentially similar observations were made upon eight other separate occasions, I feel that they represent, to a very fair extent, the conditions as they actually exist. 
If we analyze these observations more closely, we find that up to the eighteenth day the anlagen of the lateral pharyngeal lymphatic cannot, in all cases, be uniformly injected from the veins at the typical points of lymphatico-venous entry. From the eighteenth day on, however, with one exception on the twentieth day, no difficulty was experienced in forcing the injecta into the anlagen of the lateral pharyngeal lymphatic from the veins. The study of sections of injected embryos has shown that the inability to inject the anlagen of the lateral pharyngeal lymphatic in the carlier stages is due to the circumstance that, in some cases, they do not communicate with the veins, or, if a communication is present, it may be too narrow to permit the passage of the injecta into the anlagen from the veins.

On the eighteenth day we meet with the nearest approach to a uniformity, in which the lateral pharyngeal lymphatic has attained a stage of development which might be regarded as typical for this particular day. At this stage (in 18 of the 21 embryos injected) the lateral pharyngeal lymphatic was represented by a continuous vessel on both sides of the embryo which extended between the cardino-Curierian junction and the caudal end of the otocyst, at which point, in some cases, it communicated with the veins. This same condition was also met with to a lesser degree on the sixteenth (in 3 of the 16 embryos injected) and seventeenth days (in 5 of the 11 embryos injected) and is illustrated by figure 6 , which represents a reconstruction of a seventeen-day steelhead trout embryo. This condition signifies, I believe, the attainment of a necessary preliminary stage of development in which the establishment of the lymphatic drainage system for the posterior portion of the pharynx may be regarded as complete. This drainage system for the posterior region of the pharynx is still independent, however, of that of the subocular lymph sac.

From the eighteenth to the twenty-second day no indication of a uniform condition was met with and, during this period, the further derelopment of the lymphatic system is chiefly concerned in establishing a communication between this posterior drainage system of the pharynx and the subocular lymph sac. A study of sections of these injected trout embryos has shown 
that a series of independent lymph vesicles intervene between these two primary drainage centers and that they lie in the course subsequently followed by the lateral pharyngeal lymphatic. It has also been shown that the subocular lymph sacs cannot be injected from the veins until this intervening portion of the lateral pharyngeal lymphatic is completed and until the latter has established a connection with the subocular lymph sac. Such being the case, it is evident that the pronounced variability observed on the nineteenth, twentieth and twenty-first days, must be related to the difference in the rate at which a connection has been established between the primary posterior drainage center of the pharynx, and the independent anlagen (independent lymph resicles) of the lateral pharyngeal lymphatic which intervene between the primary posterior drainage system of the pharynx and the subocular lymph sac.

\section{XIT. DO THE PERIPHERAL LYMPHATICS FORM A CLOSED SYSTEM OF ENDOTHELIAL-LINED VESSELS SIMILAR TO THOSE OF THE HAEMAL SYSTEM?}

The presence of a closed system of peripheral lymphatics is generally regarded as a necessary corollary to the theory that the lymphatics sprout centrifugally and continuously throughout the body of the enbryo from the endothelium of the veins.' On the other hand, it is generally inferred that the view which calls for a local origin of lymphatic endothelium from tissues other than from a preexisting venous endothelium, demands the presence of a permanent open communication between the peripheral lymphatics and the intercellular tissue spaces. I may state that the falsity of this inference becomes apparent when we consider that recent investigations have conclusively shown that the endothelium of the entire blood-rascular system of vertebrates - which is a closed system-possesses a local origin. It is therefore evident that the view which calls for a local in situ origin of lymphatic endothelium, and for the development of lymphatic channels through the confluence of independent lymph vesicles, does not necessarily preclude the possibility that a closed system of 
peripheral lymphatics may exist and, if such is actually the case, the question can alone be decided by a direct observation of the facts.

I have hitherto paid little attention to this particular subject. I have made, howerer, certain observations which bear more or less directly upon this point.

In sections of the embryo one frequently meets with a condition in which the lumen of an endothelial-lined lymphatic opens directly into a mesenchymal-lined tissue space. One of the best and most convincing examples of this character was demonstrated by Huntington at a meeting of the American Association of Anatomists in 1911 and he has kindly permitted me to illustrate it here. Figure 41 is a photomicrograph of a transverse section taken through the periaortal lymph sinus of Chelydra serpentina. According to Huntington this lymph sinus is not connected with any vein and has developed in the mesenchyme in an area entirely free of veins. As shown clearly in the photomicrograph, this lymph sinus (25) is lined by a continuous layer of endothelium except at one end (right side of fig. 41) where the endothelium ends abruptly and the lumen of the lymph sinus opens directly into a typical mesenchymal-lined tissue space (26).

The increase in extent which this lymph sinus of Chelydra was still undergoing, at the time the embryo was killed, was being accomplished, I believe, as the result of an addition to it of this mesenchymal tissue space (26), and the continued addition to the latter of similar adjacent tissue spaces (32) would further increase its extent. It is evident that this lymph sinus of Chelydra with its communicating tissue space can in no sense be regarded as a closed endothelial-lined tube. If it should ultimately become one, this could be accomplished only as the result of a further local in situ differentiation into endothelium of the entire mesenchymal strand which forms the wall of the adjacent communicating tissue space. It is quite possible that $i$ the course of the subsequent extension of this lymph sinus, by the continued addition to it of mesenchymal spaces, a stage might ultimatcly be reached in which the mesenchymal wall of a communicating tissue space became differentiated into endothelium 
along its entire extent; in which case a closed endothelial-lined tube would result. It is also quite possible that the conditions actually observed in the embryo of Chelydra might persist in the adult. Whatever may ultimately be proved to be the ease for the peripheral lymphaties, in general, it would seem best for the present to withhold an opinion until a positive demonstration is at hand.

XIII. GENERAL CONSIDERATIONS CONCERNING THE GENESIS AND GROWTH OF THE LYMPHATIC SYSTEM IN ITS RELATIONS TO THE HAEMAL SYSTEM ${ }^{5}$

Does the endothelium of the lymphatic system arise, at any time or place, in a discontinuous manner and independently of that of the veins? As we shall see, the determination of this question constitutes a solution of the lymphatic problem.

The view that lymphatic endothelium spreads continuously and uninterruptedly throughout the body of the embryo from the endothelium of the veins, is merely an extension, and application to the endothelium of the lymphatic system, of the wellknown view held by His, that the endothelium of the intraembryonic haemal vessels grows continuously and uninterruptedly into the embryo from the yolk-sac angioblast. Such a method of origin necessarily implies that all intra-embryonic endothelium arises only from a preexisting endothelium which takes its origin in the yolk-sac, and that in the body of the embryo a discontinuity of origin never occurs.

The view opposed to the 'ingrowth' or 'angioblast' theory of His has been closely associated with the names of Rückert and Mollier ('06). This view consists in the claim that the endothelium of the intra-embryonic haemal vessels develops in situ ir the body of the embryo, and that it is not derived from the yolk-sac angioblast.

\footnotetext{
${ }^{5}$ Section XIII has already been published in practically its present form under the title of "The development of the lymphatic system in the light of the more recent investigations in the field of vasculogenesis' (McClure '15 b).
} 
Since the lymphatics merely represent a component part of a general vascular system, to which the haemal vessels also belong, the probability at least, is that, in the genesis of their endothelium, and in the establishment of a continuous system of vessels, the lymphatic and haemal ressels should follow a common genetic plan. Let us consider, in the light of the more recent investigations in the field of the vascular system, what this plan may be.

It is not necessary to review in detail the investigations of those who have hitherto maintained that the endothelium of the intra-embryonic blood-vascular system possesses a local origin. For an historical and critical account of this subject it is sufficient to refer to the investigations of Rückert and Mollier ('06), Felix ('97) and to the more recent one by Schulte ('14) on the development of the intra-embryonic blood-vascular system of mammals.

It should be clearly borne in mind that, until quite recently, the investigations which have dealt with the origin of intraembryonic rascular endothelium have not been experimental in character, but have been based largely upon a study of fixed material in which, however, a local and discontinuous origin of blood-vascular anlagon has been observed.

Let us now see how the view that the endothelium of the intraembryonic blood-rascular system develops in silu, and does not grow into the embryo from the yolk-sac, is borne out by experiment.

Two types of experiment have thus far been made to determine this question: (1) The partial separation of the embryo from the yolk-sac, or, the complete separation and isolation of a portion of the embryo from the rest of the embryo and from the yolk-sac, at a time prior to the possible invasion of the embryonic axis by the yolk-sac angioblast; (2) by observing the effects produced on the developing blood-vascular system in embryos which have been allowed to develop under the influence of anesthetics or other chemical agents.

The experimental investigations of Hahn ('09), and Miller and Mcllhorter ('14) have shown, by effecting a separation on one 
side between the body of the chick embryo and the yolk-sac, before ressels have appeared in the area pellucida, that blood vessels make their appearance in the body of the embryo in a typical manner on the operated side. These vessels differ from those on the unoperated side only in size and rate of development, differences which may be correlated with their reduced drainage area and the consequent diminished quantity of circulatory fluid.

These experiments of Hahn, and Miller and Mc Whorter have conclusively shown that the yolk-sac angioblast cannot have grown into the embryo on the operated side. In order to eliminate the possibility, however, that the vessels on the operated side may not have been formed in situ, but by an invasion of angioblast from the normal unoperated side, Reagan ('15) has recently performed a set of experiments in my laboratory which conclusively disprove this contention. Instead of separating only one side of the embryo from the yolk-sac, Reagan has been able to develop the heads of chick embryos, which had been completely separated from the rest of the embryo and from the yolk-sac, and in which endothelial-lined vascular channels of mesenchymal origin were invariably found to appear. As in the case of the experiments of Miller and MeWhorter, the operations were performed at a time before it would have been possible for the intra-embryonic tissue to have been invaded by yolk-sac angioblast.

Gräper ('07), under the direction of C. Rabl, performed a set of experiments on chick embryos, somewhat similar to those of Hahn, and Miller and NcWhorter, and, although he noted the presence of independent blood-islands in the body of the embryo, he was unable to interpret them as having been formed in situ.

Jacques Loeb ('12) was the first to observe the effects produced by certair chemicals $(\mathrm{NaCN}$ ) on the dereloping blood vessels in fish embryos. He was able to produce a condition in which a beating heart and blood were present, but no circulation; a condition which, as stated by Schulte, can hardly be reconciled with the doctrine that the vessels of the embryo have a primitive 
continuity of lumen with those of the yolk-sac, for it is inconceirable that in such circumstances, a beating heart could fail to effect a circulation.

The investigations of Stockard ('15) supplement and coincide with those of Hahn, Miller and McWhorter, Reagan, and Loeb in a most decisive manner. Stockard has shown that, not only do anesthetics arrest the development of the intra-embryonic blood vessels in the embryos of Fundulus, at an early ontogenetic stage, but in such a manner that no doubt can now exist that, under normal conditions, these vessels are formed in situ by a concrescence of independent and discontinuous anlagen, and that their endothelium is derived directly from intra-embryonic mesenchymal cells. It is interesting to note in this connection that Wenkebach ('86) had already observed in the body and yolk-sac of the living fish embryo (Belone longirostris), that mesenchymal cells play an important rôle in the formation of vessels and sprouts. In their general features the observations of Wenckebach have been confirmed by Raffaele ('92).

It is thus seen that experimentation bears out the observations made upon fixed and living material, that the intra-embryonic blood-vascular channels do not grow into the embryo from the yolk-sac, but are formed in situ by a concrescence of independent and discontinuous anlagen, whose endothelium is formed from intra-embryonic mesenchymal cells.

The vascular plexus formed in the extra-embryonic area of the vertebrate embryo, is as we know, at first represented by discontinuous, independent and circumscribed anlagen, the cells of which possess a local origin. Clefts or spaces, the future lumina of the plexus, soon make their appearance in a discontinuous manner amongst the cells of these anlagen, and it is by a concrescence of these vascular spaces that a continuous system of vascular lumina is finally formed. The cells which constitute the walls of these vascular spaces become transformed into the endothelium and, when blood-islands are present, the more centrally situated cells form the primary blood cells. It is interesting to note in this connection that McWhorter and Thipple ('12) have recently been able to demonstrate and record 
photographically the concrescence of separate vascular anlagen in the area pellucida of the chick's blastoderm in vitro.

If we compare the development of the intra-embryonic bloodvascular channels, as determined by observation and experiment, with that of the plexus which arises on the yolk-sac, we find, in the genesis of their endothelium from mesenchyme, and in their formation by a concresence of independent anlagen, that the intraand extra-embryonic blood-vascular channels follow exactly the same genetic plan.

If one attempted to follow the development of these intraor extra-embryonic blood-vascular channels by means of injections, it is evident that this method would reveal only the extent to which a continuous system of injectible lumina had been established at the time the injections were made. It would fail completely to reveal the facts which have been definitely determined by experiment, that the injectible lumina had been previously formed by a concrescence of independent and uninjectible vascular spaces, and that the endothelium which forms the walls of these lumina had been formed in situ, not from a preexisting endothelium, but from mesenchymal cells.

Since we now know that the intra-embryonic blood vessels, like those in the yolk-sac, are formed by a concrescence of independent anlagen, and that their endothelium is formed in situ from mesenchymal cells, the question naturally confronts us as to the method by means of which these independent anlagen become connected with one another to form a system of vessels with continuous lumina, that extend throughout the body of the embryo.

There appear to be only three possible methods by means of which such connections could take place: (1) Either by means of a proliferation or migration of the cells of which the original independent anlagen are composed; (2) by a further local in situ differentiation into endothelium of the embryonic cells which intervene between the independent anlagen; or (3) by a combination of these two methods.

We all recognize the fact that endothelium, like other tissues of the body, is capable of growth after it has once been formed. 
In no other manner could we account for the increase in size which blood vessels undergo in the embryo after they have attained their adult structure and form. It is also possible for anastomoses to be formed between different blood vessels by means of a growth or sprouting of their endothelial walls, so that, in some cases, an increase in their extent, through growth, may actually take place. It is therefore quite probable that growth may play a considerable rôle in establishing a concrescence between the independent endothelial-lined anlagen of the bloodvascular system. From whatever standpoint it may be considered, however, the growth of an endothelium is a feature of secondary significance as regards the problem at hand, since the main question at issue does not concern the possibility that endothelium may or may not grow, but rather how the endothelium is formed that does the growing.

The distinction between the actual genesis of endothelium and the growth it may undergo after it has once been formed is naturally one that has been disregarded by those who maintain that intra-embryonic vascular endothelium is not directly a local product of mesenchymal cells. A special specificity has therefore been attributed by the supporters of the 'angioblast' theory to the endothelium of the intra-embryonic vascular system, on the ground that it takes its origin only from the yolk-sac angioblast. In accordance with this view, it is by means of one continuous and uninterrupted growth of a preexisting endothelium (yolk-sac angioblast) throughout the body of the embryo, that the endothelium of the blood-vascular and lymphatic systems is formed.

Since the 'angioblast' theory of His no longer holds, the question of the specificity of tissues is involved in the vascular problem only to the same extent as is the case for any other tissue in the body. Whether the mesenchymal cells of the embryo are in an embryonic or undifferentiated state, and capable of further differentiation into cells which form muscle, connective tissue, endothelium, etc., is entirely beside the question; provided we know that the product of these intra-embryonic mesenchymal cells actually forms endothelium and that the latter is not de- 
rived from the yolk-sac angioblast. Also, the question concerning the origin of these mesenchymal cells, whether derived from entoderm, mesoderm or mesothelium (Bremer '14), does not concern us here. The main point at issue is the establishment of the fact that the endothelium of the intra-embryonic haemal vessels is the product of a local in situ differentiation of certain cells in the embryo which have nol been derived from the yolk-sac angioblasi.

Let us now compare these conditions of the intra-embryonic blood-vascular system, as determined by sections and experiment, with those of the embryonic lymphatic system.

Our knowledge of the embryonic lymphatic system is gradually approaching a state where, in such forms as teleosts and amphibia, it may also be possible to determine by experiment exactly how the lymphatic system is formed. A thorough knowledge of the lymphatic channels and the order of their appearance in the normal embryo would be quite essential, however, before experiment could be successfully applied. Since the anlagen of the lymphatics do not make their appearance in the embryo under normal conditions until after the veins have been established and have begun to function, it is quite possible, in cases of arrested development of the venous system, as demonstrated by Stockard in Fundulus, that development might never be successfully carried to the lymphatic stage. Be this as it may, until the problem has been tested by experiment, our knowledge and interpretation of lymphatic development must, for the present, be based upon the observation of fixed and of living material, and its comparison with the known developmental stages of the blood-vascular system, as observed in fixed and in living material, and as verified by experimental means. If it can be shown that the anlagen of the lymphatic system present exactly the same conditions in fixed and in living material, as those of the blood-rascular system, it is reasonable to infer that in their development the lymphatic and blood-vascular systems follow exactly the same genetic plan. If one were to observe that in certain cases intra-embryonic blood vessels were formed in the living embryo by a sprouting or growth of a preexisting endothelium, 
would he now be justified in claiming that all of the remaining blood ressels of the embryo were formed in the same manner? In view of the fact that we now know that intra-embryonic blood vessels are not all formed in this manner, it would seem that a a similar interpretation might also apply to the lymphatics (see E. R. Clark, '11b).

Whatever else the case may be, in view of the above-mentioned experimental investigations of Hahn, Miller and McWhorter, Reagan, and Stockard, it can now be definitely stated that the endothelium of the lymphatic system is neither directly nor indirectly a product of the yolk-sac angioblast. Such being the case, it must either arise in situ, like the endothelium of the intra-embryonic veins, from cells other than from a preexisting endothelium; or, be a product entirely of the endothelium of the veins. If the former case be true, the endothelium of the lymphatic system should present exactly the same independent and discontinuous method of origin in the embryo as that of the extraand intra-embryonic haemal vessels; and, if the development of the lymphatics were followed by the injection method, the same restrictions as regards the injectibility of its independent anlagen should also necessarily apply. On the other hand, if the lymphatic system is entirely a product of the endothelium of the veins, its origin from mesenchyme should naturally never occur. As a matter of fact, since intra-embryonic vascular endothelium has been shown by experiment to be a local product of mesenchyme, there now remains no valid reason or significance in the claim, as regards its specificity, that lymphatic endothelium is solely a product of that of the veins.

Let us examine the evidence at hand and see whether the endothelium of the lymphatics, like that of the haemal vessels, develops in situ in the mesenchyme, or whether it forms an exception to that of the haemal vessels, and sprouts throughout the body of the embryo from an endothelium (venous) already formed.

It is not the purpose of the present discussion to give an historical review of the literature bearing upon the development of the lymphatic system but merely, on the basis of comparison, to call attention to the evidence in favor of the view that the 
lymphatics, like the haemal vessels, are formed by a concrescence of independent and discontinuous anlagen, and that their endothelium arises in situ from intra-embryonic mesenchymal cells.

A principal contention of Huntington and MeClure ('07a) regarding the development of the lymphatic system has been that its anlagen arise independently and discontinuously in the embryo, and that its endothelium does not spread continuously and uninterruptedly throughout the body from the endothelium of the veins. We have repeatedly shown that the lumina of the lymphatics are formed by a concrescence of discontinuous and independent lymph vesicles or lymph spaces, and that the cells which constitute the walls of these spaces are derived in situ from mesenchyme and not from the endothelium of the veins. In the early stages of our investigations we laid especial stress upon a plan of development for the lymphatic system of mammals which we described under the name of the 'extraintimal' theory of lymphatic development, and which may be briefly described as follows: The development of the thoracic ducts (Huntington, '10, '11a) and mesenteric lymphatics (McClure, '10) in the cat is correlated with the degeneration of certain venous channels, many of which are tributaries of the azygos division of the supracardinal veins (Huntington and MeClure, '07b). A series of independent lymph spaces arise discontinuously in the mesenchyme external to the intimal lining of these degenerating vessels and, as these lymph spaces gradually become concrescent to form continuous channels, the latter, following a line of least resistance, utilize the static line vacated by these degenerating veins. In this manner certain of the main lymph channels of the mammalian embryo follow the course of and finally occupy completely the territory formerly occupied by veins. This principle of extraintimal replacement of certain evanescent embryonic venous channels by lymphatics accounts for the sinistral drainage plan finally assumed by the thoracic duct system in the embryo of the cat. The cranial or azygos division of the left thoracic duct of the embryo persists as the main line of drainage in the adult, in correlation with a degeneration in the 
embryo of the left supracardinal (left azygos) and left postcardinal veins and the left duct of Cuvier.

It is evident and appears clearly in our earlier publications, that the fundamental plan of development followed by these replacing lymph channels does not depart from that followed by other lymph channels, either in mammals or in any other vertebrates where the development of the lymphatics is unaccompanied by the replacement of degenerating veins. Where, as in the case of the trout, lymph channels do not develop along the course of degenerating veins, an extraintimal replacement of a degenerating vein by a lymphatic necessarily does not occur. It is therefore plain that the extraintimal replacement, as described by us, possesses only a mechanical significance, and is merely an adaptation of a common plan of lymphatic genesis, through the concresence of independent an'agen, to the local conditions which prevail only in certain districts of the mammalian embryo.

The same general plan of development as outlined above by Huntington and McClure for the lymphatic system of the eat has also been found by Kampmeier ('12a, '12b) to occur in the embryo of the pig. His desription of the independent and discontinuous anlagen of the thoracic ducts which he found in the injected pig embryo loaned him by Professor Sabin, needs no further comment (McClure '12).

F. T. Lewis ('05) has described the presence of a chain of discontinuous 'Trmphatic spaces' (endothelial-lined anlagen) in the rabbit embryo which lie along the azygos veins in the path of the future thoracic duct. He regards these anlagen, however, as having been detached from the veins. Concerning these multiple anlagen of Lewis, Sabin ('08) has stated as follows:

Since these spaces are lined with a definite endothelium, they form a much more scrious obstacle to the theory of growth of the lymphatics from the endothelium of the veins than the more indefinite spaces to be found in earlier embryos, and I cannot but think that if these multiple endothelial-lined isolated spaces do exist along the veins in later stages, they would form serious evidence against the theory of the origin of the lymphatics from the veins. Or at least if the lymphaties, in their growth, do pick up isolated endothelial-lined 
spaces, we shall again be left without a clue as to the origin of the lymphatic system.

It is significant to note that, although Sabin considers these isolated endothelial-lined anlagen of Lewis as having been detached from the veins, she nevertheless now recognizes their existence in the pig embryo, and regards them as entering into the formation of the thoracic duct ('11, p. 424).

The point I wish to emphasize in this comnection is that Sabin now recognizes the fact that lymphatics may be formed by the concrescence of multiple and independent endothelial-lined anlagen and that she has thus far presented no valid evidence that these anlagen have been detached from the veins.

Sala ('00) and more recently Miller ('13) have shown that the thoracic ducts of the common fowl are formed by a concrescence of independent and discontinuous lymph spaces and that their endothelium is formed in situ from cells other than those which constitute the endothelium of the veins. Miller has further made the important discovery that groups of blood cells develop in the mesenchyme along the line of the thoracic duct and that the latter subsequently convey these blood cells to the venous circulation. Te therefore find that hematopoiesis may actually occur in connection with the development of certain lymph channels, a condition which Huntington ('14) has also recently verified for certain lymphatics of mammals.

West ('14, '15), by a study of injected and uninjected embryos, has recently found that the posterior lymph heart of the common fowl develops in the mesenchyme and secondarily establishes a connection with the veins. He has also found that hematopoiesis occurs in the mesenchyme in relation to the independent anlagen of the lymph heart, and states that the blood cells thus formed are not to be confounded with those which may later back into the lymph heart from the veins (E. L. Clark, '12).

Huntington ('11b), in a paper on the development of the lymphatic system in reptiles (chelonia, lacertilia), has shown that the systemic lymphatics develop in the mesenchyme independently of the endothelium of the veins. A particular feature 
of his investigation is that he was able to demonstrate that the periaortic lymph channel in Chelydra serpentina arises in the mesenchyme in an area entirely free of veins.

Stromsten's investigations ('10, '11, '12) on the development of the lymphatic system in reptiles (chelonia) have led him to conclude that the lymphatics are formed by a concrescence of independent and discontinuous lymph spaces and that lymphatic endothelium is formed in situ from mesenchymal cells. His observations were based largely upon a study of injected embryos, and showed that the injecta did not reach the independent anlagen of the lymphatics, prior to their concrescence with one another to form a system of continuous lumina which had established a communication with the veins.

Fedorowicz ('13) and more recently Kampmeier ('15), have shown that the continuous lumina of certain lymphatics are formed in the amphibia (anura) by the concrescence of originally independent and discontinuous lumina. They conclude, however, that the endothelial walls of these lumina have been derived from the endothelium of the veins. E. R. Clark ('11b) regards the lumina of the developing lymphatics in amphibia (in tail of larval amphibia) as always continuous and capable of injection, while Fedorowicz and Kampmeier describe them as discontinuous at the start.

In the preceding pages the writer has demonstrated the presence of discontinuous and independent lymph vesicles in the trout embryo, which cannot be injected from other lymphatic anlagen or from the veins. Many of these vesicles arise in the mesenchyme remote from the veins, and no connection can be observed between their endothelium and that of the reins or that of any other lymphatic anlagen. One of these independent lymph vesicles, the subocular lymph sac, can actually be observed in the living trout embryo. On account of the relatively large size of this vesicle it has proved a most farorable object for experimentation and for study in sections, not only in proof of the fact that it arises independently of the veins, but also that its endothelium is of mesenchymal origin. 
Allen ('13) has investigated the development of the lymphatic system in Polistotrema (Bdellostoma) stouti and speaks of the lymphatics of fishes as veno-lymphatics. He states: "I expect to show that the main factor in the construction of the venolymphatic system is the same as was described for the caudal lymph hearts, namely, the formation and union of certain mesenchymal spaces."

Allen, independently of Miller, has also observed that an active hematopoiesis occurs in the mesenchyme in relation to the developing caudal lymph hearts of Polistotrema.

Except for differences of opinion regarding the origin of lymphatic endothelium, it may be observed that the above-mentioned investigators agree for the most part that the continuous lumina of the lymphatics, like those of the haemal vessels, are formed by a concrescence of independent and discontinuous anlagen.

If we disregard entirely the personal equation which may have influenced any or all of the above-mentioned investigators to interpret their findings in accordance with one or the other view, the fact still remains that the anlagen of the lymphatic system, as observed in sections of injected and uninjected embryos, have been found to be identical with those of the intra-embryonic blood-vascular system, which has been shown by sections and experiment to be formed by a concrescence of independent anlagen, and its endothelium to be formed in situ from mesenchymal cells. Since we possess exactly the same kind of evidence in favor of the mesenchymal origin of lymphatic endothelium, as we formerly did for that of the intra-embryonic haemal channels, before experiment was applied, it therefore seems highly improbable that the endothelium of two sets of similarly appearing anlagen, belonging to the same general organ system and developing side by side, should differ in its mode of origin, rather than follow a common genetic plan.

We know that the lymphatics, both in the embryo and in the adult, establish a permanent communication with the veins at typical points (McClure and Silvester '09, and Silvester '12). The question therefore arises, what rôle, if any, 
may be played by the veins in establishing such communi"ations with the independently formed lymphaties? In the drolopment of the general rascular system which includes the arteries, reins and lymphaties, the end result desired is the formation of a connected system of vessels which subserve definite functions in the economy of the general rascular system. If the general vascular system develops progressively in a uniform manner, by a concrescence of independently formed anlagen, and the lymphatics, as is the case, form the last link in completing the chain, it is evident that the same factors should account for the establishment of a connection between the veins and the independently formed lymphatics, as between the independently formed anlagen of which the reins and lymphatics are originally composed. Such a connection could alone be established, either by a growth or sprouting of the endothelium of the veins; by means of a further in situ differentiation into endothelium of the mesenchymal cells which intervene between the veins and the independent anlagen of the lymphaties; or, both of these factors might be involved. If a connection should be established by a sprouting of the endothelium of the reins, such sprouts would possess no significance beyond the fact which we all recognize, that all rascular endothelium is capable of growth after it has once been formed. The question, however, is not whether endothelium is capable of growth, but rather what are its limitations and how is the endothelium formed that does the growing. It is therefore evident, if, at the points at which the lymphatics establish permanent communications with the veins, venous endothelium should contribute to the formation of the lymphatics, it would play only a subsidiary rôle, and serve only as a means, in common with the endothelium of other independently formed rascular anlagen, of bringing two independently formed portions of the vascular system into communication with each other to form a continuous system of channels. Such veno-lymphatic comections have been hitherto described by Huntington and McClure ('10) under the name of 'venolymphatics.' It is evident, however, that these 'venolymphatics' would not differ, in any sense, from other connections, where a similar growth of 
endothelium is concerned, when marle for the purpose of establishing a connection between any of the other independently formed anlagen of the general vascular system.

To sum up: The development of the general vascular systemhaemal and lymphatic vesels is a uniform process, which consists in a local origin (genesis) of endothelium from mesenchymal cells and a growth of endothelium after it has once been formed.

In view of what has been said above, it would therefore appear that the lymphatic problem, in its broadest sense, should not be interpreted in terms either of a venous or non-venous origin, but rather in terms of the uniform phases of genesis and growth which may characterize the establishment of vascular channels in general.

One of the principal conclusions arrived at in the course of this investigation, is a further substantiation of the view that the continuous luninit of the lymphaties, like those of the haemal vessels, are formed by a confuence of originally independent and discontinuous vascular spaces; a circumstance which proves that the method of injection throws no light upon the actual mode of origin of the lymphatic system.

The functional rôle played by the independent lymph vesicles of the embryo has already been described by the writer ('15a) in a former paper, to which the reader is referred. 


\section{LITERATURE CITED}

Altex, W. F. 1906 Distribution of the lymphatics in the head, and in the dorsal, pectoral and ventral fins, of Scorpaenichthys marmoratus. Proc. Washington Acad. Sei., vol. 8.

1913 Studies on the development of the veno-lymphatics in the tail region of Polistotrema (Bdellostoma) stouti. Quart. Jour. Micr. Sci., vol. 59 .

Bremer, J. L. 1914 The earliest blood-vessels in man. Am. Jour. Anat., vol. 16.

Clark, E. L. 1912 General observations on early superficial lymphatics in chick embryos. Anat. Rec., vol. 6.

Clark, E. R. 1911 a An examination of the methods used in the study of the development of the lymphatic system. Anat. Rec., vol. 5 .

1911 b Further observations on living growing lymphatics; their relation to mesenchymal cells. Am. Jour. Anat, vol. 13.

Clarke, W. C. 1914 Experimental mesothelium. Anat. Rec., vol. 8.

Favaro, G. 1906 Ricerche intorno alla morfologia ed allo sviluppo dei vasi, seni e cuori caudali nei Ciclostomi e nei Pesci. Atti del Reale Istituto Veneto di Scienze, Tomo 65, Parte II.

Fedorowicz, Z. 1913 Untersuchungen über die Entwicklung der Lymphgefässe bei Anurenlarven. Bull. de l'Acad. de Sci. de Cracovie, Juin.

Felix, W. 1897 Beiträge zur Entwickelungeschichte der Salmoniden, Teil I, Anat. Hefte, Bd. 8 .

Gräper, L. 1907 Untersuchungen über die Herzbildung der Vögel. Archiv. Entwickmech., Bd. 24.

HAHN, H. 1909 Experimentelle Studien über die Entstehung des Blutes und der ersten Gefässe beim Hünchen, T. I., Intraembryonale Gefässe. Archiv Entwickmech., Bd. 27.

Huntivgton, G. S. 1910 Ueber die Histogenese des Lymphatischen Systems beim Säuger-embryo. Anat. Anz., Ergänz. z. Bd.37, Verh. 2, Internat. Anat. Kiongr., Brüssel.

1911 a The anatomy and development of the systemic lymphatic vessels in the domestic cat. Memoirs of 'The Wistar Institute of Anatomy and Biology, No. 1.

$1911 \mathrm{~b}$ The development of the lymphatic system in reptiles. Anat. Rec., vol. 5.

1914 The development of the mammalian jugular lymph sac, of the tributary primitive ulnar lymphatic and the thoracic ducts from the viewpoint of recent investigations of lymphatic ontogeny, together with a consideration of the genetic relations of lymphatic and haemal vascular channels in the embryos of amniotes. Am. Jour. Anat., vol. 16.

Huntington, G. S., And MicClure, C. F. W. 1907 a The development of the main lymph channels of the cat in their relation to the venous system. Anat. Rec., vol. 1. 
Huntington, G. S., and McClure, C. F. W. 1907 b Development of postcava and tributaries in the domestic cat. Anat. Rec., vol. 1.

1908 The anatomy and development of the jugular lymph sacs in the domestic cat. Anat. Rec, vol. 2.

1910 The anatomy and development of the jugular lymph sacs in the domestic cat (Felis domestica). Am. Jour. Anat, vol. 10.

Hyrtu, Jos. 1843 Ueber die Caudal und Kopf-Sinuse der Fische, und das damit zusammenhängende Seiten-gefäss-System. Archiv für Anat. und Phys.

Kampmeier, O. F, 1912 a The value of the injection method in the study of lymphatic development. Anat. Rec., vol. 6.

$1912 \mathrm{~b}$ The development of the thoracic duct in the pig. Am. Jour. Anat., vol. 13.

1915 On the origin of lymphaties in Bufo. Am. Jour. Anat., vol. 17.

LENis, F. T. 1905 The development of the lymphatic system in rabbits. Am. Jour. Anat, vol. 5.

Loeb, Jacques 1912 The mechanistic conception of life. Pop. Sci. Monthly, vol. 80 .

McClure, C. F. W. 1910 The extra-intimal theory and the development of the mesenteric lymphatics in the domestic cat, Anat. Anz., Ergänz. z. Bd. 37, Verh. 2. Internat. Anat. Kongr., Brüssel.

1912 A few remarks relative to Mr. Kampmeier's paper on the value of the injection method in the study of lymphatic development. Anat. Ree., vol. 6.

1913 The development of the lymphatic system in fishes. Proc. 17th Internat. Congr. of Medicine, London.

1914 The development of the lymphatic system in the trout. Proc. Am. Ass. Anat., Anat. Rec, vol. 8.

1915 a On the provisional arrangement of the embryonic lymphatic system. (An arrangement by means of which a centripetal lymph flow toward the venous circulation is controlled and regulated in an orderly and uniform manner, from the time lymph begins to collect in the intercellular spaces, until it is forwarded to the venous circulation). Anat. Ree., vol. 9.

$1915 \mathrm{~b}$ The development of the lymphatic system in the light of the more recent investigations in the field of vasculogenesis. Anat. Rec., vol. 9.

IcClure, C. F. W., And Silvester, C. F. 1909 A comparative study of the lymphatico-venous communications in adult mammals. Anat. Rec., vol. 3.

IICWhorter, J. E., And Whipple, A. O. 1912 The development of the blastoderm of the chick in vitro. Anat. Ree., vol. 6.

Miller, A. M. 1913 Histogenesis and morphogenesis of the thoracic duct in the chick; development of blood-cells and their passage to the blood stream via thoracic duct. Am. Jour. Anat., vol. 15. 
Miller, A. M., And McWhorter, J. E. 1914 Experiments on the development of blood vessels in the area pellucida and embryonic body of the chick. Anat. Rec., vol. 8.

Mǒzejko, B. 1913 Ueber das Lymphgefässystem der Fische. Anat. Anz., Bd., 45.

Raffaele, F. 1892 Ricerche sullo sviluppo del sistema vascolare nei Selacei. Mitth. Zool. Stat. Neapel, Bd. 10.

Reagan, F. P. 1914 A useful modification of Mann's methyl blue-eosin stain. Anat. Rec., vol. 8.

1915 Vascularization phenomena in fragments of embryonic bodies completely isolated from yolk-sac blastoderm. Anat. Rec., vol. 9.

Rüchert, J., AND Mollier, S. 1906 See Hertwig's Handbuch d. vergl. und exper. Entwickelungslehre d. Wirbeltiere, Bd. 1, T. 2.

SABIN, F. R. 1902 On the origin of the lymphatic system from the veins, and the development of the lymph hearts and thoracic duct in the pig. Am. Jour. Anat., vol. 1.

1908 Further evidence on the origin of the lymphatic endothelium from the endothelium of the blood-vascular system. Anat. Rec., vol. 2 ,

1911 A critical study of the evidence presented in several recent articles on the development of the lymphatic system. Anat. Rec., vol. 5. 1913 The origin and development of the lymphatic system. The Johns Hopkins Hospital Reports Monographs, New Series, No. 5.

SALA, L. 1900 Sullo sviluppo dei cuori linfatici e dei dotti toracici nell' embrione di pollo. Ricerche fatta nel Laborat. di Anat. norm. della R. Univ. di Roma, tom. 7.

Schulte, H. von W. 1914 Early stages of vasculogenesis in the cat (Felis domestica) with especial reference to the mesenchymal origin of endothelium. Memoirs of The Wistar Institute of Anatomy and Biology, No. 3.

Silvester, C. F. 1904 The blood-vascular system of the tile-fish (Lopholatilus chamaeleonticeps). Bulletin of the Bureau of Fisheries, vol. 24, Washington.

1912 On the presence of permanent communications between the lymphatic and venous system at the level of the renal veins in adult South American monkeys. Am. Jour. Anat., vol. 12.

Stockard, C. R. 1915 An experimental study of the origin of blood and vascular endothelium in the teleost embryo. Proc. Amer. Ass. Anat., Anat. Rec., vol. 9.

1915 The origin of blood and vascular endothelium in embryos without a circulation of the blood and in the normal embryo. Am. Jour. Anat., vol. 18.

Stromsten, F. A. 1910 A contribution to the anatomy and development of the posterior lymph hearts of turtles. Publication 132 of the Carnegie Institution of Washington.

1911 On the relation between the mesenchymal spaces and the development of the posterior lymph hearts of turtles. Anat. Rec., vol. 5 
Stromsten, F. A. 1912 On the development of the prevertebral (thoracic) ducts in turtles as indicated by a study of injected and uninjected embryos. Anat. Rec., vol. 6.

Wenckebach, K. F, 1886 Beitrüge zur Entwicklungsgeschichte der Knochenfische. Archiv mikr. Anat., Bd. 28.

WEST, R. 1914 The origin and early development of the posterior lymph heart in the chick. Anat. Rec., vol. 8.

1915 The origin and early development of the posterior lymph heart in the chick. Am. Jour. Anat, vol. 17. 


\section{DESCRIPTION OF FIGURES}

The structures shown in the following figures are designated by numerals:

Figures 1 to 13, inclusive, represent reconstructions of the arteries, veins and lymphatics found in the regions of the head and pharynx in the embryos of the trout (figs. 1 to 11, inclusive) and Amia (figs. 12 and 13). The arteries are shown in red, the veins in black and the lymphatics in green. The vascular system of the trout embryos (figs. 1 to 11 , inclusive) and that of the $10 \mathrm{~mm}$. embryo of Amia (fig. 12) were reconstructed after the method of Born, at a magnification of 200 diameters; while that of the $19 \mathrm{~mm}$. embryo of Amia (fig. 13) was reconstructed after the method of Born at a magnification of 138 diameters. In order to display the smaller reconstructions to the best advantage, a uniform reduction has not been followed in reducing the size of the figures in the plates.

\section{PLATE 1}

\section{EXPLANATION OF FIGURES}

Figs. 1-2 Lateral view of the arteries, veins and lymphaties found on the left and right sides, respectively, of the head and pharynx in a fourteen-day steel hear trout embryo; injected embryo. P. E. C. ${ }^{7} 696$.

\section{REFEUENCES}

1, Subocular lymph sac.

$3^{\prime \prime \prime}$, Cardino Cuvierian lymph sac; anlage of the lateral pharyngeal lymphatic which may arise opposite to the cardino-Cuvierian junction or between the latter and the otic lymph sac

6, Precardinal or jugular vein

$s$, Cranial end of otocyst
$8^{\prime}$, Caudal end of otocyst
11, Postcardinal vein
12, Duct of Cuvier
14, Dorsal aorta
15, Hyoidean artery
20, Caudal end of eye
22, Carotid artery
23 , Infraorbital vein

6 The photomicrographs (except fig. 41) were made by Mr. C. F. Silvester, and figures 1 to 13, inclusive, were drawn from reconstructions by Mr. Anthony J. Walter.

${ }^{7}$ Princeton Embryological Collection. 
PLATE 2

EXPLANATION OF FIGURES

Figs. 3-4 Lateral view of the arteries, veins and lymphaties found on the left and right sides, respectively, of the head and pharynx in a fifteen-day steelhead trout embryo; injected embryo. P. E. C. 726.

\section{REFERENCES}

1, Subocular lymph sac

$3^{\prime \prime}$, Otic lymph sac; anlage of the lateral pharyngeal lymphatic which lies near the caudal end of the otocyst and which may establish a communication with the precardinal vein at the otic communication

3"', Cardino-Cuvierian lymph sac; anlage of the lateral pharyngeal lymphatic which lies between the cardino-Cuvierian junction and the otic lymph sac

6, Precardinal or jugular vein
9, Cardino-Cuvierian communication; the point at which the lateral pharyngeal lymphatic communicates with the precardinal vein in the cardinoCuvierian district

12, Duct of Cuvier

14, Dorsal aorta

15, Hyoidean artery

16, First efferent aortic arch

17, Second efferent aortic arch

18, Third efferent aortic arch

19 , Fourth efferent aortic arch

22 , Carotid artery 
PLATE 2
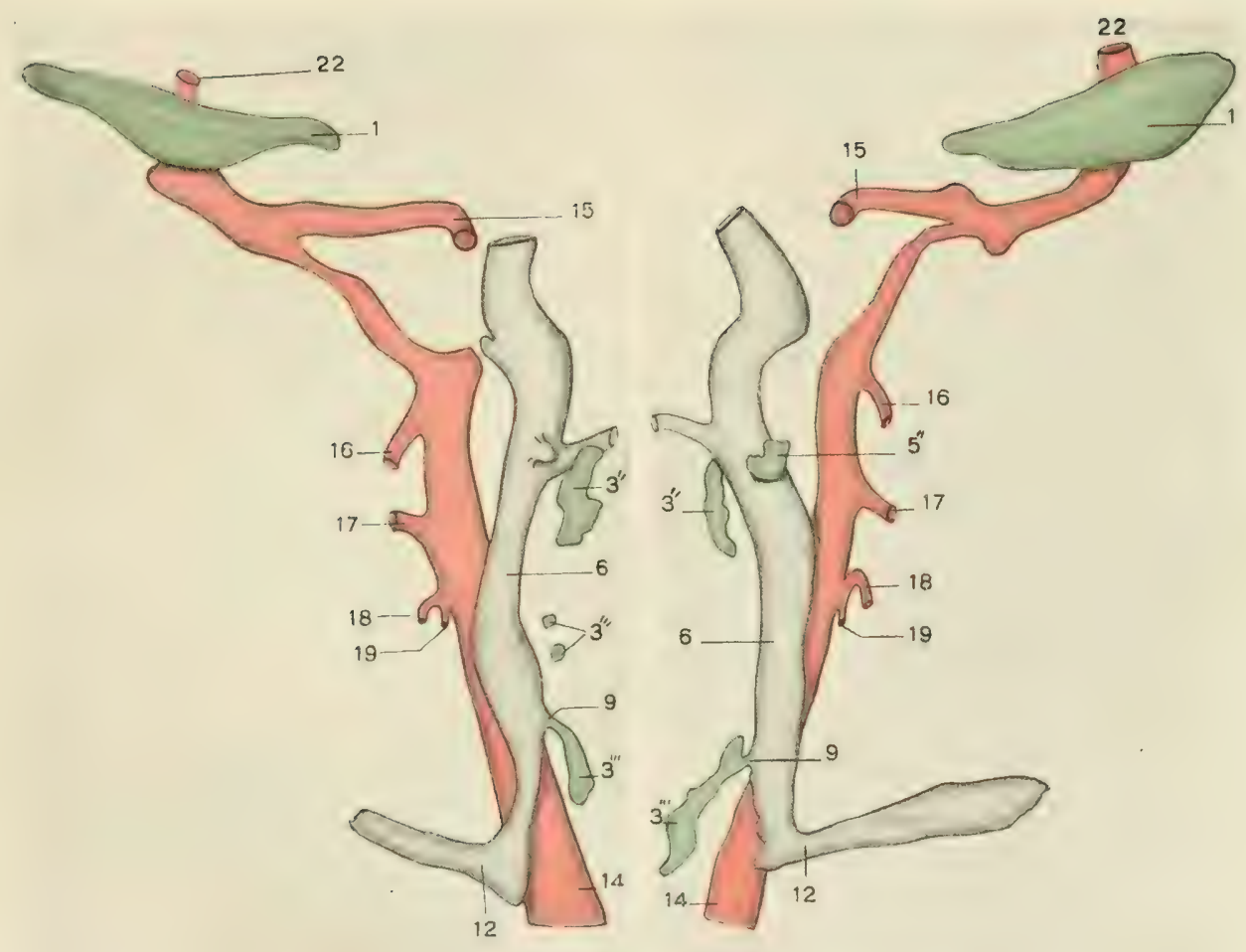

3

4 
PLATE 3

\section{EXPLANATION OF FIGURE}

Fig. 5 Ventral view of the arteries, veins and lymphaties found in the head and pharynx of a sixteen-day steelhead trout embryo; injected embryo. P. E. C. 751.

\section{REFERENCES}

1, Subocular lymph sac

3 ', Independent anlage of the lateral pharyngeal lymphatic which lies anterior to the otic communication $3^{\prime \prime}$, Otic lymph sac; anlage of the lateral pharyngeal lymphatic which lies near the caudal end of the otocyst and which may establish a communication with the precardinal vein at the otic communication

$3^{\prime \prime \prime}$, Cardino-Cuvierian lymph sac; anlage of the lateral pharyngeal lymphatic which lies opposite to the cardino-Cuvierian junction

5". Anlage of the precardina lymphatic which lies contiguous to the otic communication and which establishes a connection with the lateral pharyngeal lymphatic

6 , Precardinal or jugular vein

7, Point at which the precardinal lymphatic communicates with the lateral pharyngeal lymphatic

8, Cranial end of otocyst
9, Cardino-Cuvierian communication; the point at which the lateral pharyngeal lymphatic communicates with the precardinal vein in the cardinoCuvierian district

10, Lymphatic of the lateral line of the trunk

11, Postcardinal vein

12, Duct of Cuvier

13, Otic communication; the point at which the lateral pharyngeal lymphatic communicates with the precardinal vein near the caudal. end of the otocyst

14, Dorsal aorta

15, Hyoidean artery

16, First efferent aortic arch

17, Second efferent aortic arch

18, Third efferent aortic arch

19 , Fourth efferent aortic arch

20, Caudal end of eye

22, Carotid artery

23 , Infraorbital vein

24, Cardino-Cuvierian junction

27 , Root of dorsal aorta 
PLATE 3

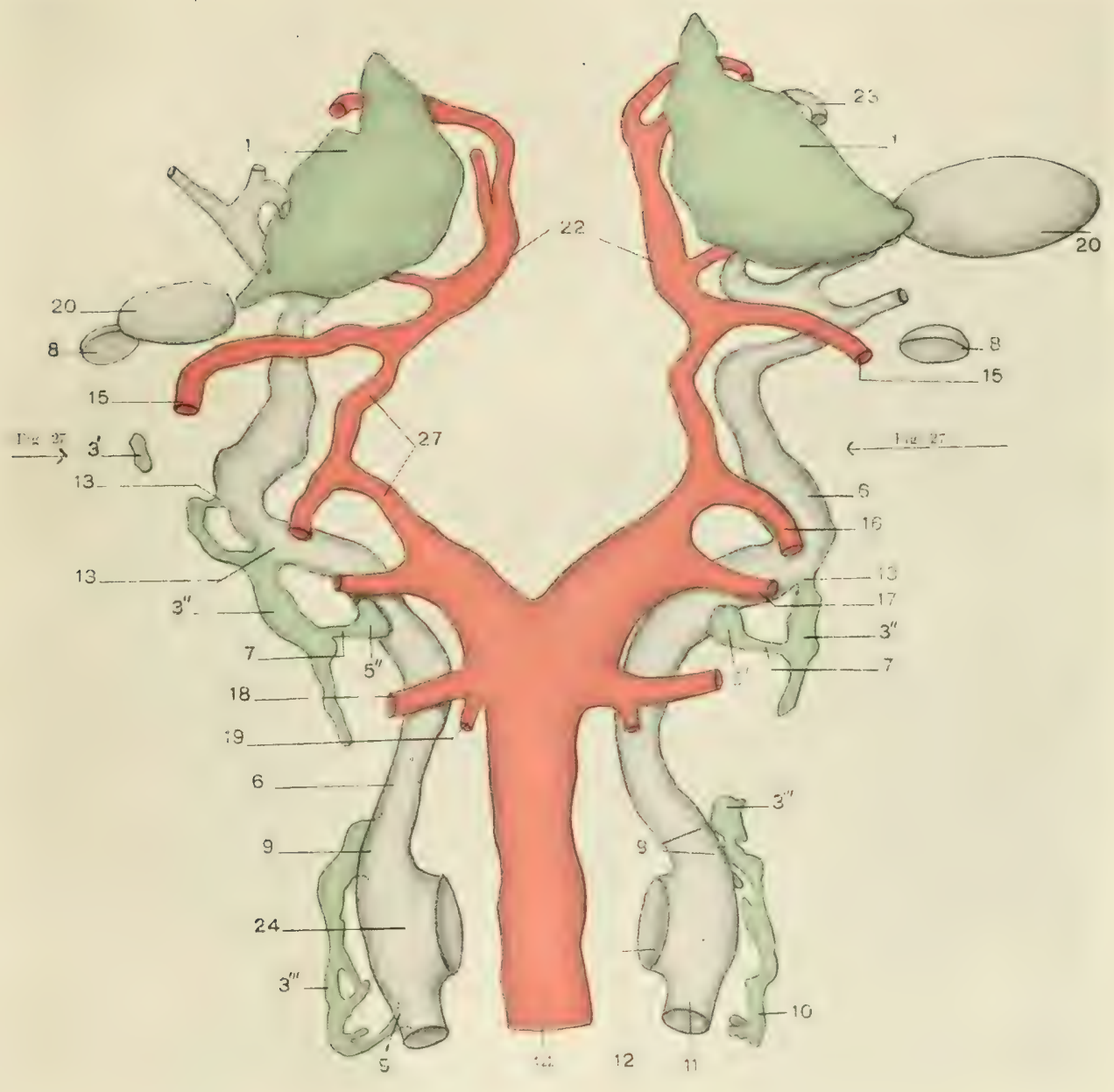




\section{PLATE 4}

\section{EXPLANATION OF FIGURE}

Fig. 6 Ventral view of the arteries, veins and lymphatics found in the head and pharynx of a seventeen-day steelhead trout embryo; injected embryo. P. E. C. 740 .

\section{REFERENCES}

1, Subocular lymph sac

3 ', Independent anlagen of the lateral pharyngeal lymphatic which lie anterior to the otic communication

$3^{\prime \prime}$, Otic lymph sac; anlage of the lateral pharyngeal lymphatic which lies near the caudal end of the otocyst and which may establish a communication with the precardinal vein at the otic communication

$3^{\prime \prime \prime}$, Cardino-Cuvierian lymph sac anlage of the lateral pharyngeal lymphatic which lies opposite to the cardino-Cuvierian junction and between the latter and the otic lymph sac $5^{\prime \prime}$, Anlage of the precardinal lymphatic which lies contiguous to the otic communication and which establishes a connection with the lateral pharyngeal lymphatic
6, Precardinal or jugular vein

8, Cranial end of otocyst

9, Cardino-Cuvierian communication; the point at which the lateral pharyngeal lymphatic communicates with the precardinal vein in the cardinoCuvierian district

10, Lymphatic of the lateral line of the trunk

14, Dorsal aorta

15, Hyoidean artery

16, First efferent aortic arch

17 , Second efferent aortic arch

18, Third efferent aortic arch

19 , Fourth efferent aortic arch

20, Caudal end of eye

22, Carotid artery

24, Cardino-Cuvierian junction

27 , Root of dorsal aorta 
PLATE 4

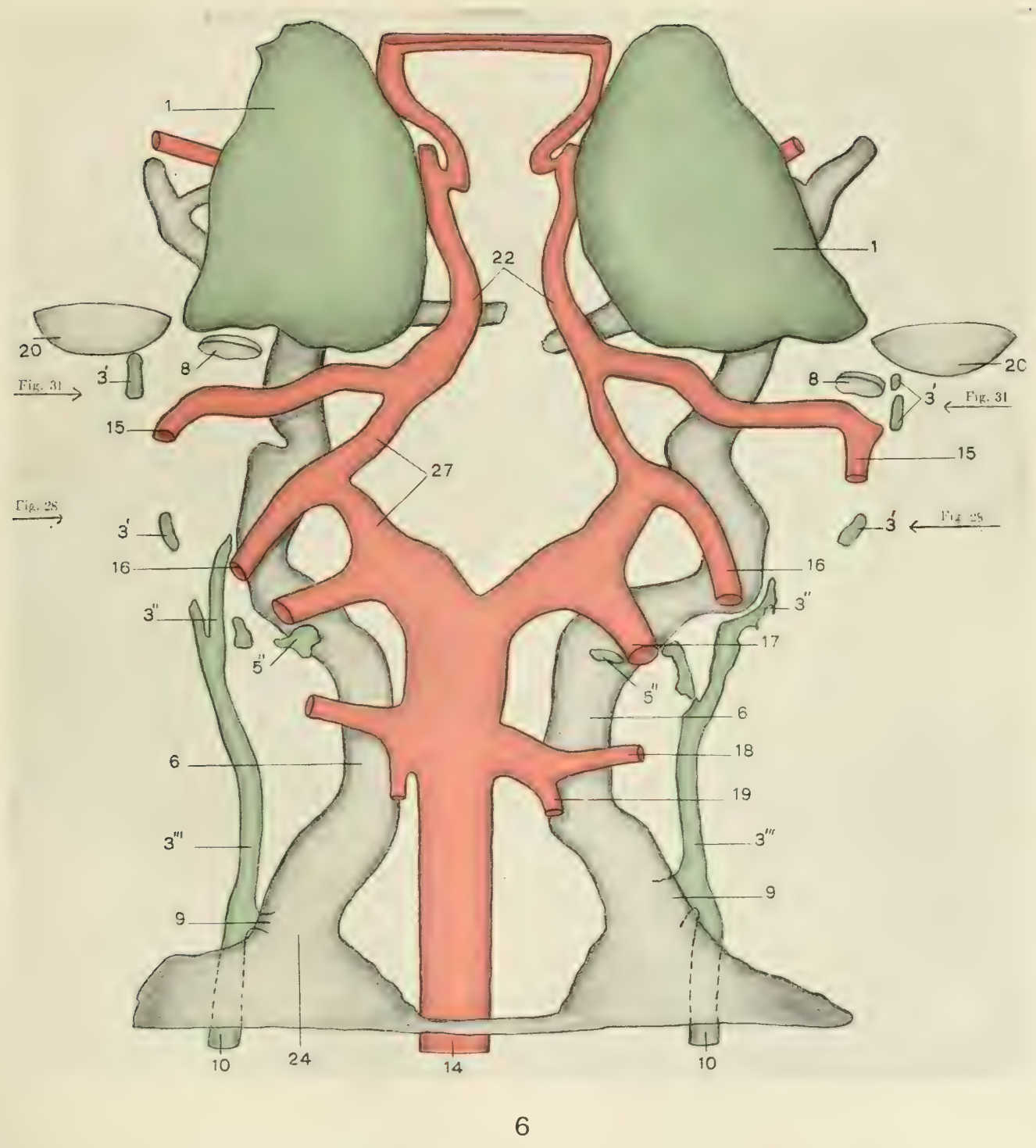




\section{PLA'TE 5}

\section{EXPLANATION OF FIGURE}

Fig. 7. Ventral view of the arteries, veins and lymphatics found in the head and pharynx of a nineteen-day rainbow trout embryo; injected embryo. P. E. C. 672 .

\section{REFERENCES}

1, Subocular lymiph sac

$3^{\prime}$, Independent anlagen of the lateral pharyngeal lymphatic which lie anterior to the otic communication

$3^{\prime \prime}$, Otic lymph sac; anlage of the lateral pharyngeal lymphatic which lies near the caudal end of the otocyst and which may establish a communication with the precardinal vein at the otic communication

$3^{\prime \prime \prime}$, Cardino-Cuvierian lymph sac; anlage of the lateral pharyngeal lymphatic which lies opposite to the cardino-Cuvierian juriction and between the latter and the otic lymph sac

$5 "$, Anlage of the precardinal lymphatic which lies contiguous to the otic communication and which establishes a connection with the lateral pharyngeal lymphatic

$5^{\prime \prime \prime}$, Independent anlage of the precardinal lymphatic which lies, approximately, opposite to the origin of the third efferent aortic arch
6, Precardinal or jugular vein

S, Cranial end of otocyst

9, Cardino-Cuvierian communieation; the point at which the lateral pharyngeal lymphatic communicates with the precardinal vein in the cardinoCuvierian district

10, Lymphatic of the lateral line of the trunk

14, Dorsal aorta

15, Hyoidean artery

16, First efferent aortic arch

17 , Second efferent aortic arch

18 , Third efferent aortic arch

19 , Fourth efferent aortic arch

20, Caudal end of eye

22, Carotid artery

27, Root of dorsal aorta

31 , Independent anlagen of a lymphatic which arises along the course of the hyoidean artery; these anlagen have been omitted in most of the reconstructions 
PLATE 5

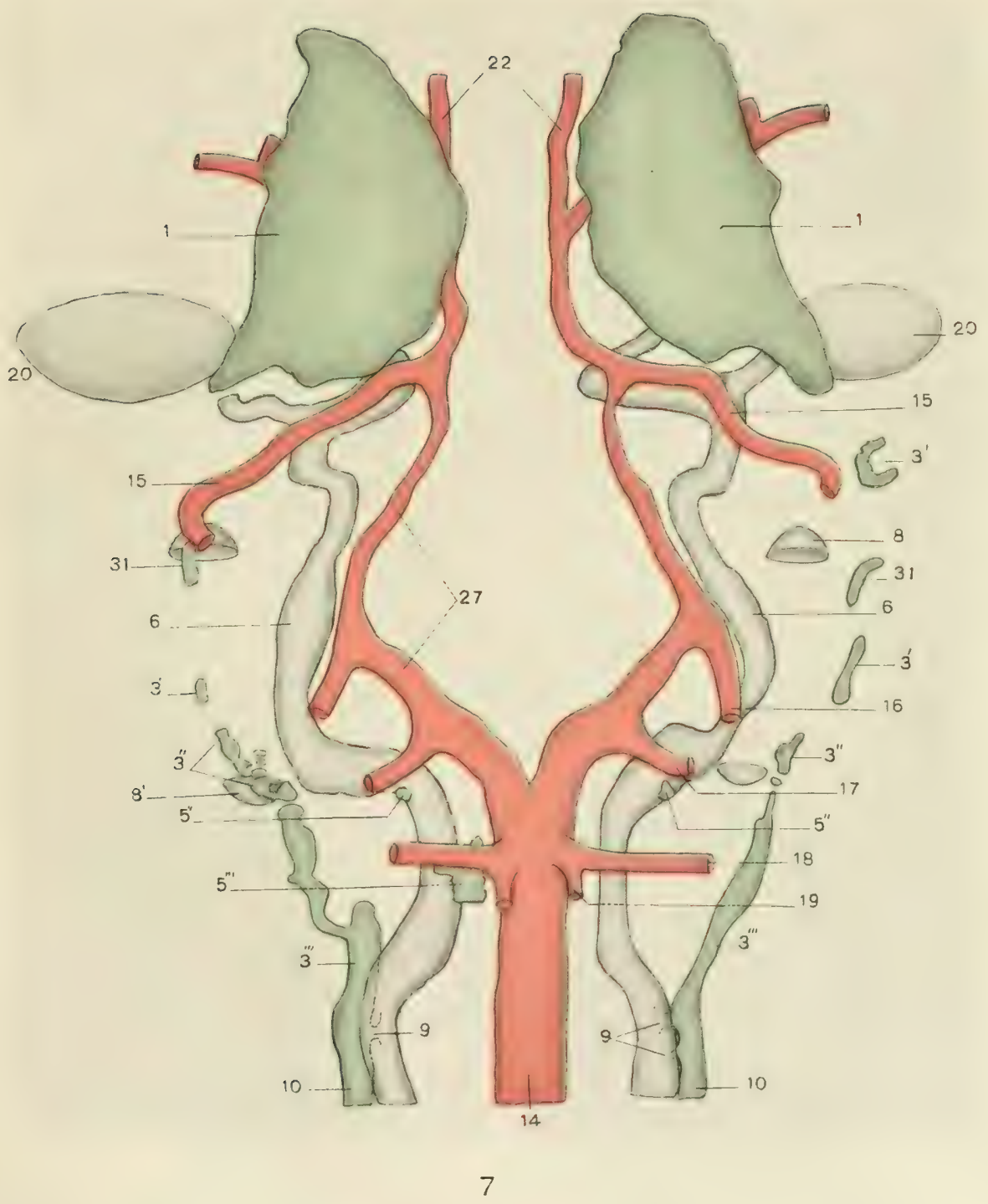




\section{PLATE 6}

\section{EXPLANATION OF FIGURE}

Fig. 8. Ventral view of the arteries, veins and lymphatics found in the head and pharynx of a twenty-day rainbow trout embryo; injected embryo. P.E. C. 668 .

\section{REFERENCES}

1, Subocular lymph sac

$3^{\prime}$, Independent anlagen of the lateral pharyngeal lymphatic which lie anterior to the otic communication

$3^{\prime \prime}$, Otic lymph sac; anlage of the lateral pharyngeal lymphatic which lies near the caudal end of the otocyst and which may establish a communication with the precardinal vein at the otic communication

$3^{\prime \prime \prime}$, Cardino-Cuvierian lymph sac; anlage of the lateral pharyngeal lymphatie which lies opposite to the cardino-Cuvierian junction and between the latter and the otic lymph sac

$5 "$, Anlage of the precardinal lymphatic which lies contiguous to the otic communication and which establishes a connection with the lateral pharyngeal lymphatic

6 , Precardinal or jugular vein

8 , Cranial end of otocyst
9, Cardino-Cuvierian communication; the point at which the lateral pharyngeal lymphatic communicates with the precardinal vein in the cardinoCuvierian district

10, Lymphatic of the lateral line of the trunk

11 , Posteardinal vein

14 , Dorsal aorta

15, Hyoidean artery

16, First efferent aortic arch

17, Second efferent aortic arch

18, Third efferent aortic arch

19, Fourth efferent aortic arch

20 , Caudal end of eye

22, Carotid artery

27 , Root of dorsal aorta

31 , Independent anlage of a lymphatic which arises along the course of the hyoidean artery; these anlagen have been omitted in most of the reconstructions 
PLATE 6

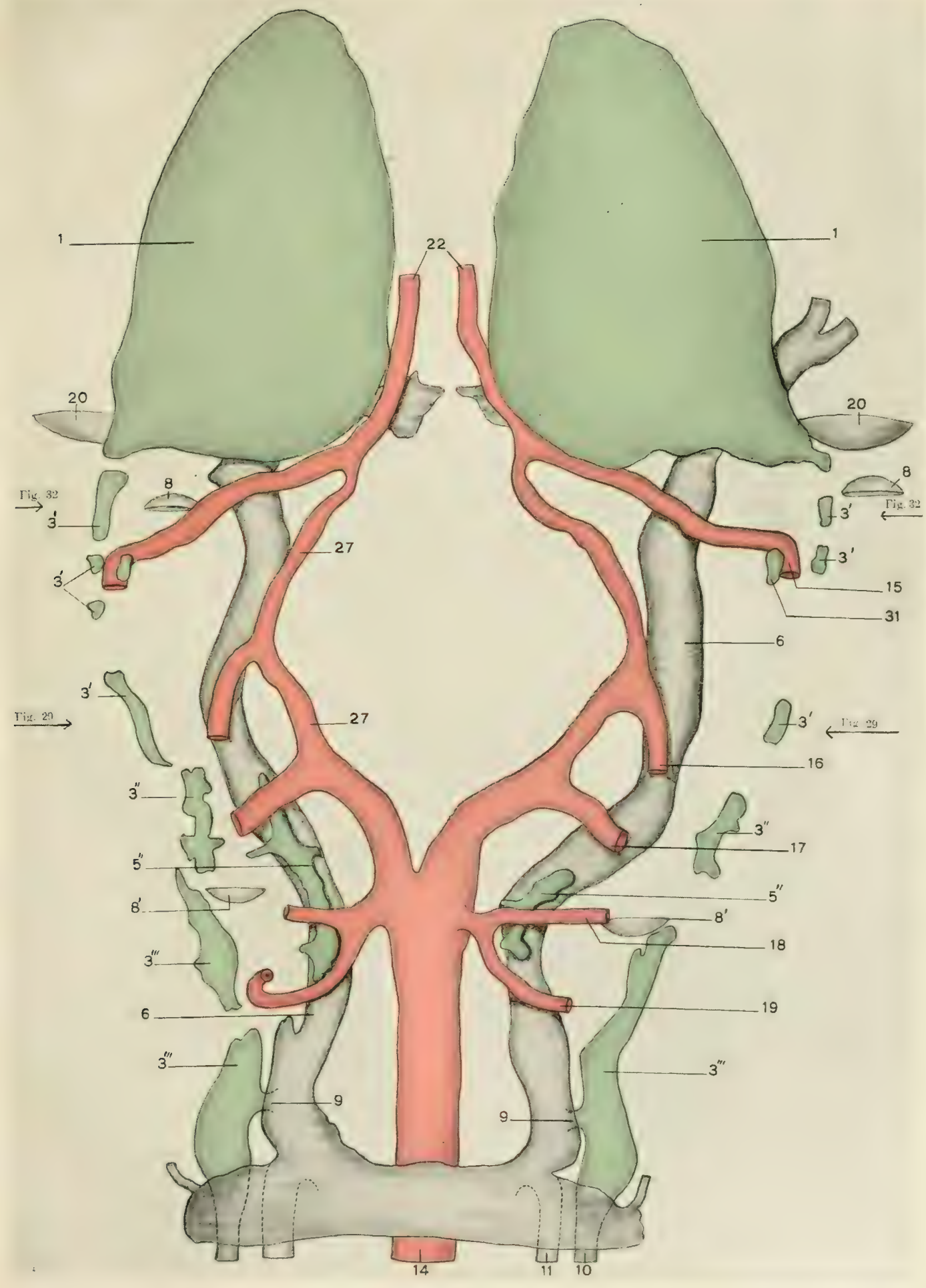




\section{PLATE 7}

\section{EXPLANATION OF FIGURF}

Fig. 9 Ventral view of the arteries, veins and lymphatics found in the head and pharynx of a twenty-one-day rainbow trout embryo; injected embryo. P. E. C. 646 .

\section{REFERENCES}

1, Subocular lymph sac

2, Medial pharyngeal communication; the point at which the medial pharyngeal lymphatic communicates with the precardinal vein

3 , Independent anlagen of the lateral pharyngeal lymphatic which lieanterior to the otic communication

$3^{\prime \prime}$, Otic lymph sac; anlage of the lateral pharyngeal lymphatic which lies near the caudal end of the otoeyst and which may establish a communication with the precardinal vein at the otic communinication

$3^{\prime \prime \prime}$, Cardino-Cuvierian lymph sac; anlage of the lateral pharyngeal lymphatic which lies opposite to the cardino-Cuvierian junction and between the latter and the otic lymph sac

4, Medial pharyngeal lymphatic

5", Anlage of the precardinal lymphatic which lies contiguous to the otic communieation and which establishes a connection with the lateral pharyngeal lymphatic

$5^{\prime \prime \prime}$, Anlage of the precardinal lymphatic which lies, approximately, opposite to the origin of the third efferent aortic arch

6 , Precardinal or juguiar vem

7 , Point at which the precardinal lymphatic communicates with the lateral pharyngeal lymphatic

9. Cardino-Cuvierian communication; the point at which the lateral pharyngeal lymphatic communicates with the precardinal vein in the cardino-Cuvierian district

10, Lymphatic of the lateral line of the trunk

11, Posteardinal vein

13, Otic communication; the point at which the lateral pharyngeal lymphatic communicates with the precardinal vein near the caudal end of the otocyst

15, Hyoidean artery

16, First efferent aortic arch

17. Second efferent aortic arch

18, Third efferent aortic areh

19, Fourth efferent aortic arch

$2 \cdot 2$, Carotid artery

27, Root of dorsal aorta

31, Independent anlage of a lymphatic which arises along the course of the hyoidean artery 



\section{PLATE 8}

\section{EXPLANATION OF FIGURE}

Fig. 10 Ventral view of the arteries, veins and lymphatics found in the head and pharynx of a twenty-two-day rainbow trout embryo; not injected. P. E. C. 648 .

\section{REFERENCES}

1, Subocular lymph sac

2, Medial pharyngeal communication; the point at which the medial pharyngeal lymphatic communicates with the precardinal vein

3 , The lateral pharyngeal lymphatic, a continuous vessel through which the subocular lymph sac drains into the veins in the trout

4, Medial pharyngeal lymphatic

5 , Precardinal or jugular lymphatic 5 , Independent anlage of the precardinal lymphatic which lies contiguous to the precardinal vein and just caudal to the medial pharyngeal communication

6, Precardinal or jugular vein

7, Point at which the precardinal lymphatic communicates with the lateral pharyngeal lymphatic

9, Cardino-Cuvierian communication; the point at which the lateral pharyn- geal lymphatic communicates with the precardinal vein in the cardinoCuvierian district

10, Lymphatic of the lateral line of the trunk

11, Posteardinal vein

12, Duct of Cuvier

13, Otic communication; the point at which the lateral pharyngeal lymphatic communicates with the precardinal vein near the caudal end of the otocyst

14, Dorsal aorta

15 , Hyoidean artery

16, First efferent aortic arch

17, Second efferent aortic arch

18, Third efferent aortic arch

19, Fourth efferent aortic arch

20, Caudal end of eye

22, Carotid artery

24, Cardino-Cuvierian junction

27 , Root of dorsal aorta 
PLATE 8

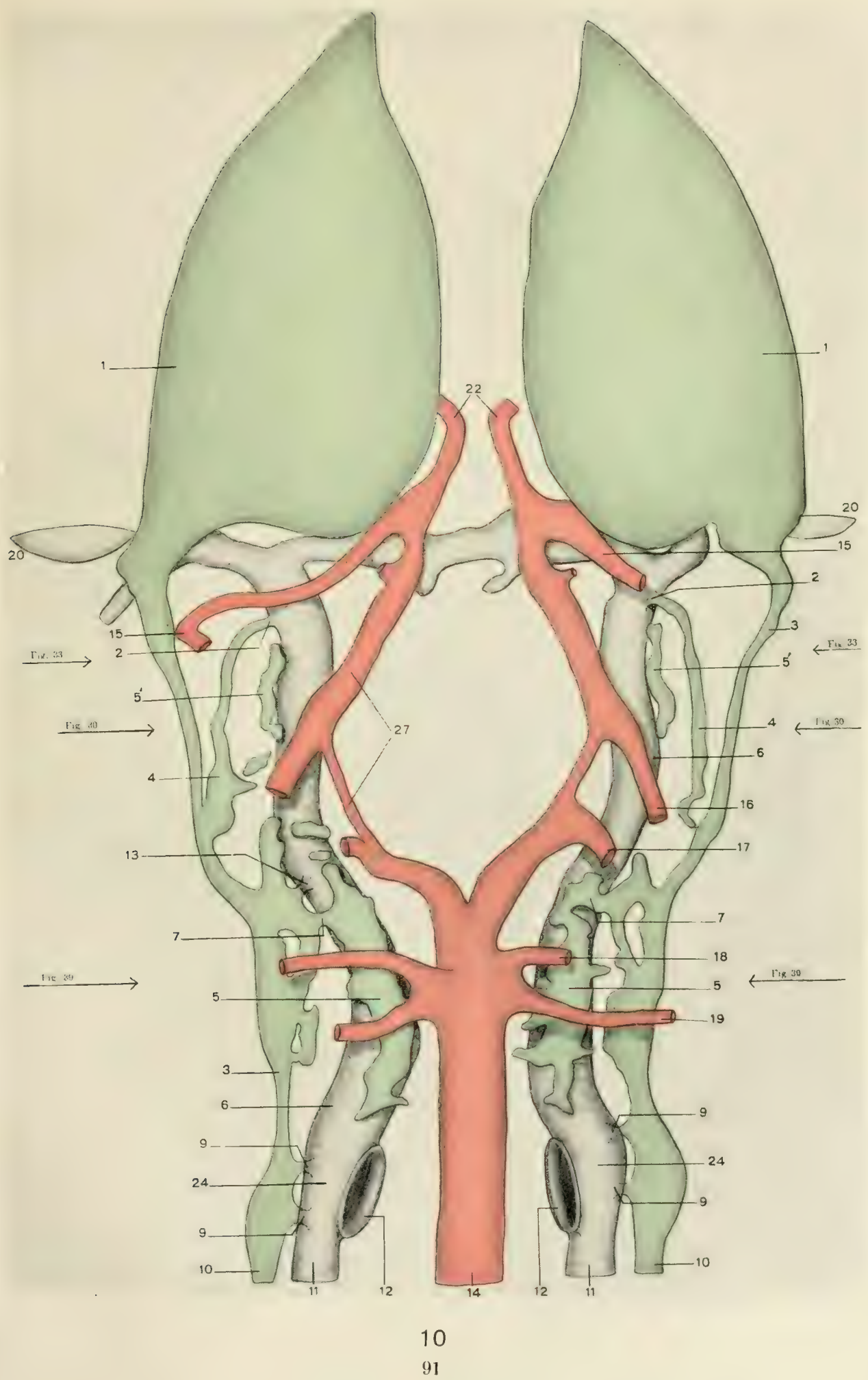


PLATE 9

EXPLANATION OF FIGURE

Fig. 11 Ventral view of the arteries, veins and lymphatics found on the left side of the head and pharynx in a $17.5 \mathrm{~mm}$. brook trout embryo. P. E. C. 393.

\section{REFERENCES}

1, Subocular lymph sac

2, Medial pharyngeal communication; the point at which the medial pharyngeal lymphatic communicates with the precardinal vein

3, The lateral pharyngeal lymphatic

4, Medial pharyngeal lymphatic

5 , Precardinal or jugular lymphaties

6 , Precardinal or jugular vein

9, Cardino-Cuvierian communication; the point at which the lateral pharyngeal lymphatic communicates with the precardinal vein in the cardinoCuvierian district

10, Lymphatic of the lateral line of the trunk
13, Otic communication; the point at which the lateral pharyngeal lymphatic communicates with the precardinal vein near the caudal end of the otocyst

14, Dorsal aorta

15', Efferent pseudobranchial artery (ophthalmic artery)

16, First efferent aortic arch

17. Second efferent aortic arch

18, Third efferent aortic arch

19 , Fourth efferent aortic arch

21, Superficial facial lymphatic

22, Carotid artery

30 , Pericardial lymphatic 


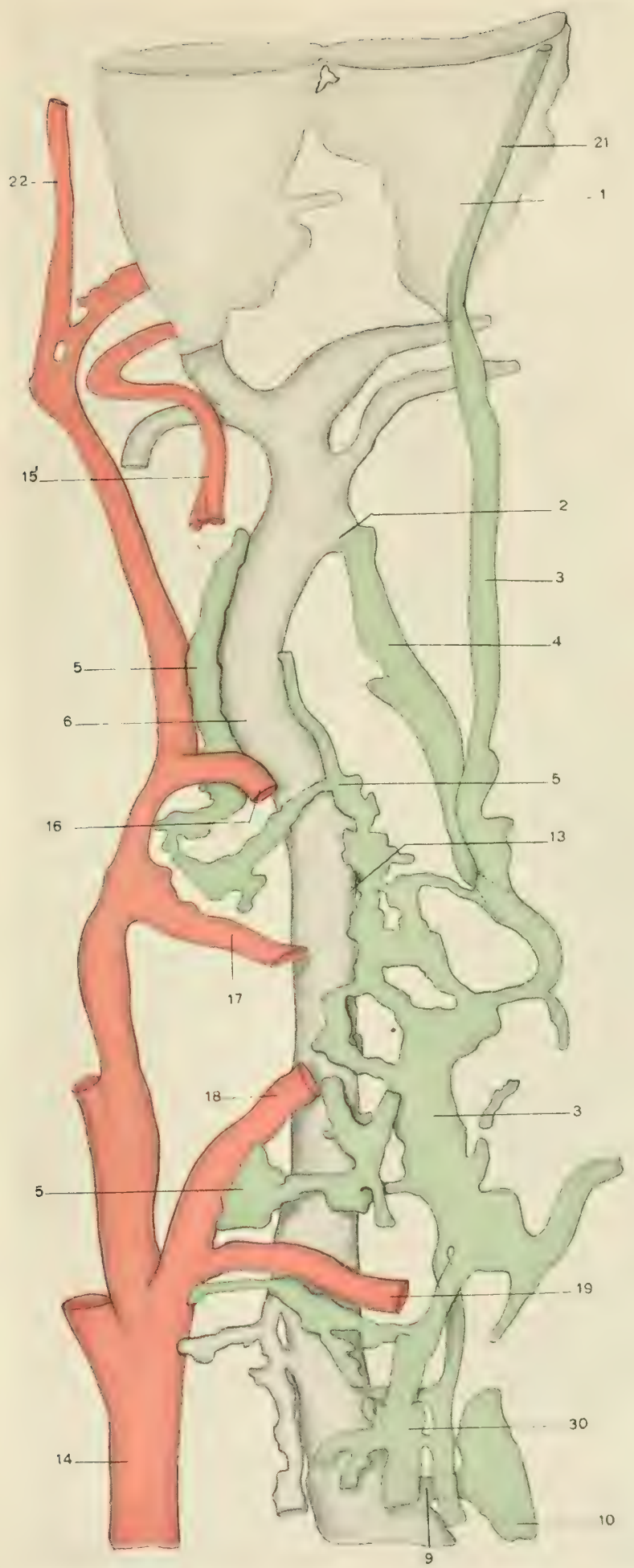




\section{PLATE 10}

\section{EXPLANATION OF FIGURE}

Fig. 12 Ventral view of the arteries, veins and lymphatics found on the left side of the head and pharynx in a $10 \mathrm{~mm}$. embryo of Amia calva; semi-diagrammatic. P. E. C. 4.47 .

\section{REFERENCES}

1, Subocular lymph sac

2, Medial pharyngeal communication; the point at which the medial pharyn geal lymphatic communicates with the precardinal vein $3^{\prime \prime \prime}$, Independent anlagen of the lateral pharyngeal lymphatic

4, Medial pharyngeal lymphatic

6, Precardinal or jugular vein
11, Postcardinal vein

12, Duct of Cuvier

14 , Dorsal aorta

15 , Hyoidean artery

21, Superficial facial lymphatic

29 , Temporary connection established between the subocular lymph sac and the veins in the embryos of Amia and Lepidosteus 
PIATE 10

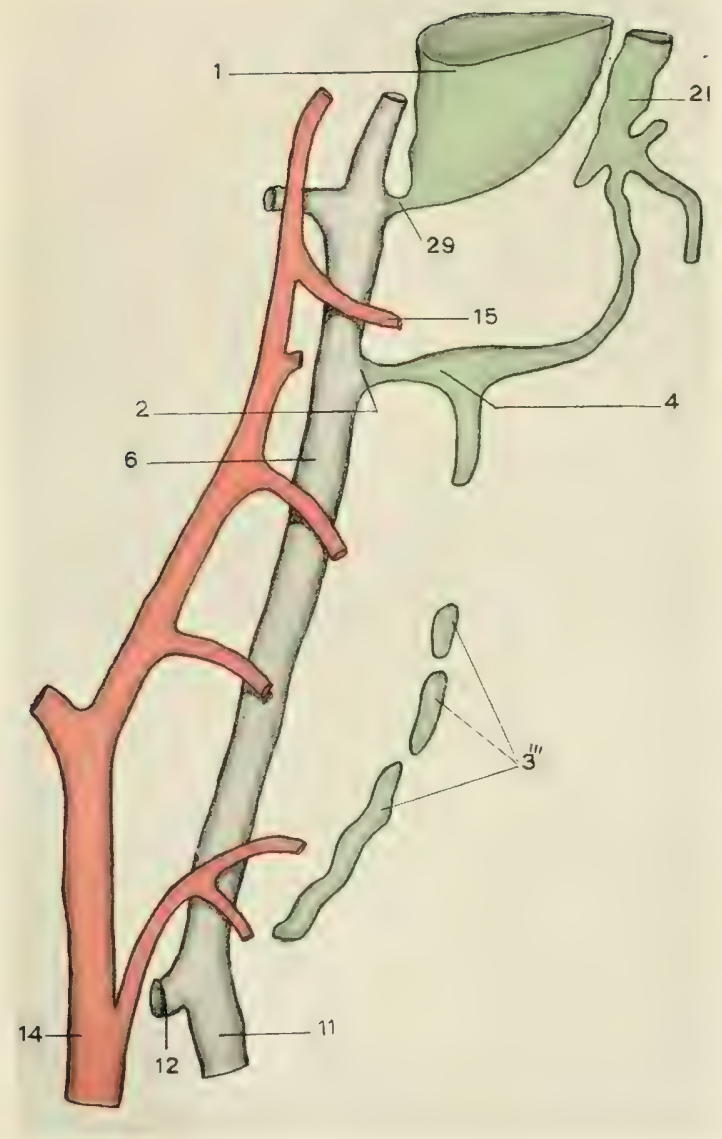




\section{PLATE 11}

\section{EXPLANATION OF FIGURE}

Fig. 13 Ventral view of the arteries, veins and lymphatics found on the left side of the head and pharynx in a $19 \mathrm{~mm}$. embryo of Amia calva; semi-diagrammatic. P. E. C. 387.

\section{REFERENCES}

1, Subocular lymph sac

2, Medial pharyngeal communication; the point at which the medial pharyngeal lymphatic communicates with the precardinal vein

3 , The lateral pharyngeal lymphatic

4, Medial pharyngeal lymphatic

5 , Precardinal or jugular lymphaties

6 , Precardinal or jugular vein

9, Cardino-Cuvierian communication: the point at which the lateral pharyn- geal lymphatic communicates with the precardinal vein in the cardinoCuvierian district

10, Lymphatic of the lateral line of the trunk

11, Postcardinal vein

12, Duct of Cuvier

14 , Dorsal aorta

$15^{\prime}$, Efferent pseudobranchial artery

21 , Superficial facial lymphatic

30 , Pericardial lymphatic 
PLATE 11

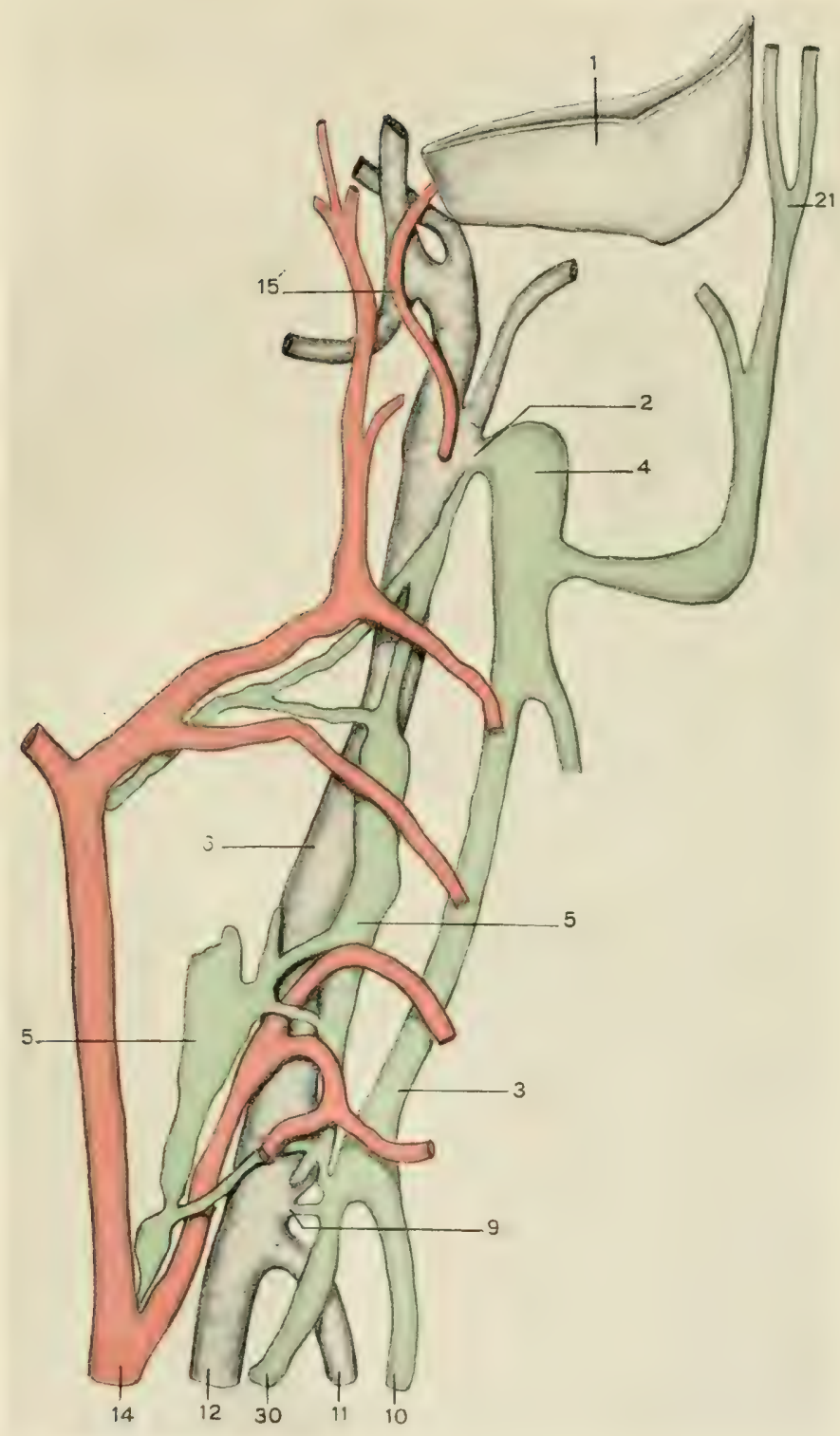


PLATE 12

EXPLANATJON OF FIGURES

Fig. 14 Photomicrograph of a sagittal section taken through the head and pharynx of a twenty-two-day rainbow trout embryo; showing the relations of the subocular lymph sac (1) to the eye, the hyoidean artery (15) and the olfactory pit (33); injected embryo. P. E. C. 816.

Fig. 15 Photomicrograph of a transverse section taken through the subocular lymph sacs of a twenty-day steelhead trout embryo. The subocular sac (1) on the right side of the figure is filled with blood, which has passed into the sac from the veins through the lateral pharyngeal lymphatic. P. E. C. 636, slide 1, section 67 .

\section{REFERENCES}

1, Subocular lymph sac

6 , Precardinal or jugular vein
15, Hyoidean artery

33 , Olfactory pit 

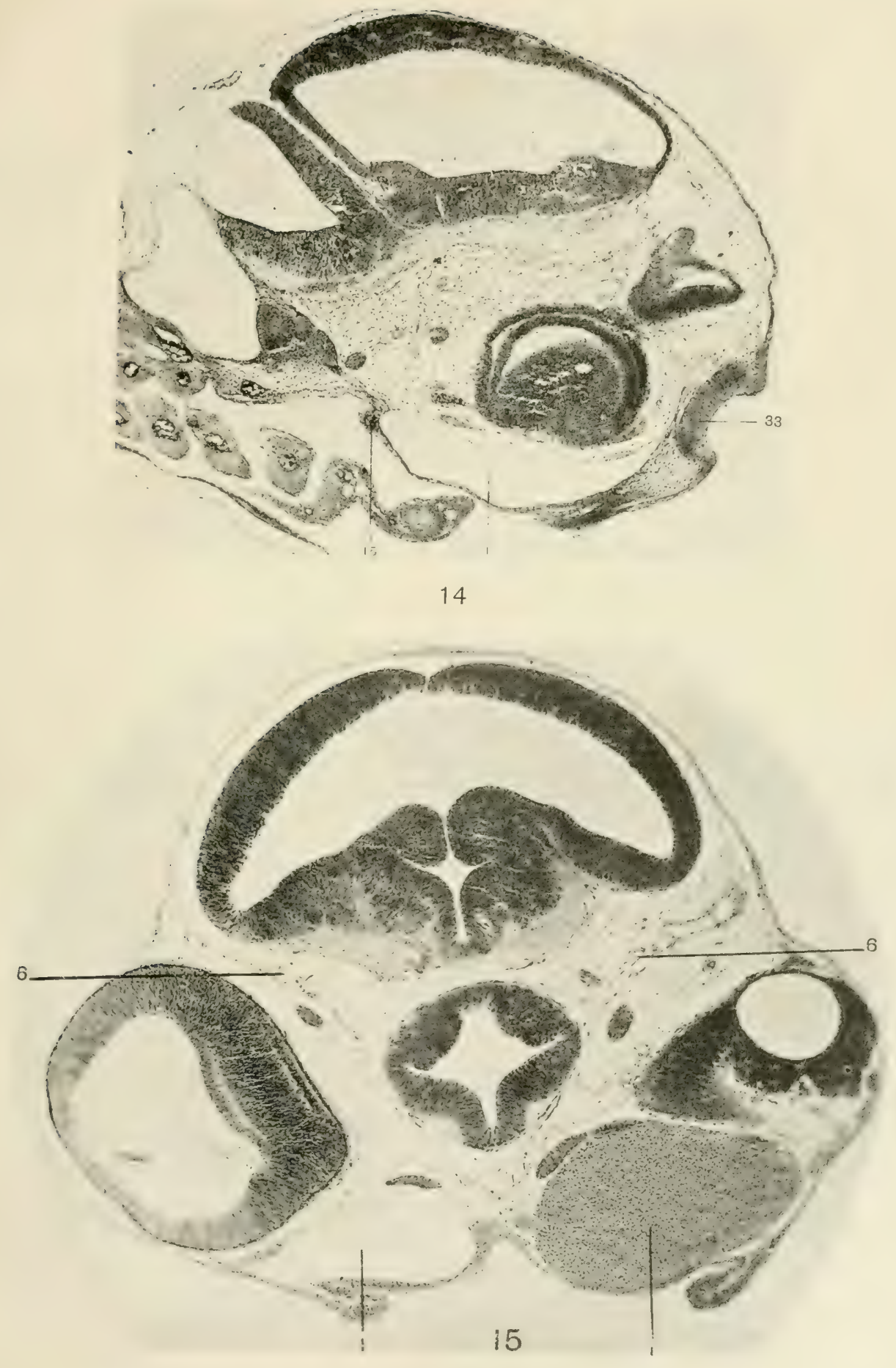
PLATE 13

EXPLANATION OF FIGURES

Fig. 16 Photomicrograph of a transverse section taken through the caudal end of the right subocular lymph sac (1) of an $18.25 \mathrm{~mm}$. rainbow trout embryo in which the subocular sac has become detached from the lateral pharyngeal lymphatic (3). The lateral pharyngeal lymphatic is filled with blood. P. E. C. 944 , slide 1, section 134 .

Fig. 17 Photomicrograph of a transverse section taken through the subocular lymph sacs (1) of an $18.25 \mathrm{~mm}$. rainbow trout embryo at the level of the optic nerves, showing the position occupied by the superficial facial lymphatic (21) which is filled with blood. P. E. C. 944, slide 1, section 78.

REFERENCES

1, Subocular lymph sac

3 , The lateral pharyngeal lymphatic
6 , Precardinal or jugular vein 21 , Superficial facial lymphatic 

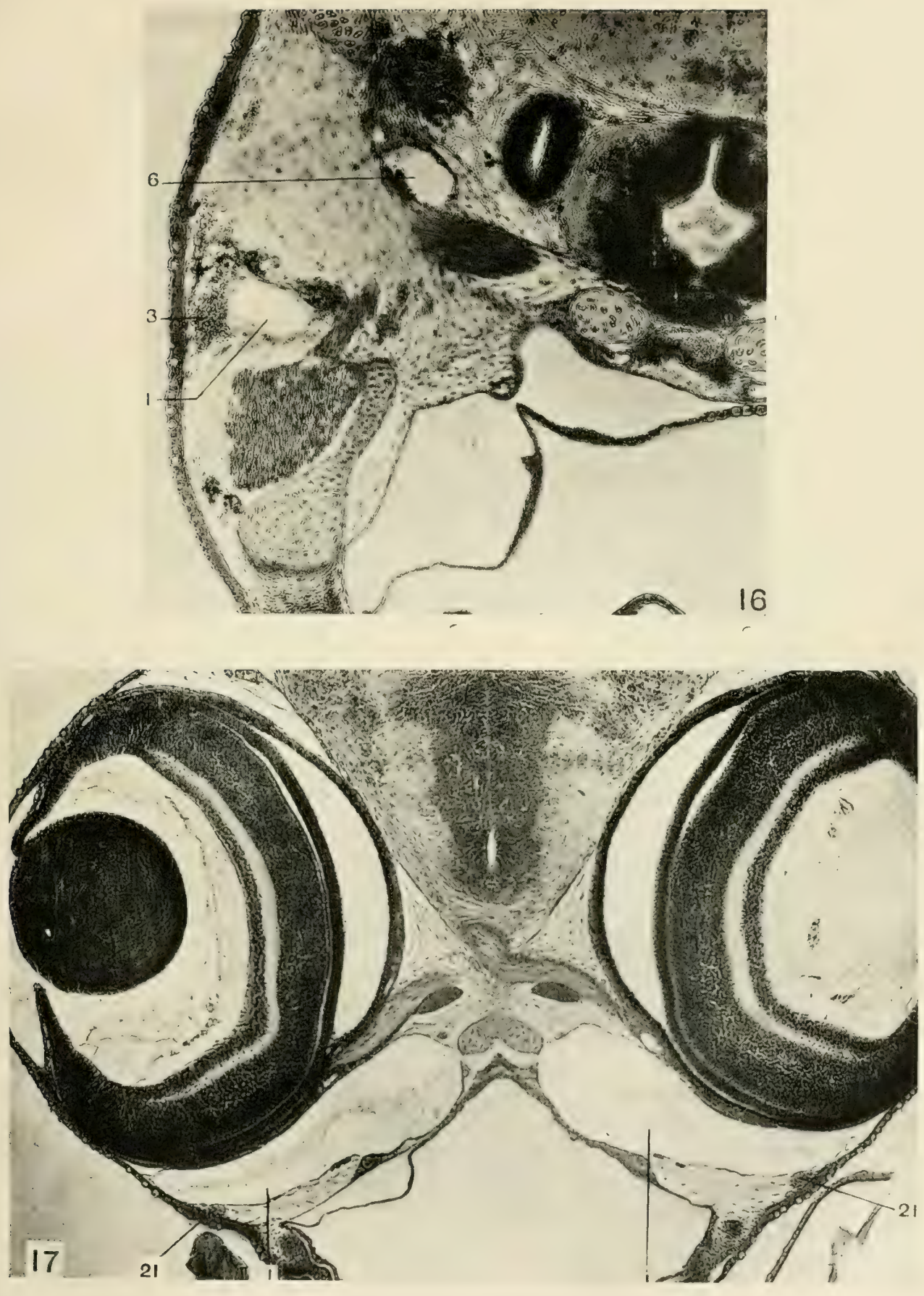


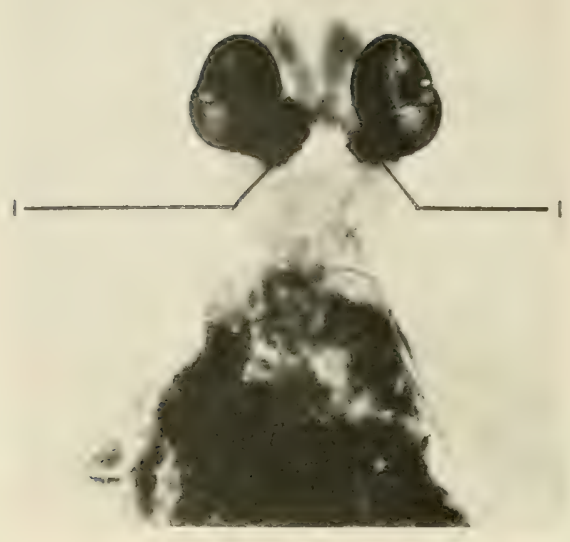

Fig. 1s Photograph of the rentral aspect of the head of a twenty-day rain. bow trout embryo on which an attempt was made to inject the lymphatics and the veins by injecting into the subocular lymph sacs (1); Spalteholz preparation.

PLATE 14

EXPLANATION OF FIGURE

Fig. 19 Photomicrograph of a frontal section taken through the anlagen of the subocular lymph sacs (1) in a fourteen-day steelhead trout embryo. P. E. C. 697 , slide 1 , section 69 ; injected embryo.

\section{REFERENCES}

1, Subocular lymph sac

6, Precardinal or jugular vein
22, Carotid artery

28, Infundibulum 
PLATE 14

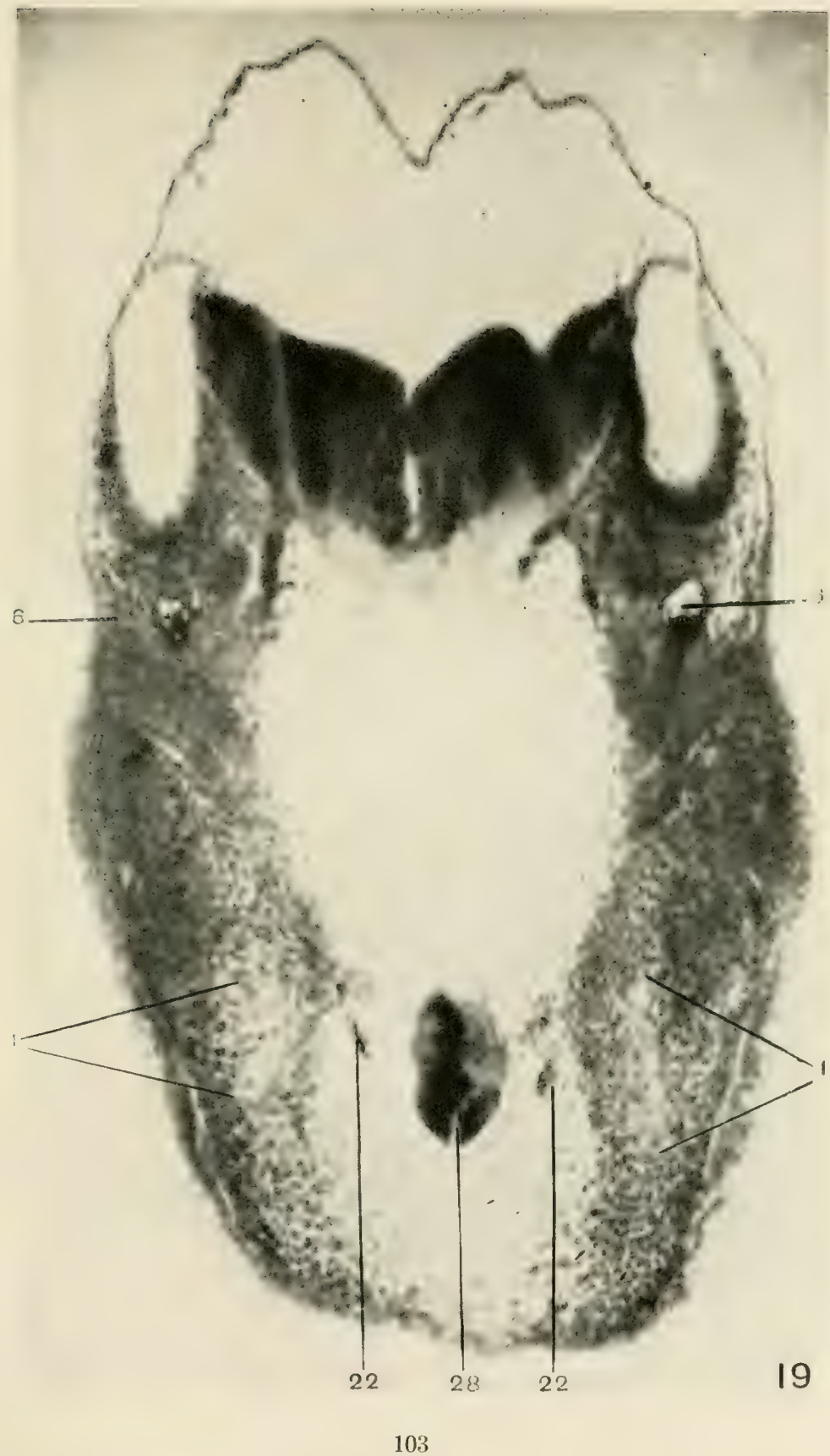




\section{PLATE 15}

\section{EXPLANATION OF FIGURE}

Fig. 20 Photomicrograph of a frontal section taken through the anlagen of the subocular lymph sacs (1) in a fourteen-day steelhead trout embryo. P. E. C. 696 , slide 1, section 69 ; injected embryo.

\section{REFERENCES}

1, Subocular lymph sac

6, Precardinal or jugular vein
22, Carotid artery

28 , Infundibulum 


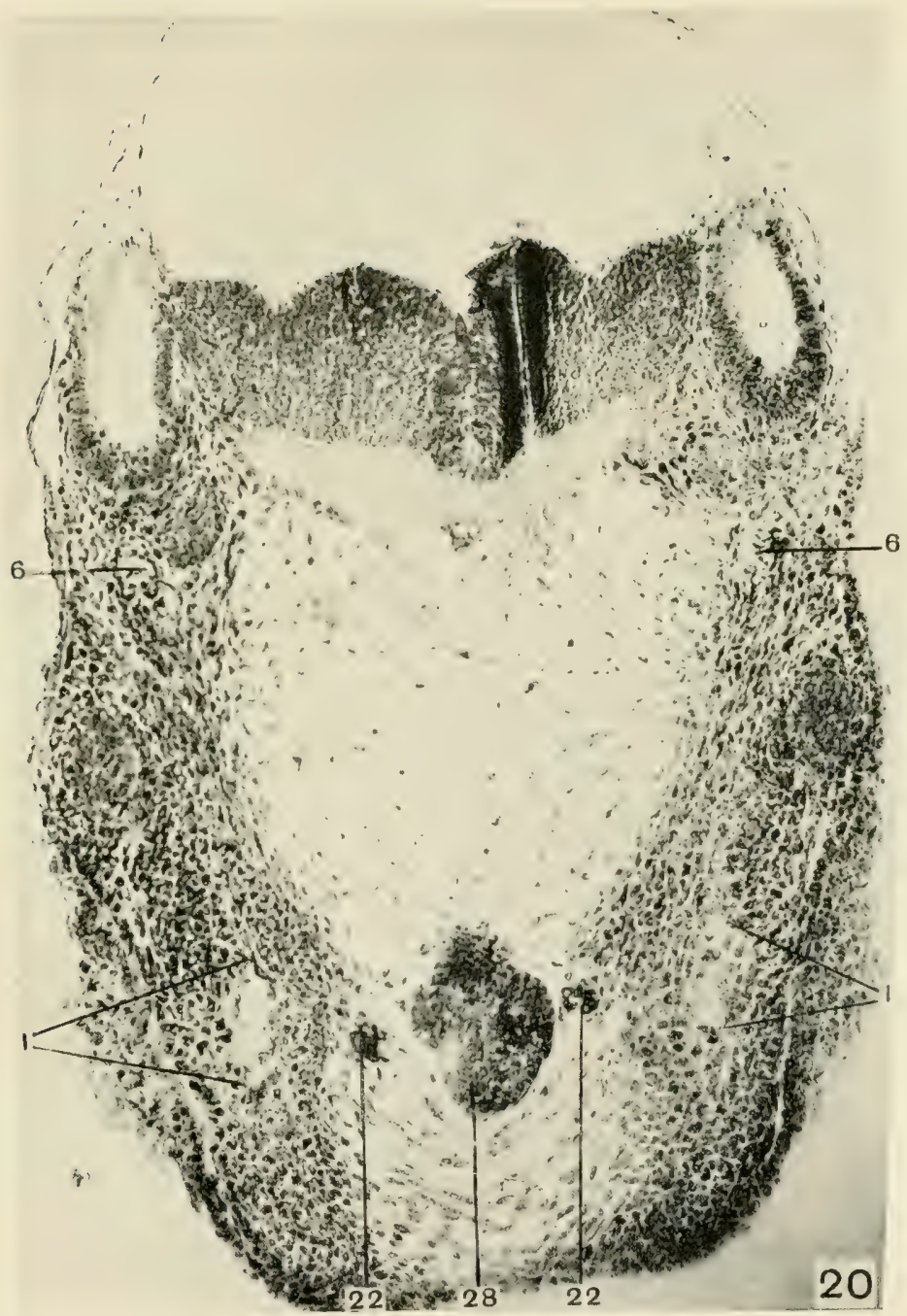


PLATE 16

EXFLANATION OF FIGL'TiF

Fig. 21 Photomicrograph of a transverse section taken through the subocular lymph sac (1) in a seventeen-day steelhead trout embryo in which the sac presents a multilocular appearance; high magnification. P. E. C. 522, slide 1, section 95; injected cmbryo.

IREFERENCES

1, Subocular lymph sac

22, Carotid artery 
PLATE 16

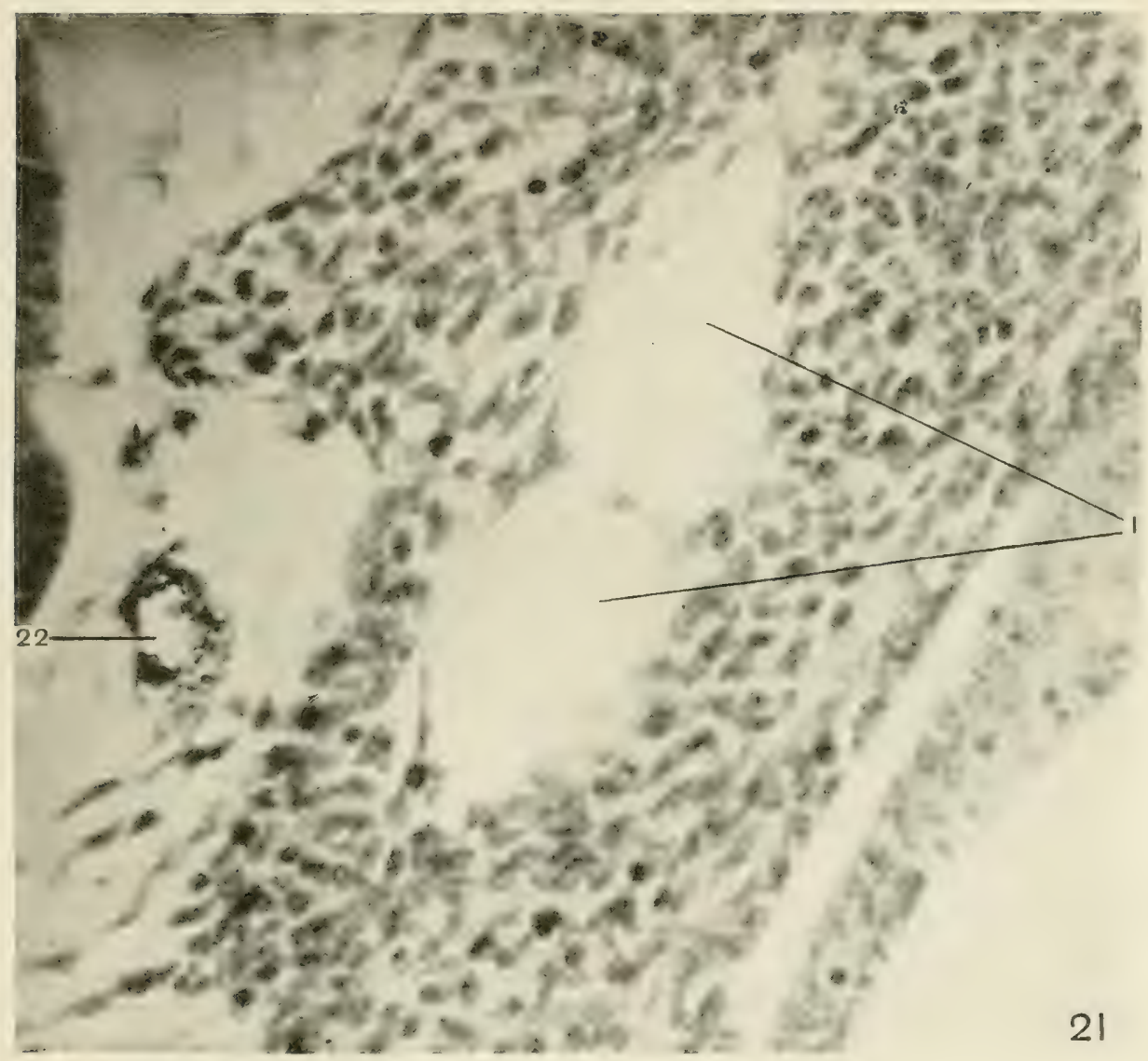


PLATE 17

EXPLANATION OF FIGURH

Fig. 22 Photomicrograph of a transverse section taken through the subocular lymph sacs (1) in a fourteen-day steelhead trout embryo. P. E. C. 695 , slide 1 , section 70; injected embryo.

REFERENCES

1, Subocular lymph sac

6 , Precardinal or jugular vein

20, Caudal end of eye
22, Carotid artery

28, Infundibulum 
PLATE 17

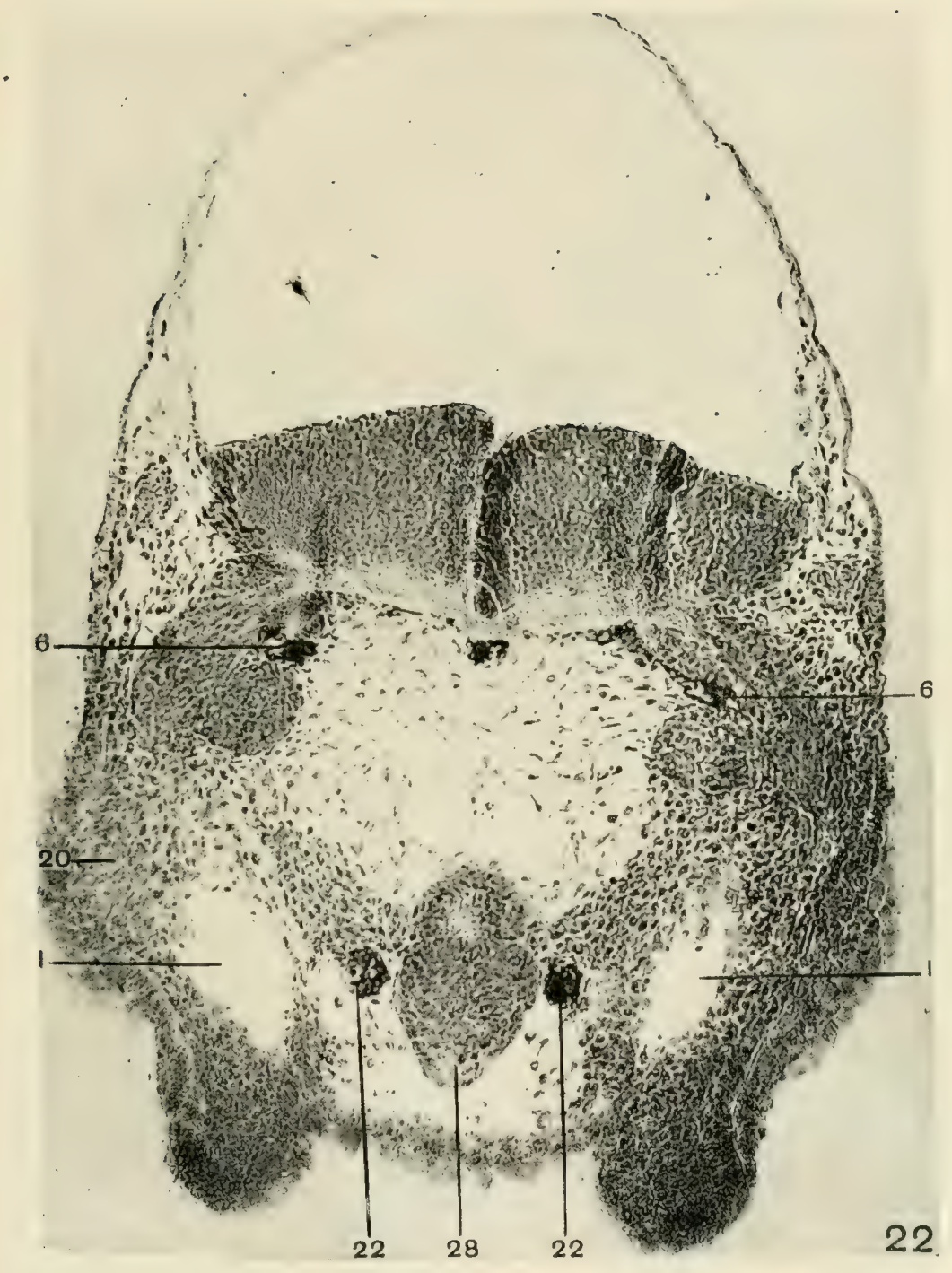


PLATE 18

EXPLANATION OF FIGURES

Fig. 23 Photomicrograph of a transverse section taken through the subocular Iymph sacs (1) of a fifteen-day steelhead trout embryo. P. E. C. 726, slide 1, section 78 ; injected embryo.

Fig. 24 Photomicrograph of a transverse section taken through the subocular lymph sacs (1) of a sixteen-day rainbow trout embryo at the level of the infraorbital veins (2S); showing that the veins are fully injected and that none of the injecta has passed into the sacs. P. E. C. 751, slide 1 , section 66 .

REFERENCES

1, Subocular lymph sac

6 , Precardinal or jugular vein

15, Hyoidean artery

20, Caudal end of eye
22, Carotid artery

23, Infraorbital vein

28, Infundibulum 

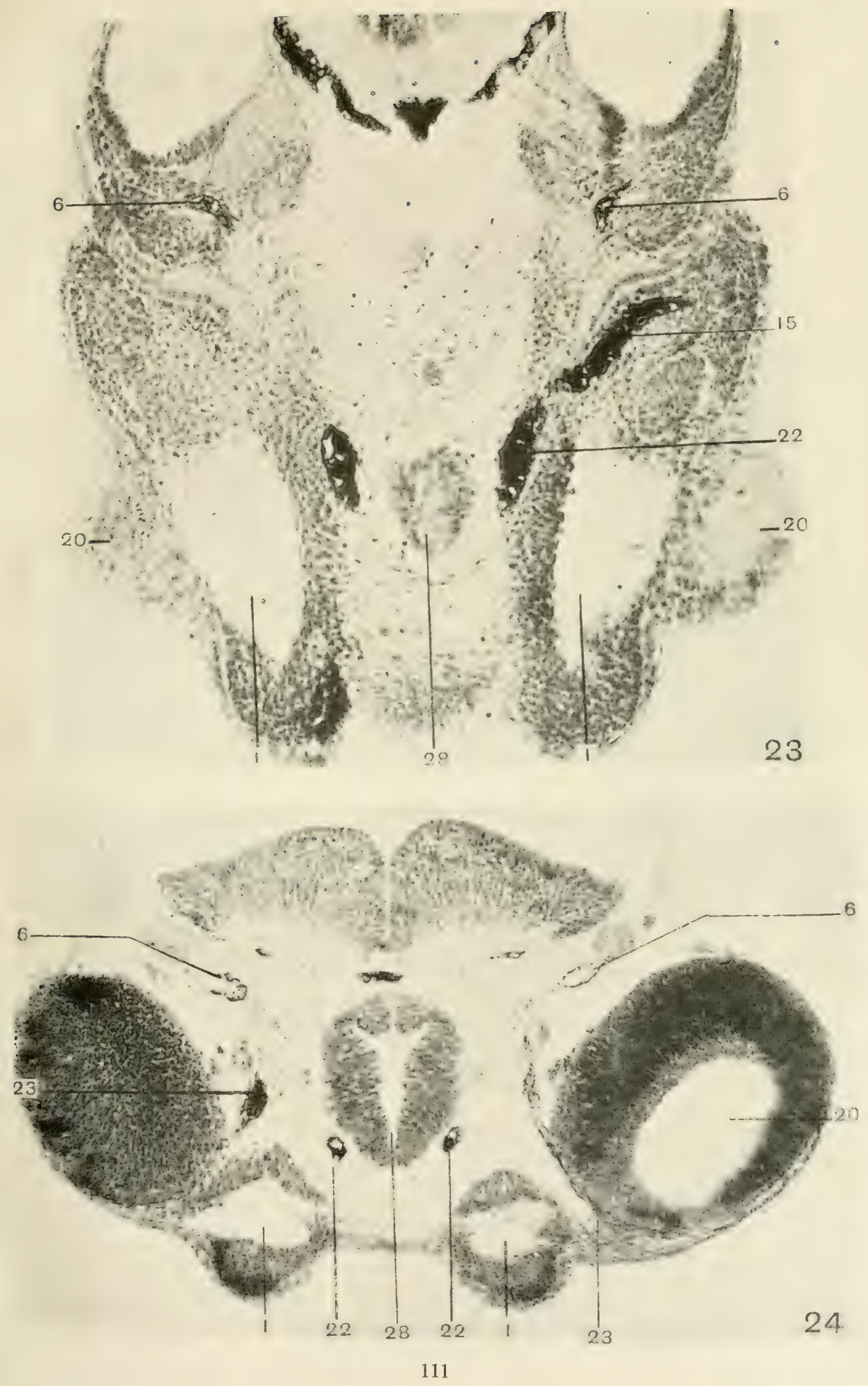


\section{PLATE 19}

\section{EXPLANATION OF FIGURE}

Fig. 25 Photomicrograph of a transverse section of a fourteen-day steelhead trout embryo, taken at the level of the infraobital veins (23); showing that in the course of their forward extension, the subocular lymph sacs have not reached the level of the infraorbital veins. P. E. C. 696, slide 1, section 61 injected embryo.

\section{REFERENCES}

6, Precardinal or jugular vein

20, Caudal end of eye

22 , Carotid artery
23 , Infraorbital vein

28 , Infundibulum 
PLATE 19

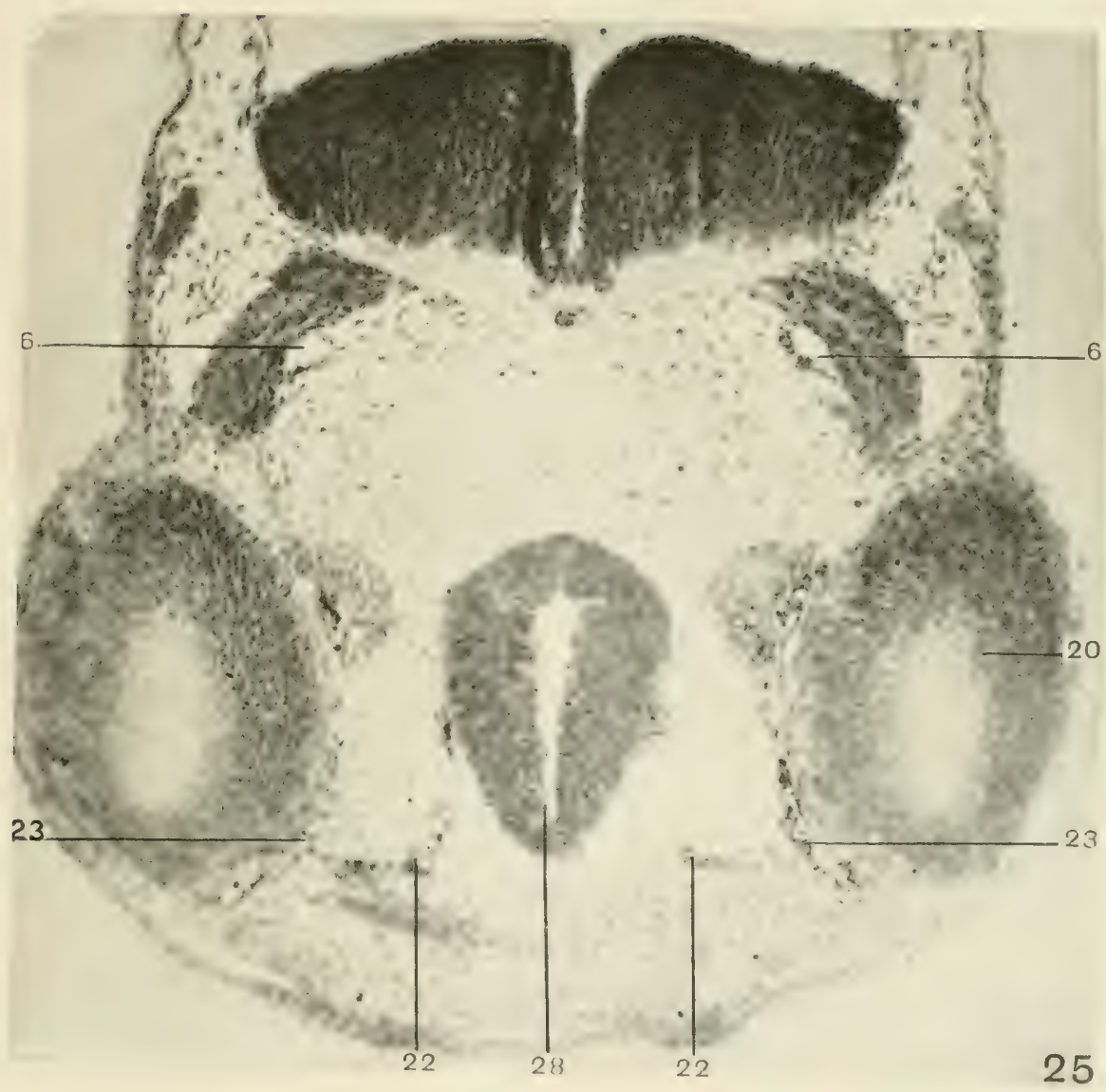




\section{PLATE 20}

\section{EXPLANATION OF FIGURF}

Fig. 26 Photomicrograph of a transverse section of a twenty-two-day rainbow trout embryo taken through the anterior end of the left subocular lymph sac (1); showing that the anterior extension of the sac is brought about by a confluence of independent anlagen. P. E. C. 648 , slide 1 , section 48 .

REFERENCES

1, Suboeular lymph sae 


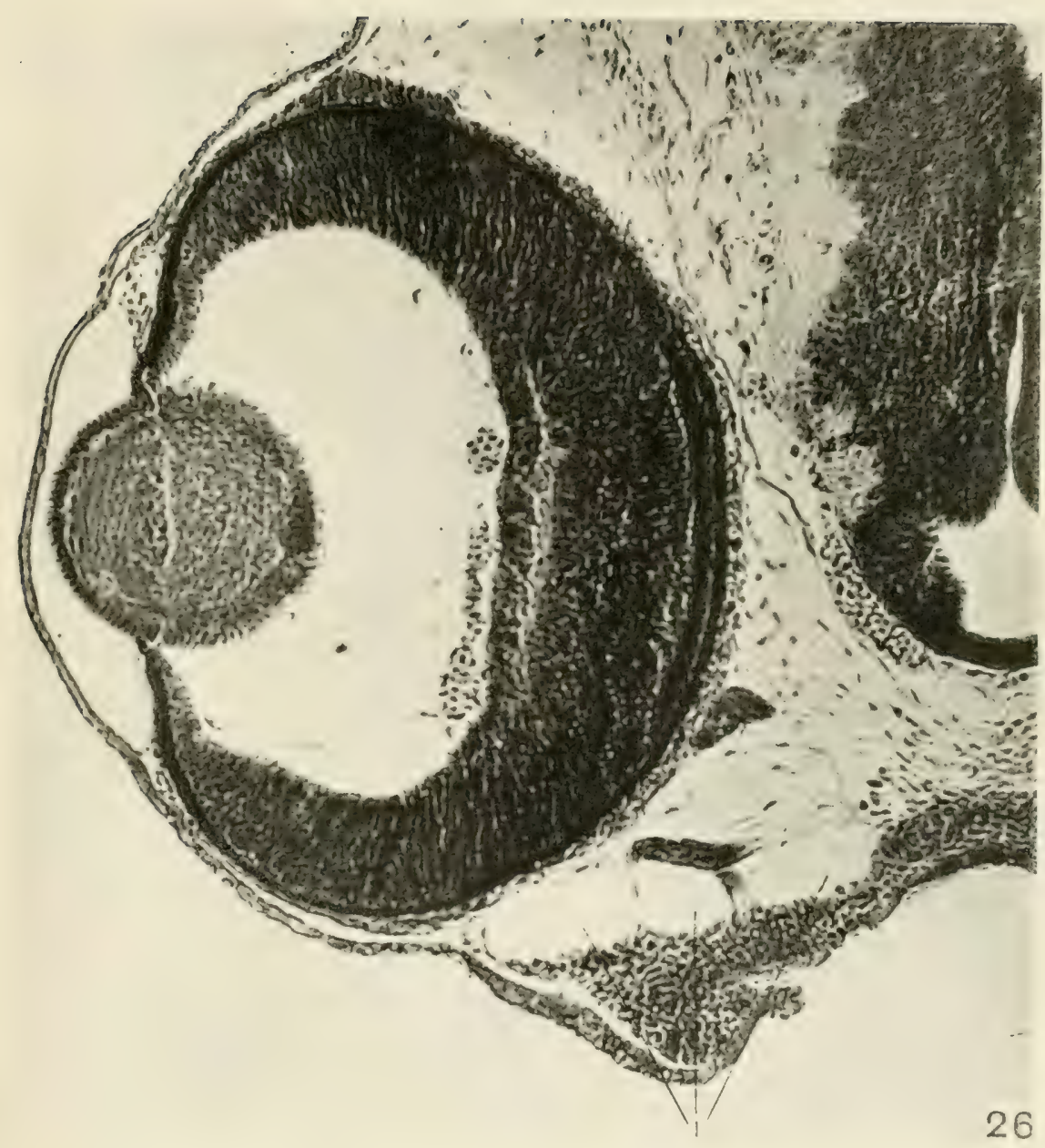


PLATE 21

EXPLANATION OF FIGURES

Fig. 27 Photomicrograph of a transverse section of a sixteen-day steelhead trout embryo, taken through an independent anlage $\left(3^{\prime}\right)$ of the lateral pharyngeal lymphatic, at about the level of the first efferent aortic arches; compare $3^{\prime}$ in figures 5 and 27 . P. E. C. 751 , slide, 1, section 91 ; injected embryo.

Fig. 28 Photomicrograph of a transverse section of a seventeen-day steelhead trout embryo, taken through independent anlagen $\left({ }^{\prime}\right)$ of the lateral pharyngeal lymphatic, at about the level of the first efferent aortic arches; compare $3^{\prime}$ in figures 6,7 and 28 . P. E. C. 740 , slide 1, section 103; injected embryo,

\section{IREFERENCES}

3', Independent anlagen of the lateral pharyngeal lymphatie which lie anterior to the otic communication

6. Precardinal or jugular vein
15, Hyoidean artery

16 , First efferent aortic arch

27 , Root of dorsal aorta 


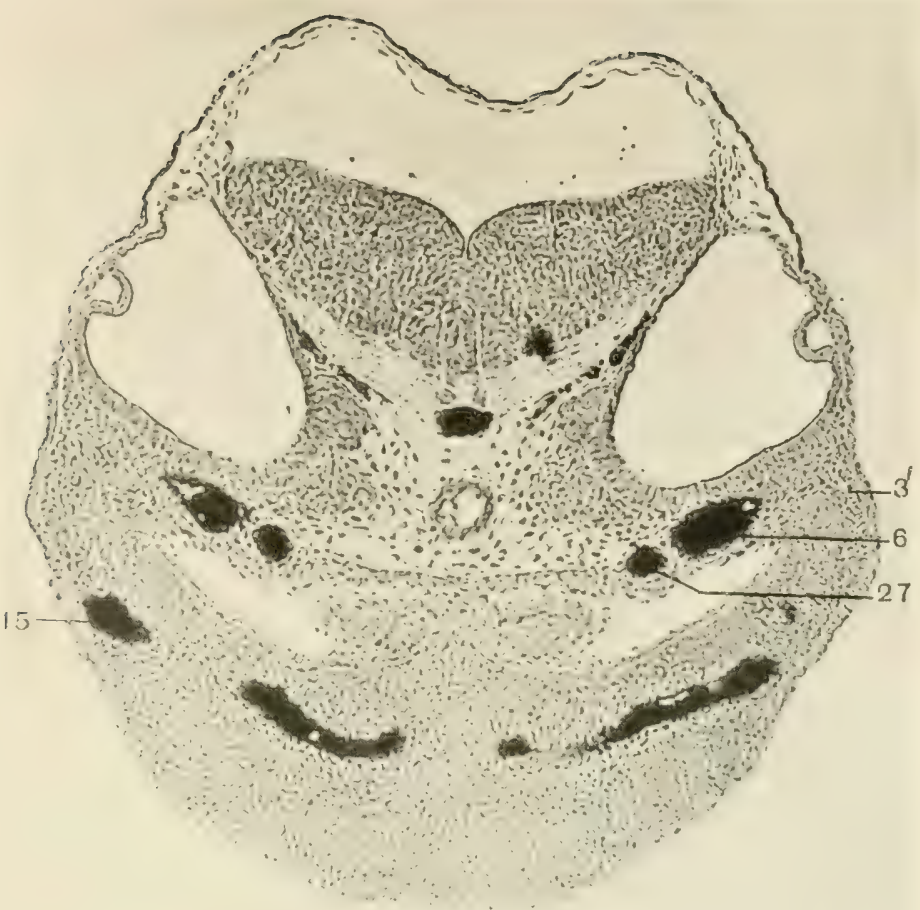

27

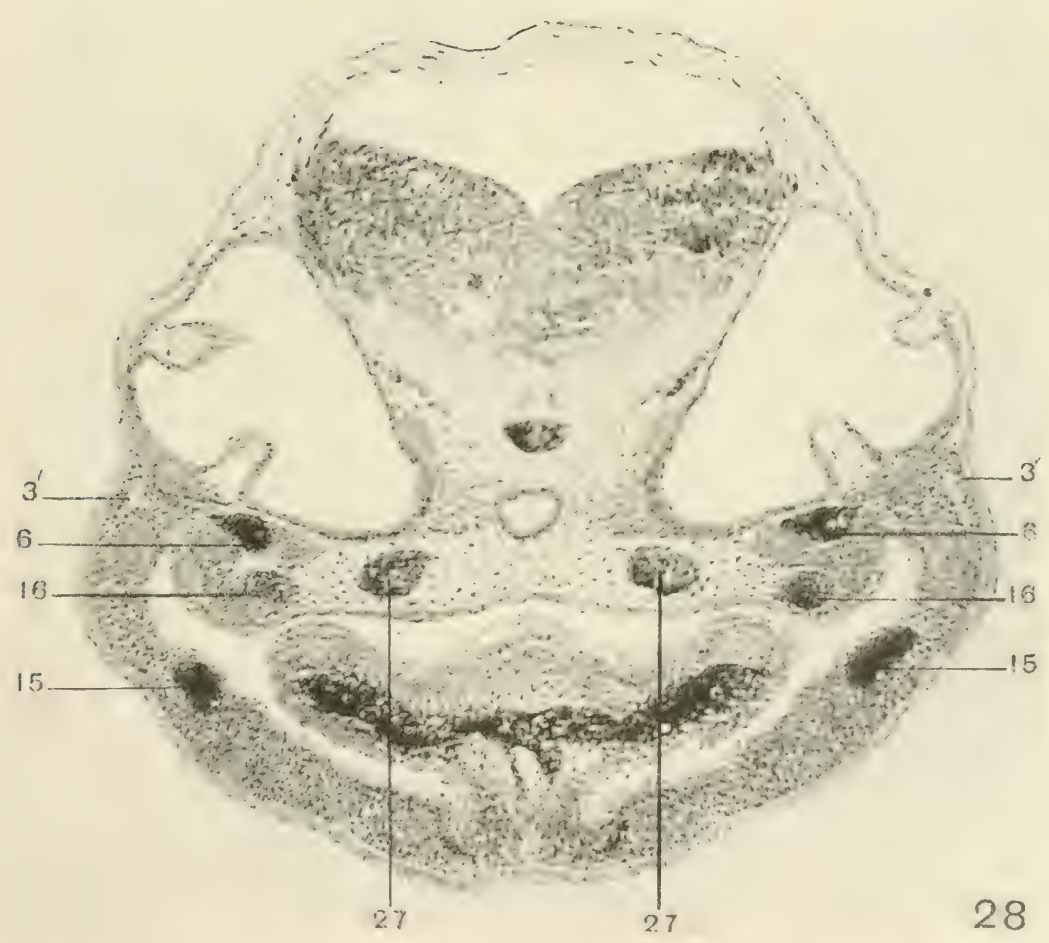


PLATE 22

\section{EXPLANATION OF FIGURE}

Fig. 29 Photomicrograph of a transverse section of a twenty-day rainbow trout embryo, taken through independent anlagen $\left(3^{\prime}\right)$ of the lateral pharyngeal lymphatic, at about the level of the first efferent aortic arches; compare $3^{\prime}$ in figures 8 and 29. P. E. C. 668 , slide 1, section 122; injected embryo.

\section{REFERENCES}

$3^{\prime}$, Independent anlagen of the lateral pharyngeal lymphatic which lie anterior to the otic communication 6 , Precardinal or jugular vein
15, Hyoidean artery

16, First efferent aortic arch

27 , Root of dorsal aorta 


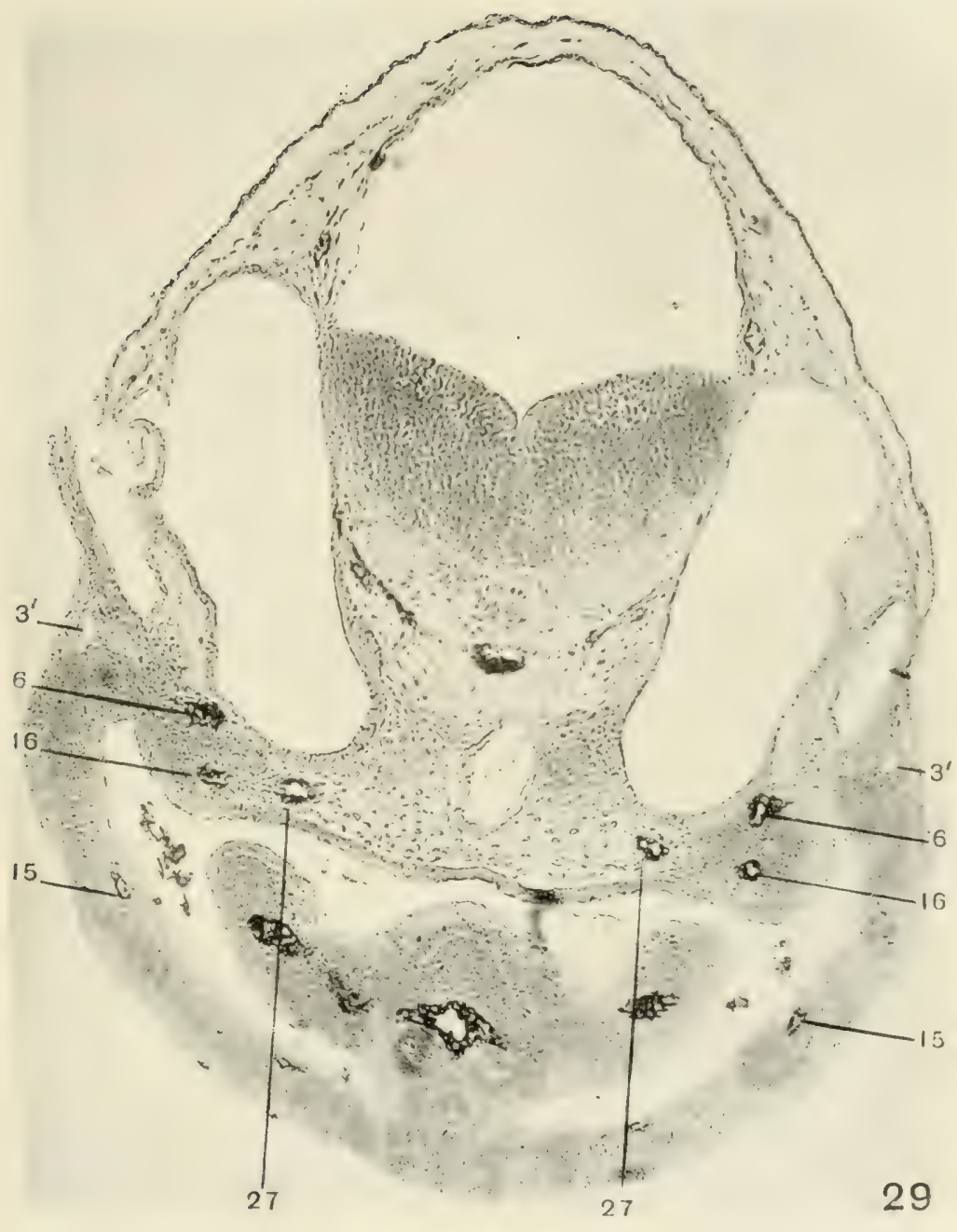




\section{PLATE 23}

\section{EXPLANATION OF FIGURES}

Fig. 30 Photomicrograph of a transverse section of a twenty-two-day rainbow trout embryo, taken at about the level of the first efferent aortic arches; showing that the continuous lateral pharyngeal lymphatic ( 3 in figures 10 and 30 ) occupies the same relative position in the walls of the pharynx as its independent anlagen ( $3^{\prime}$ in figures 27, 28 and 29) of earlier stages. The medial pharyngeal lymphatic (4) and independent anlagen of the precardinal lymphatics $\left(5^{\prime}\right)$ are also shown in figure 30 . P. E. C. 648 , slide 2, section 17 .

Fig. 31 Photomierograph of a transverse section of a seventeen-day steelhead trout embryo, taken through independent anlagen $\left(3^{\prime}\right)$ of the lateral pharnygea lymphatic at about the level of the hyoidean arteries; compare $3^{\prime}$ in figures 6 and 31 . P. E. C. 740 , slide 1, section 88 ; injected embryo.

\section{REFERENCES}

3, The lateral pharyngeal lymphatic: a continuous vessel through which the subocular lymph sac drains into the veins in the trout

$3^{\prime}$, Independent anlagen of the lateral pharyngeal lymphatic which lie anterior to the otic communication 4, Medial pharyngeal lymphatic
5 ', Independent anlage of the precardinal lymphatic which lies contiguous to the precardinal vein and just caudal to the medial pharyngeal communication (see fig. 10)

6 , Precardinal or jugular vein

15 , Hyoidean artery

$2 \overline{7}$, Root of dorsal aorta 

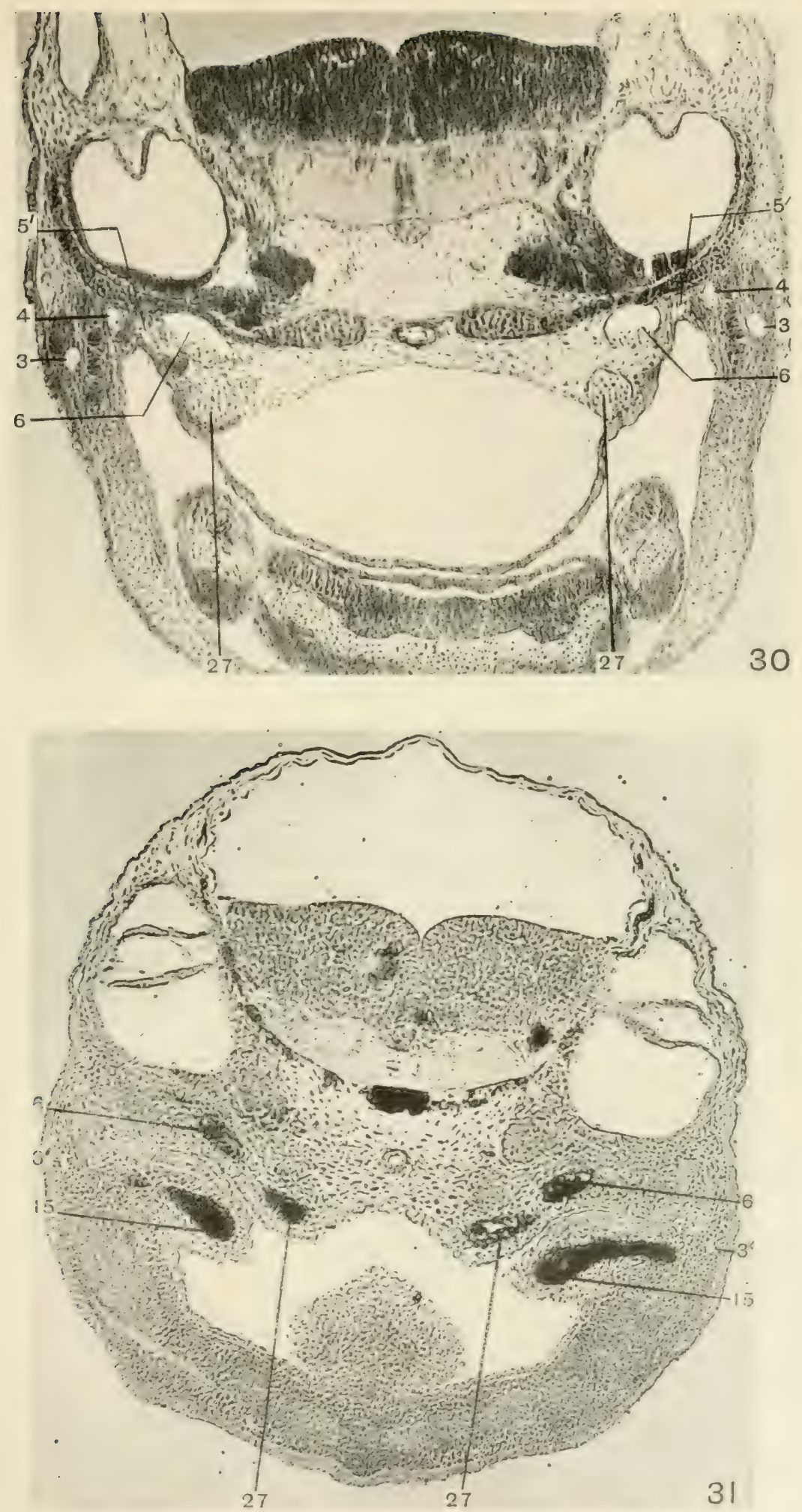
PLATE 24

EXPLANATION OF FIGURE

Fig. 32 Photomicrograph of a transverse section of a twenty-day rainbow trout embryo, taken through independent anlagen $\left(3^{\prime}\right)$ of the lateral pharyngeal lymphatic, at about the level of the hyoidean arteries; compare $3^{\prime}$ in figures 8 and 32. P. E. C. 668, slide 1, section 98; injected embryo.

REFERENCFS

$3^{\prime}$, Independent anlagen of the lateral pharyngeal lymphatic which lie anterior to the otic communication 6 , Precardinal or jugular vein
8, Cranial end of otocyst

15 , Hyoidean artery

27, Root of dorsal aorta 


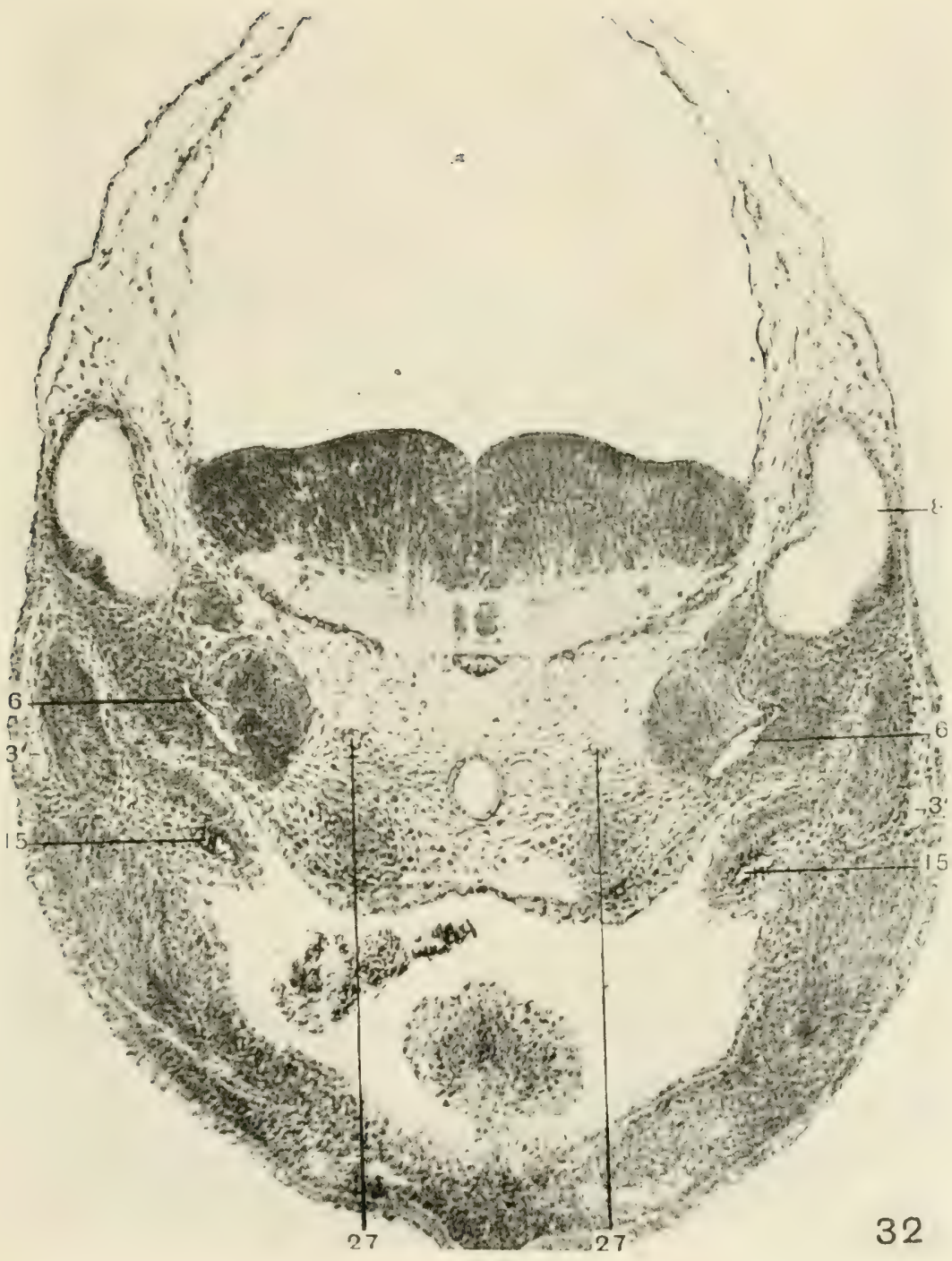




\section{PLATE 25}

\section{EXPLANATION OF FIGURE}

Fig. 33 Photomicrograph of a transverse section of a twenty-two-day rainbow trout embryo, taken at about the level of the hyoidean arteries; showing that the continuous lateral pharyngeal lymphatic ( 3 in figures 10 and 33 ) occupies the same relative position in the walls of the pharynx, as its independent anlagen ( $3^{\prime}$ in figures 31 and 32 ) of earlier stages. The medial pharyngeal lymphatic (4) and independent anlagen $\left(5^{\prime}\right)$ of the precardinal lymphatics are also shown in figure 33 . P. E. C. 648, slide 2, section 10.

\section{REFEREXCES}

3, The lateral pharyngeal lymphatic; a continuous vessel through which the subocular lymph sac drains into the veins in the trout

4 , Medial pharyngeal lymphatic

$5^{\prime}$, Independent anlage of the precardinal lymphatic which lies con- tiguous to the precardinal vein and just caudal to the medial pharyngeal communication (see fig. 10)

6 , Precardinal or jugular vein

15, Hyoidean artery

27 , Root of dorsal aorta 


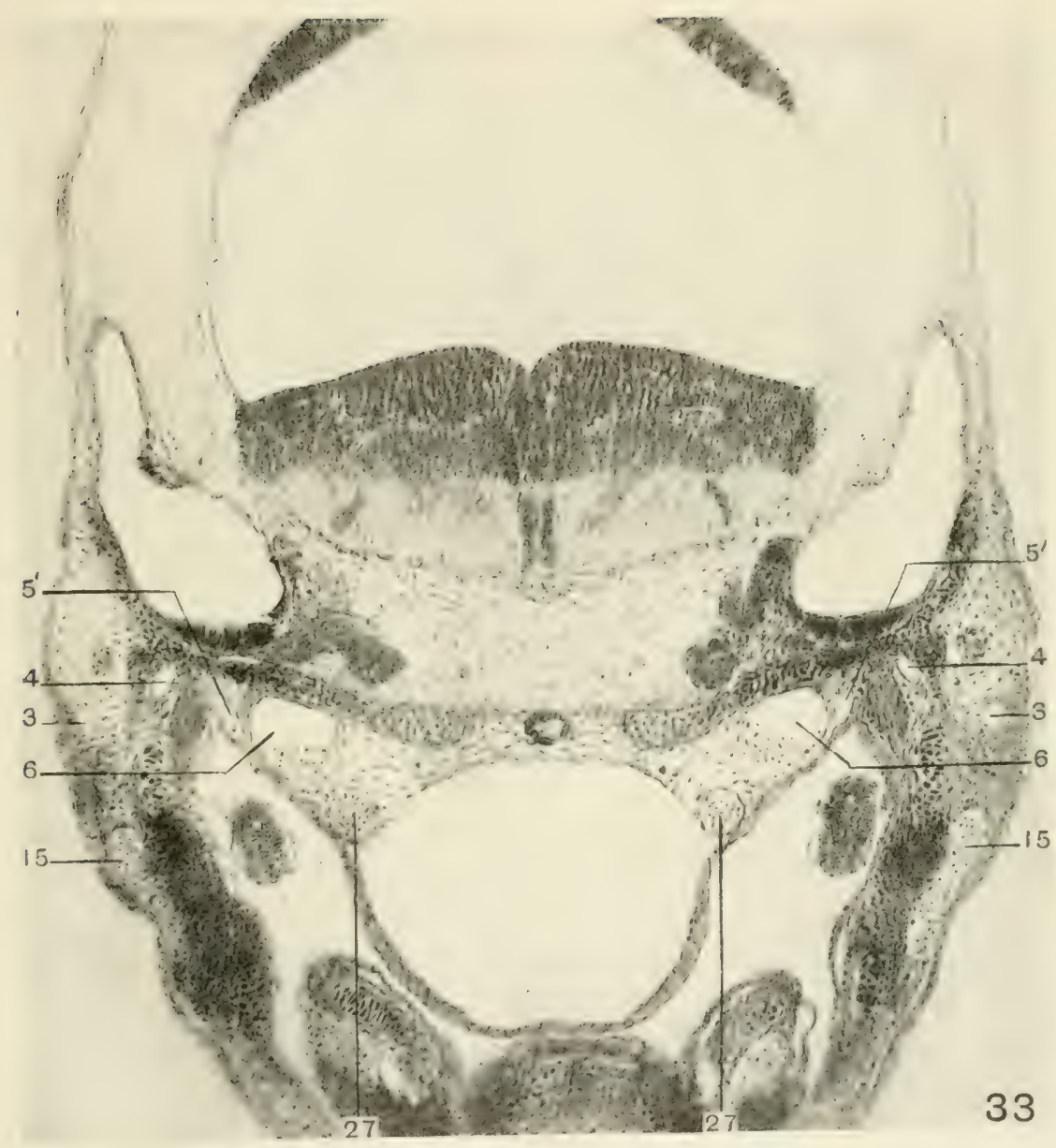


PLATE 26

EXPLANATION OF FIGURE

Fig. 34 Photomicrograph of a transverse section of a fourteen-day steelhead trout embryo, taken through the cardino-Cuvierian lymph sac ( $\left.3^{\prime \prime \prime}\right)$ found on the left side and through the more anterior of the two cardino-Cuvierian lymph sacs $\left(3^{\prime \prime \prime}\right)$ found on the right side of the embryo; see reconstructions o embryo, figures 1 and 2. P. E. C. 696, slide 1, section 119; injected embryo.

\section{REFERENCES}

$3^{\prime \prime \prime}$, Cardino-Cuvierian lymph sac; anlage of the lateral pharyngeal lymphatic which lies opposite to the cardino-Cuvierian junction
6, Precardinal or jugular vein 14, Dorsal aorta 


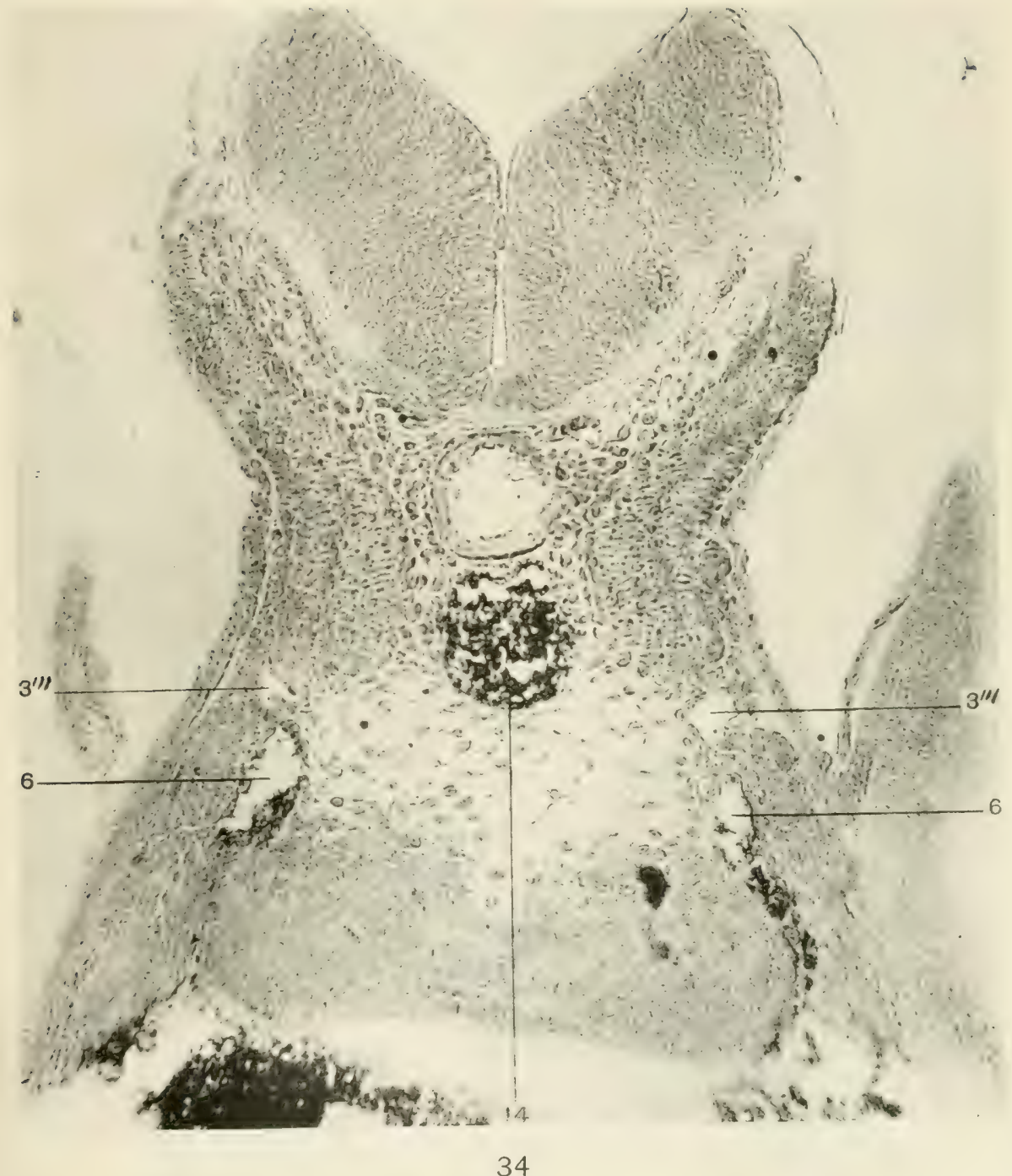




\section{PLATE 27}

\section{EXPLANATION OF FIGURES}

Fig. 35 Photomicrograph of a transverse section of a 'ourteen-day steelhead trout embryo, taken through the more posterior of the two cardino-Cuvierian lymph sacs $\left(3^{\prime \prime \prime}\right)$ found on the right side of this embryo; see reconstruction, figure 2. P. E. C. 696 ; slide 1 , section 122 ; injected embryo.

Fig. 36 Photomicrograph of a transverse section of a fifteen-day steelhead trout embryo, taken through the right otic lymph sac $\left(3^{\prime \prime}\right)$ and an independent anlage $\left(5^{\prime \prime}\right)$ of the precardinal (jugular) lymphatic; compare $3^{\prime \prime}$ and $5^{\prime \prime}$ in figures 4 and 36. P. E. C. 726, slide 1, section 116; injected embryo.

\section{REFERENCES}

$3^{\prime \prime}$, Otic lymph sac; anlage of the lateral pharyngeal lymphatic which lies near the caudal end of the otocyst and which may establish a communication with the precardinal vein at the otic communication

$3^{\prime \prime \prime}$, Cardino-Cuvierian lymph sac; anlage of the lateral pharyngeal lymphatic which lies opposite to the cardino-Cuvierian junction $5^{\prime \prime}$, Anlage of the precardinal lymphatic which lies contiguous to the otic communication and which establishes a connection with the lateral pharyngeal lymphatic

6 , Precardinal or jugular vein

14, Dorsal aorta

17 , Second efferent aortic arch 

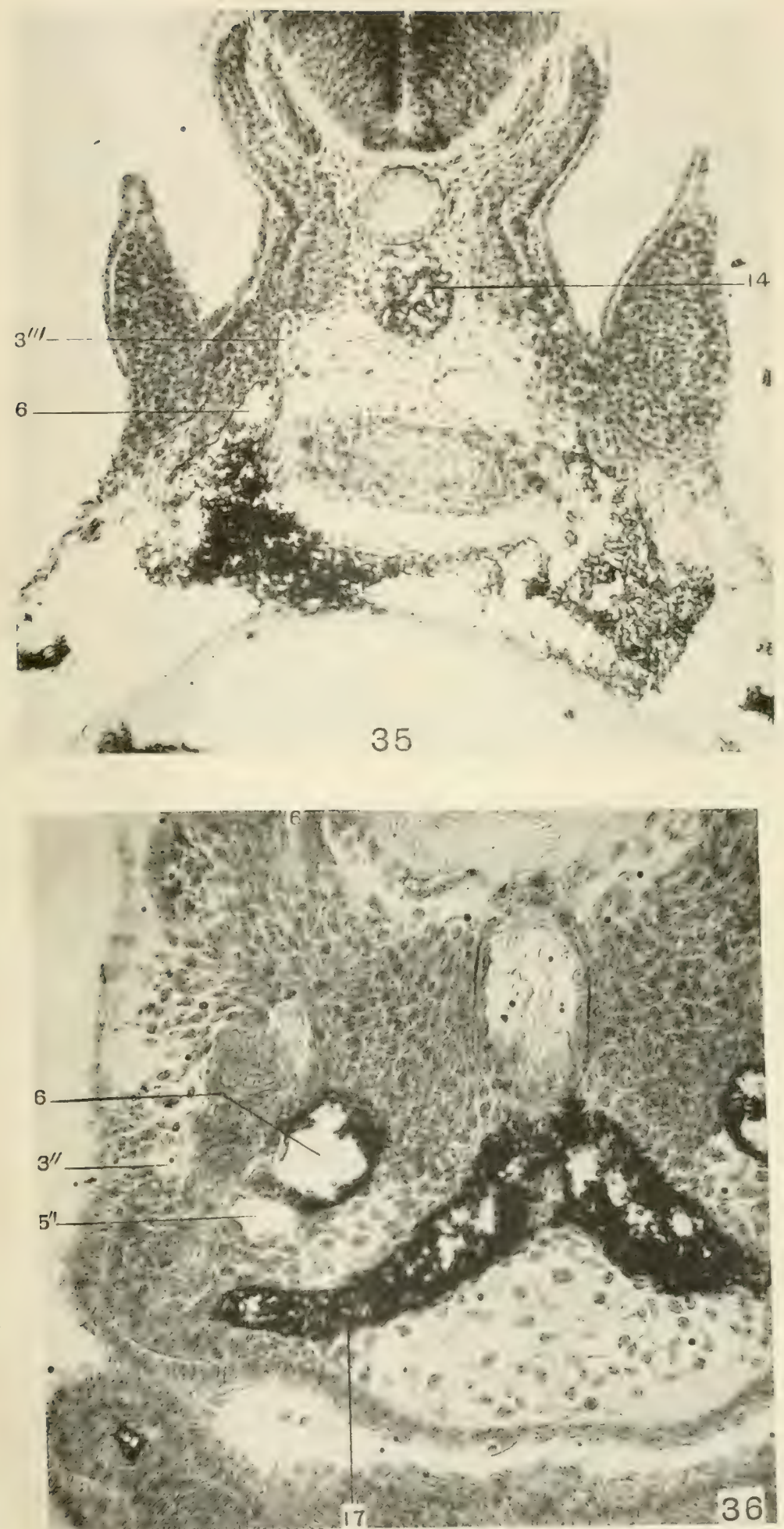


\section{PLATE 28}

\section{EXPLANATION OF FIGURES}

Fig. 37 Photomicrograph of a transverse section of a twenty-three-day rainbow trout embryo, taken through the caudal end of the left subocular lymph sac (1); showing that the superficial facial (21) and lateral pharyngeal lymphatic communicate with the subocular lymph sae at this stage of development; compare figure 37 with figure 16 . P. E. C. 968 , slide 1 , section 112.

Fig. 38 Photomicrograph of a transverse section of a twenty-three-day rainbow trout embryo, taken through the left subocular lymph sac (1) eleven sections anterior to the point (fig. 37) where the superficial facial lymphatic (21) communicates with the lateral pharyngeal lymphatic and the subocular sac. $P$. E. C. 968, slide 1, section 101 .

\section{REFERENCES}

1, Subocular lymph sac

21, Superficial facial lymphatic 

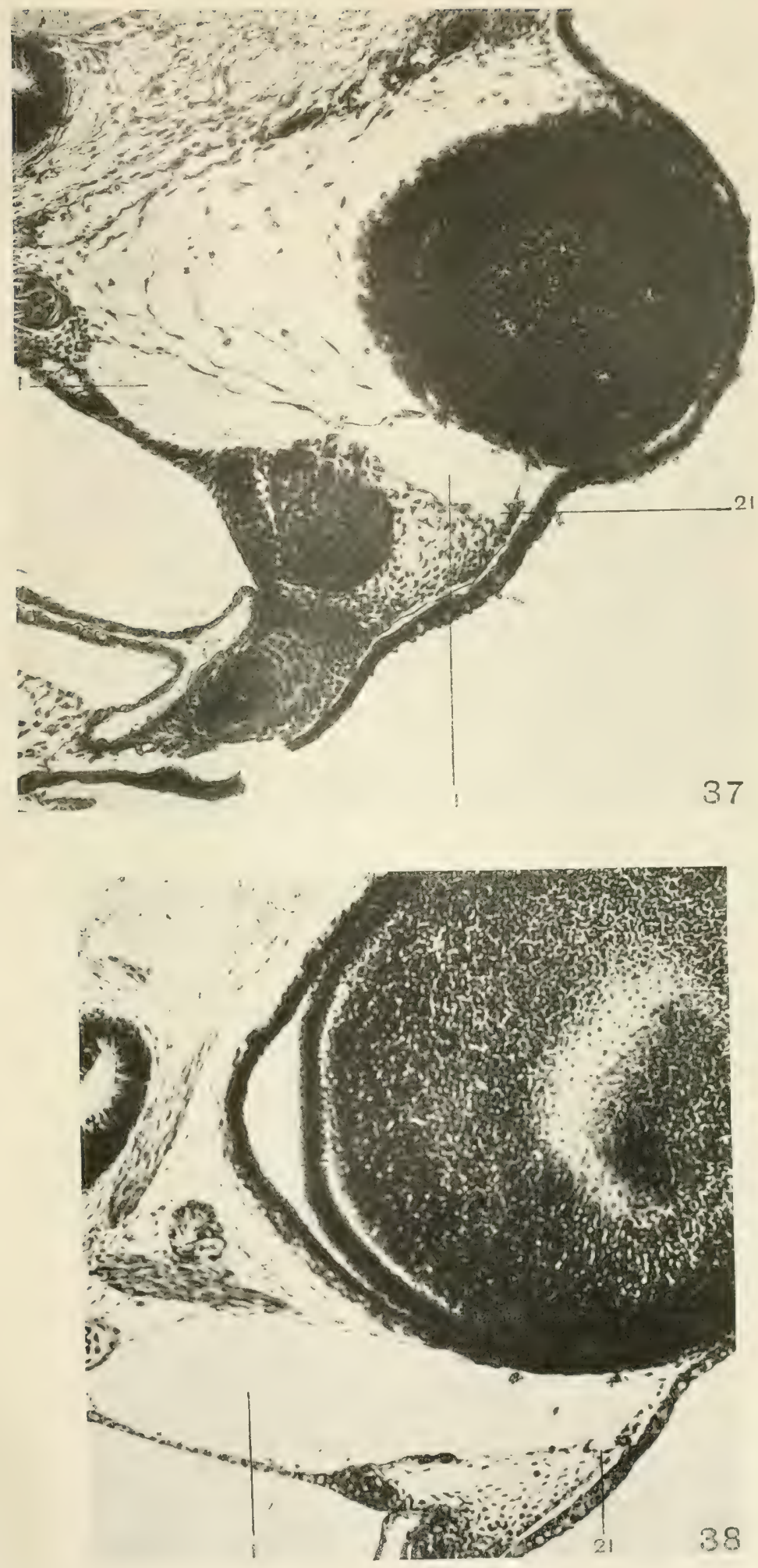
PLATE 29

\section{EXPLANATION OF FIGURE}

Fig. 39 Photomicrograph of a transverse section of a twenty-two-day rainbow trout embryo, taken at the level of the third and fourth efferent aortic arches (18 and 19 in figure 10); showing the relations of the precardinal lymphatics (5) to the precardinal veins (6) in the posterior region of the pharynx. P.E. C. 648, slide 2, section 51 .

\section{REFERENCES}

3, The lateral pharyngeal lymphatic; a continuous vessel through which the subocular lymph sae drains into the veins in the trout.
5 , Precardinal or jugular lymphatics

6 , Precardinal or jugular vein $8^{\prime}$, Caudal end of otocyst 14, Dorsal aorta 


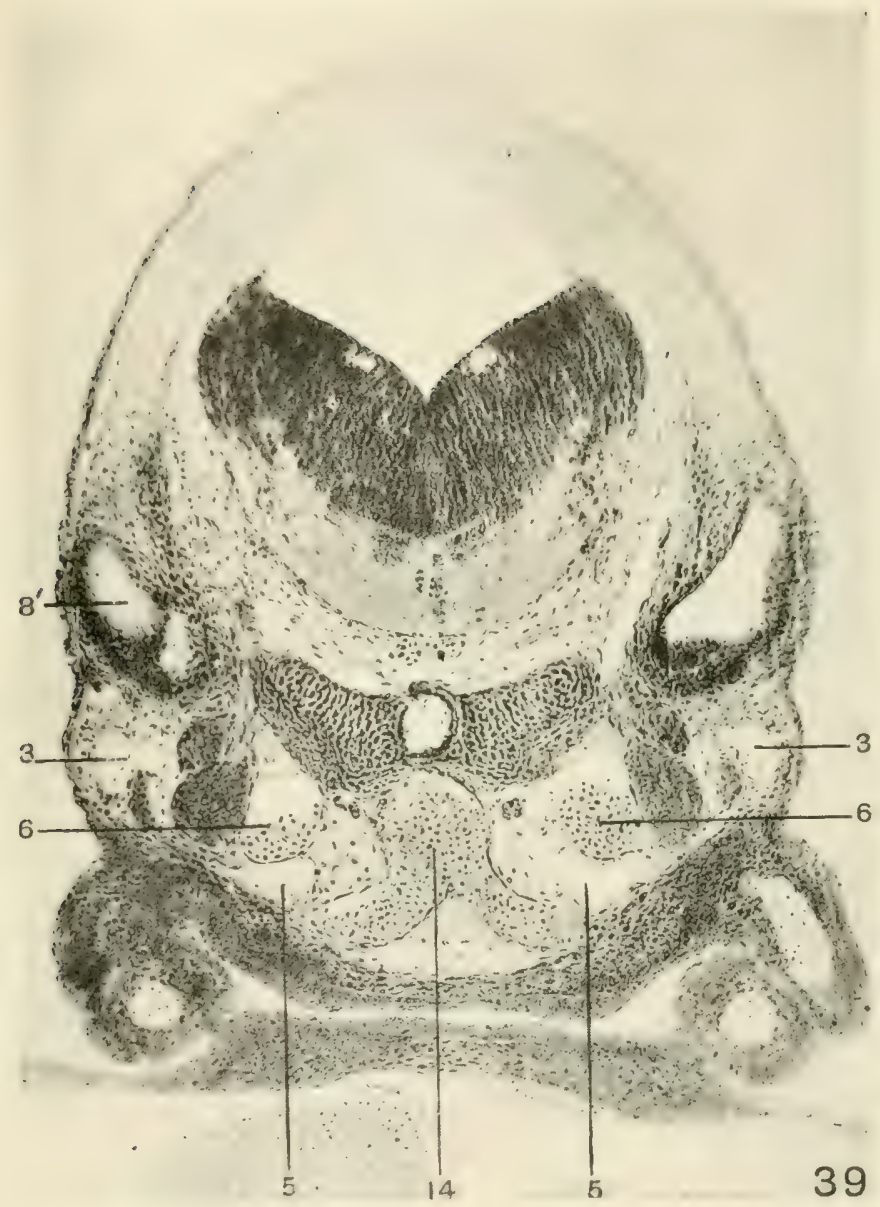


PLATE 30

EXPLANATION OF FJGURE

Fig. 40 Photomicrograph of a transverse section of a $7.5 \mathrm{~mm}$. embryo of Amia calva, taken through the independent anlage of the medial pharyngeal lymphatic $\left(4^{\prime}\right)$ which does not communicate with the precardinal vein $(6)$, nor does it connect with the latter by means of solid endothelial strand. P. E. C. 459, slide 1, section 76 .

\section{REFERENCES}

$4^{\prime}$, Independent anlage of the medial pharyngeal lymphatic in Amia
6, Precardinal or jugular vein 27, Root of dorsal aorta 


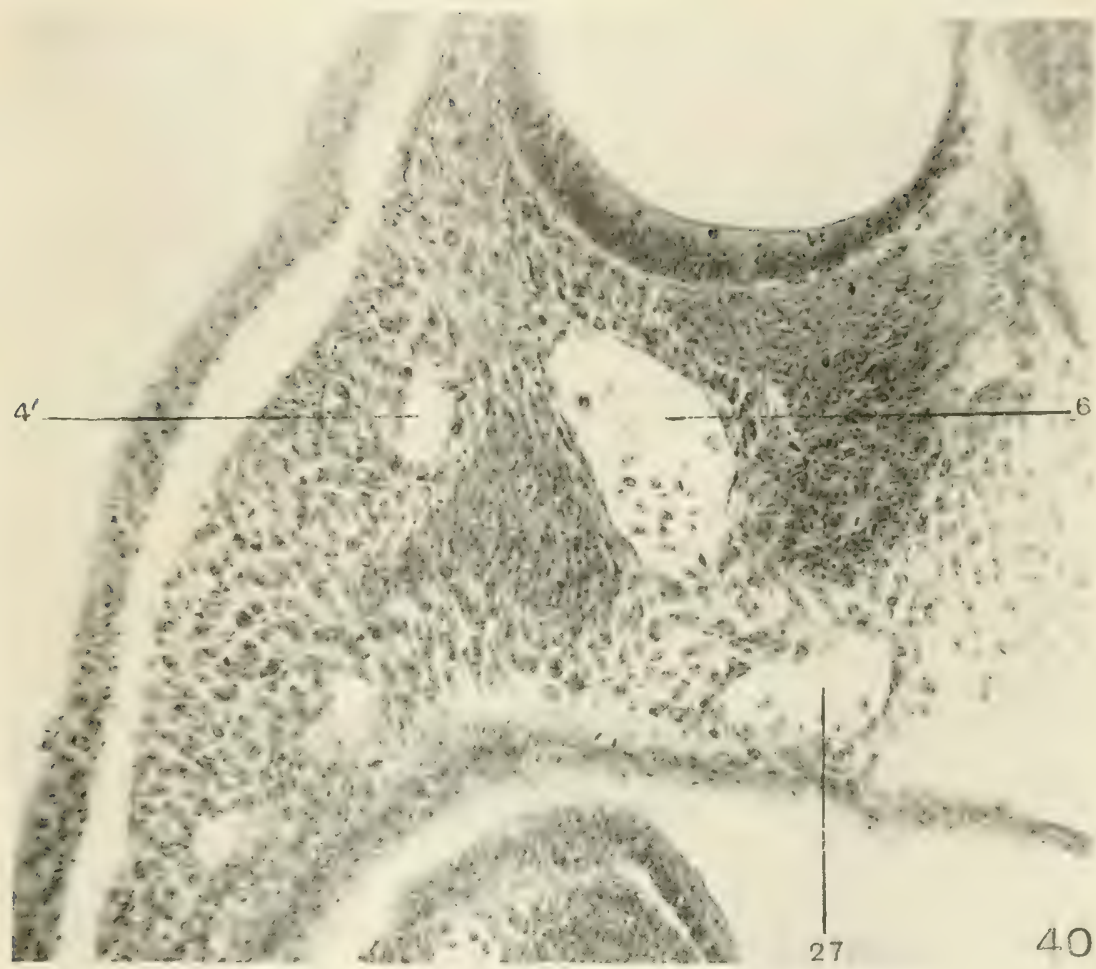


PLATE 31

EXPLANATION OF FJGURE

Fig. 41 Photomicrograph of a transverse section of a $15 \mathrm{~mm}$, embryo of Chelydra serpentina, taken through the periaortal lymph sinus; showing that this endothelial-lined lymph sinus (25) is in direct and open communication with a typical mesenchymal-lined tissue space (26). Columbia Embryological Collection (Col. of P. and S.) 317, slide 12, section 9.

Fig. 42 Photomicrograph of a transverse section taken through the subocular lymph sacs of a twenty-one-day rainbow trout embryo in which, as independent structures, the sacs (1) have reached the maximum stage of their development. P. E. C. 646 , slide 1 , section 70 ; injected embryo.

\section{REFERENCES}

6 , Precardinal or jugular vein

20, Caudal end of eye

22, Carotid artery

25, Periaortal lymph sinus of Chelydra serpentina

26, Mesenchymal tissue space which communicates directly with the peri- aortal lymph sinus of Chelydra serpentina

32, Mesenchymal tissue spaces which lie in the line of extension of the periaortal lymph sinus of Chelydra serpentina 

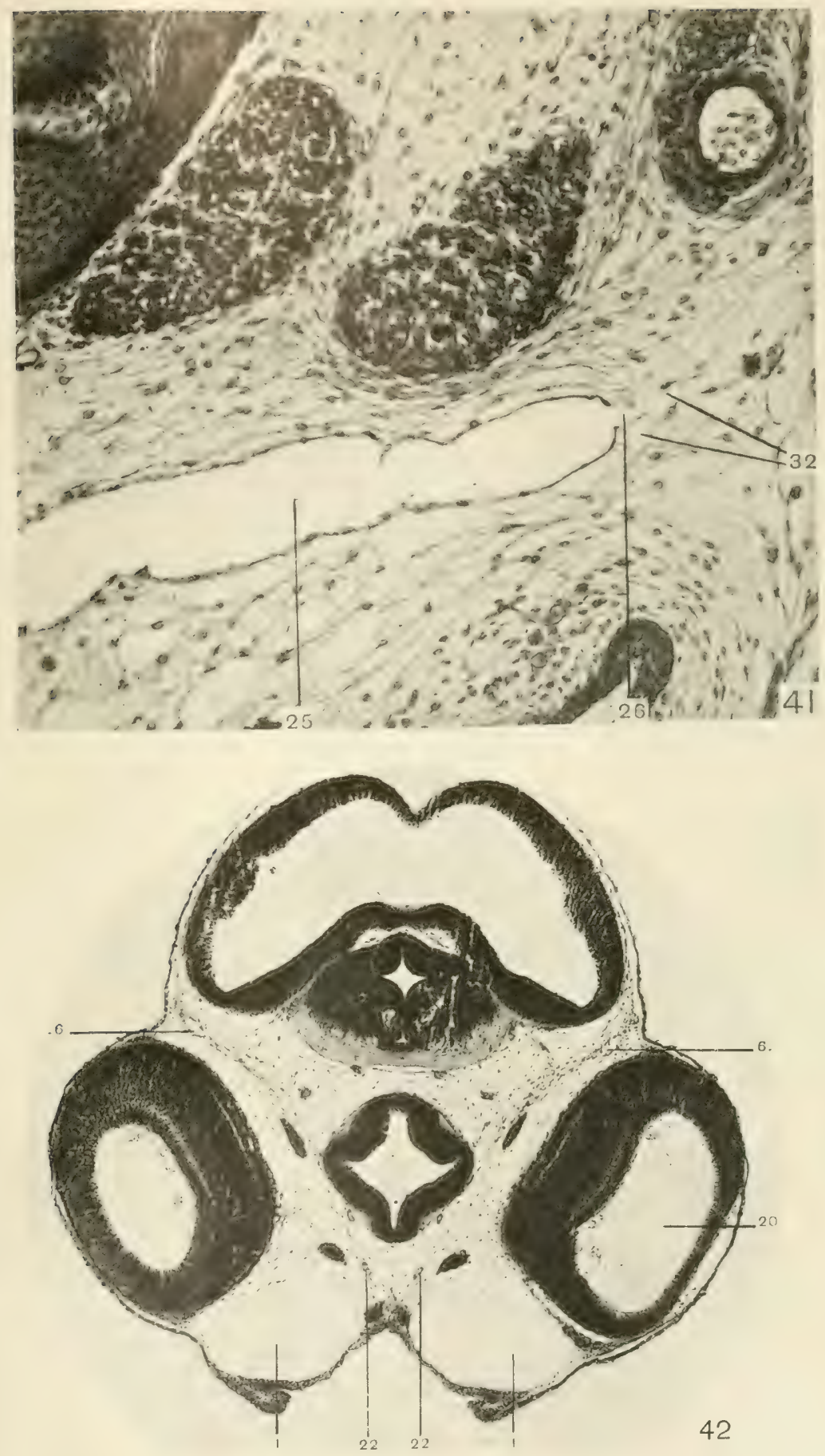



\section{E MO I RS}

The publication of this series of Inatomical Monographs has been undertalien with the purpose of presenting the results of original iniestigation in anatomy which are too extensive for incorporation in the already over-crowded curvent periodicals.

No. 1. The Anatomy and Development of the Systemic Lymphatic Vessels in the Domestic Cat, by George S. Huntington, Professor of Anatomy, Columbia University, New York City, states in a few pages the various theories held in regard to lymphatic development in general and then proceeds to present the result of six years' careful investigation on mammalian lymphatic development. Part I deals with the development of the systemic lymphatic vessels in their relation to the blood vascular system. Part II deals with the development of the preazygos and azygos segments of the thoracic duct. 175 pages of text, 8 text figures (two in color), 254 photo micrographs and 21 colored plates. Sent post paid to any country for $\$ 4.00$.

1911.

No. 2. Contribution to the Study of the Hypophysis Cerebri with Especial Reference to its Comparative Histology, by Frederick Tilney, Associate in Anatomy, Columbia University, New York City. Part I contains a historical review of the literature. Part II deals with the comparative histology of the pituitary gland and gives a report of six hypophysectomies performed upon cats. 72 pages of text, 2 text figures, 60 photomicrographs and plates. Sent post paid to any country for $\$ 1.50$.

1911.

No. 3. Early Stages of Vasculogenesis in the Cat (Felis Domestica) with Especial Reference to the Mesenchymal Origin of Endothelium, by H. Von W. Schulte, Department of Anatomy, Columbia University, New York City. 90 pages of text and 33 figures of which 14 are in colors. Sent post paid to any country for $\$ 1.50$.

1914.

No. 4. The Development of the Lymphatic System in Fishes, with Especial Reference to its Development in the Trout, by C.F. IV. MeClure Department of C'omparative Anatomy, Princeton I'niversity. 138 pages, 42 figures, of which 13 are in colors. Sent post paid to any country for $\$ 2.50$. 1915 .

No. 5. The Development of the Albino Rat, Mus Norvegicus Albinus: I. From the pronuclear stage to the stage of mesoderm anlage; end of the first to the end of the ninth day: II. Abnormal ova; end of the first to the end of the ninth day; by G. Carl Huber, Department of Anatomy, University of Michigan, and the Division of Embryology, Wistar Institute of Anatomy and Biology, Philadelphia. 142 pages of text and 42 figures from drawings by the author. Sent post paid to any country for $\$ 2.50$. 1915 .

No. 6. The Rat, compiled and edited by Henry II. Donaldson. Reference tables and data for the Albino Rat (Mus Norvegicus Albinus) and the Norway Rat (Mus Norvegieus). 278 pages, eloth binding. Sent post paid to any count ry for $\$ 3.00$.

1915.

No. 7. The Origin of Blood and Vascular Endothelium in Embryos without a Circulation of the Blood and in the Normal Embryo, by Charles R. Stockard, Department of Anatomy, Cornell University Medical School, New York City. 178 pages. Sent post paid to any country for $\$ 2.50$.

1915.

Orders should be addressed and checks made payable to

THE WISTAR INSTITUTE OF ANATOMY AND BIOLOGY Philadelphia, Pa. 



QL McClure, Charles Freeman

841 Williams

M3 The development of the lymphatic system in fishes

- BioMsd

PLEASE DO NOT REMOVE

CARDS OR SLIPS FROM THIS POCKET

UNIVERSITY OF TORONTO LIBRARY 
W.

(5)

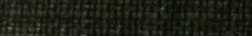

1.

(6)

-

(1)

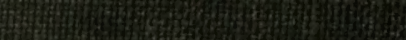

14

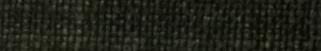

赫

(1)

(3)

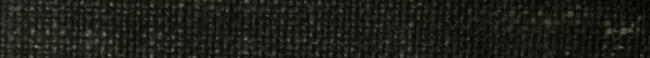

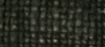

Hain

Hen

D.

(5)

$+4$ 